\title{
Christine Weder
}

\section{Die \\ Schlaraffenlandkarte um 1700}

Geografie und Ökonomie einer multimedialen Fantasie

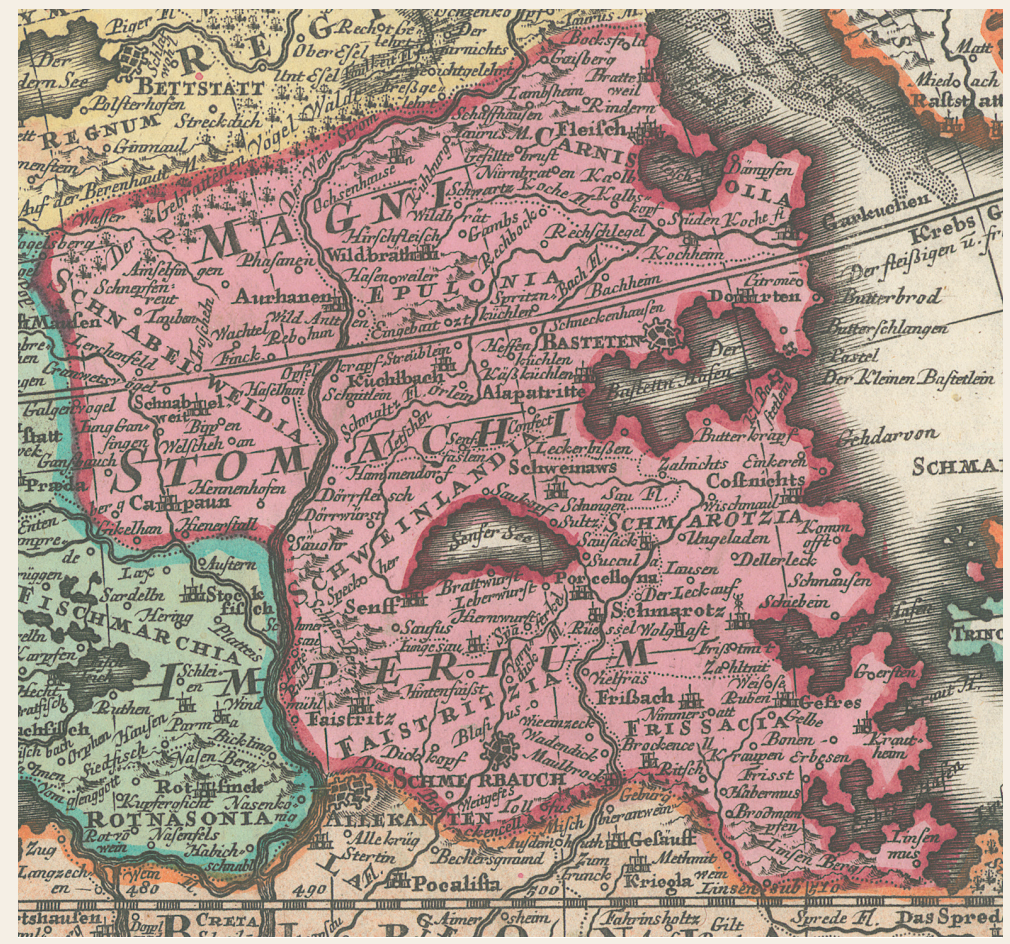

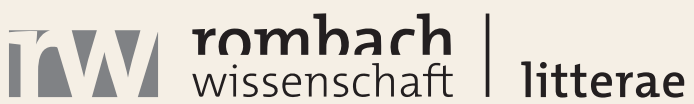


Christine Weder

Die Schlaraffenlandkarte um 1700

Geografie und Ökonomie einer multimedialen Fantasie 


\section{ROMBACH WISSENSCHAFT • REIHE LITTERAE}

herausgegeben von Günter Schnitzler, Maximilian Bergengruen

und Thomas Klinkert

mitbegründet von Gerhard Neumann

Band 253 


\section{Die Schlaraffenlandkarte um 1700}

Geografie und Ökonomie einer multimedialen Fantasie 
Auf dem Umschlag:

Detail aus: Accurata Utopiae Tabula, in: Johann Baptist Homann: Atlas novus terrarum orbis imperia regna et status exactis tabulis geographice demonstrans, Nürnberg 1716 (Universitätsbibliothek Graz).

Publiziert mit Unterstützung des Schweizerischen Nationalfonds zur Förderung der wissenschaftlichen Forschung.

Die Deutsche Nationalbibliothek verzeichnet diese Publikation in der Deutschen Nationalbibliografie; detaillierte bibliografische Daten sind im Internet über http://dnb.d-nb.de abrufbar.

1. Auflage 2021

(c) Christine Weder

Publiziert von

Rombach Wissenschaft - ein Verlag in der Nomos Verlagsgesellschaft mbH \& Co. KG

Waldseestraße 3-5 | 76530 Baden-Baden

www.rombach-wissenschaft.de

Gesamtherstellung:

Nomos Verlagsgesellschaft mbH \& Co. KG

Waldseestraße 3-5 | 76530 Baden-Baden

ISBN (Print): 978-3-96821-829-8

ISBN (ePDF): 978-3-96821-830-4

DOI: https://doi.org/10.5771/9783968218304

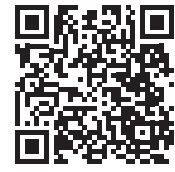

Onlineversion Nomos elibrary

\section{(c) $(\Theta \Theta \Theta$}

Dieses Werk ist lizenziert unter einer Creative Commons Namensnennung - Nicht kommerziell - Keine Bearbeitungen 4.0 International Lizenz. 
Für Lynn 
Inhalt

Vorab

Landkarte der Leidenschaft

I. Land des Luxus

Fantasien des Überflusses im Umbruch um 1700

Die Accurata Utopiae Tabula als Landkarte der Laster 22

Zum Vergleich: Fénelons Voyage dans l'île des plaisirs oder Überfluss produziert Überdruss

II. Mangel im Überfluss

Kredit und Ruin in Schlaraffia und frühneuzeitlicher

Ökonomie 46

Schlaraffisches Geld und luxuriöse Logik $\quad 47$

(Dis-)Kreditierung: Das Credit Gebiet der Accurata Utopiae Tabula $\quad 50$

Gutgläubige Gläubiger und das Risiko des Ruins 57

III. Hüben und drüben zugleich

Fantastische Raumlogik und die Grenzen des

Schlaraffenlandes 64

Schlaraffischer Grenzverkehr $\quad 65$

Hüben und drüben: Fiktive Topologie 72

Fiktion als Grenzüberschreitung: Ein Spiel mit Grenzen 81

IV. Medienwechsel Literatur - Landkarte

Die schlaraffische Utopia als heimliche Heimat der Riesen

Rabelais'/Fischarts

Grand-Goschier, Kaiser über Schlaraffia-Utopia 87

Sprachluxus im Medienwechsel: Vom flächigen Erzählen zur Wortschatzkarte

Literaturverzeichnis

Abbildungsverzeichnis 126

Dank 128

$\begin{array}{ll}\text { Personenregister } & 129\end{array}$ 
Vorab

Landkarte der Leidenschaft

Dieses kleine Buch handelt vom obskuren Objekt einer Obsession. Mit der Accurata Utopiae Tabula, einer anonymen undatierten Landkarte des Schlaraffenlandes, widmet es sich einem abseitigen, obschon in den öffentlichen Bibliotheken der westlichen Welt weit verbreiteten Gegenstand. Die Karte ist wohl - samt einem Begleitbuch - erstmals in der zweiten Hälfte des 17. Jahrhunderts erschienen. ${ }^{1}$ Insbesondere in der ersten Hälfte des 18. Jahrhunderts ist sie separat sowie als spielerische Beigabe zu seriösen Atlanten immer wieder in leicht variierten Ausgaben vertrieben worden. Heute lagert die Schlaraffenlandkarte zahlreich in den kartografischen Abteilungen der Bibliotheken - und ist in einem Nachdruck von 1999 auch als Dekoration für die private Wand bestellbar. ${ }^{2}$

Am besten erkunden lässt sich die alte Karte jedoch als Digitalisat im neusten Medium, obwohl oder gerade weil dessen Möglichkeiten, besonders das Heranzoomen und Umherfahren, ihre exzessive Ausstaffierung mit schlaraffischen Ortsbezeichnungen bis zur Verursachung von Schwindel und Übelkeit veranschaulichen. Dies zeigt etwa die raffinierte, frei zugängliche elektronische Präsentation der Universitätsbibliothek Bern, bei der man sich ganz in die Karte, einen Kupferstich à 47 x 55 cm, für den der Katalog 1730 als vermutliches Erscheinungsjahr angibt, verlieren kann, sodass die knapp 1800 Namen auf rund einem Viertelquadratmeter Fläche als buchstäblicher Dichtestress erfahrbar werden. ${ }^{3}$ Die sprechenden Namen verorten die schlaraffischen Genüsse und (Un-)Tätigkeiten in bunter Sprachmischung - bei deutschsprachigem Schwerpunkt mit Latein und anderen tonangebenden Sprachen Europas verfeinert - auf der Karte: vom bodenständigen Linsen Berg oder Frißach über das delikatere Latwergen oder Feigen, das Tobackrollen Gebürg bei Lange Pfeiffen auf der Insel Tobago und Porto Rico oder Goldingen in Reichemannia bis hin zum Venus Waldt in der Nähe von Frauenfeld, Hohe Schu, Amazonia, Freudenstein, Kreusenhar, Cuncubina und Bastarda; von Schwelgendorff und Sauffausen über Oberlausleben bis Schmarotzia; von Schachmatt und Dantzfurt, Spatauf, Lentini und Vaullentzia bis nach

1 Zur Datierungsfrage vgl. in Kap. I, S. 22-27

2 Karte des Schlaraffenlandes (Schlarraffenland) 1694, Bad Langensalza, Reprint 1999 (Verlag Rockstuhl).

3 https://biblio.unibe.ch/web-apps/maps/zoomify.php?col=ryh\&pic=Ryh_8303_28 [letzter Zugriff 18.06.2021]. 
Rammlingen und Hurfurt. Soweit als erste Kostprobe (alle weiteren wegen Übersättigungsgefahr in mundgerechten Bissen).

Die aufgezählten Orte sind nicht nur aufgrund der Namensdichte schwierig zu finden auf einer solchen Karte, die sich kaum handlich ‘zitieren lässt und so zum Suchbild wird. Dank einem Netz von Längen- und Breitengraden in Atlanten-Manier ${ }^{4}$ wären zwar Angaben nach dem Muster geografischer Koordinaten theoretisch möglich, indes, da das Gradnetz sehr grobmaschig und bloß am Rand nummeriert ist, bei viel (allzu bierernster) Mess- und Rechenarbeit dennoch unpraktisch zur Lokalisierung. Orientierungshilfe bietet zunächst die Unterteilung dieses Schlaraffenlandes in einzelne Königreiche, welche namentlich die Universitätsbibliothek Graz in ihre digitale Darbietung übernommen und mit Auflistungen der Örtlichkeiten versehen hat. ${ }^{5}$ Präsentiert wird dort ein Kartenexemplar, das aus einem Homann'schen Atlas, dem Atlas novus terrarum orbis imperia regna et status exactis tabulis geographice demonstrans von 1716, stammt. Dieses Exemplar (Abb. 6 in Kap. I) dient im Folgenden, wo nicht anders vermerkt, als Referenzobjekt und ist auch für die Illustrationen reproduziert, die freilich eine Selbsterkundung nicht ersetzen.

Eine andere Art der Orientierung gibt das zu dieser Schlaraffenlandkarte gehörige Buch: Seinerseits anonym, ohne vermerktes Erscheinungsjahr und in leicht unterschiedlichen Ausgaben überliefert, wird es jedoch in den Bibliotheken separat bei den Büchern verwahrt und ist weit weniger verbreitet. Obwohl kein Ensemble von Karte und Buch aufgefunden wurde, erscheint die gegen 400 Seiten starke Beschreibung der schlaraffischen Länder und Leute als direkter Begleittext. Die Karte verweist in ihrer Kartusche auf das erklärende Buch: Accurata UTOPIE TABULA [...] samt einer Erklaerung (Abb. 3 und 4 in Kap. I). Umgekehrt bezieht sich das Buch bereits im Titel auf die Karte: Erklaerung der Wunder=seltzamen Land=Charten UTOPIE [...] (Abb. 5 in Kap. I). Die Erklaerung wird hier in erster Linie gemäß einem Buchexemplar im Duodez-Format der Herzog August Bibliothek Wolfenbüttel zitiert, für das im Katalog 1730 als ungefähres Erscheinungsjahr der Ausgabe und Johann Andreas Schnebelin (gestorben 1705) als ursprünglicher Verfasser angegeben werden. ${ }^{6}$ Als Leseausgabe

4 Genaueres dazu vgl. in Kap. III, S. 81f., und Kap. IV.

5 http://sosa2.uni-graz.at/sosa/karten/schlaraffia/index.php [letzter Zugriff 18.06.2021].

6 Anonym [Johann Andreas Schnebelin?]: Erklaerung der Wunder=seltzamen Land=Charten UTOPIÆ, so da ist das neu=entdeckte Schlarraffenland [...], Arbeitshausen in der Graffschaft Fleissig [Nürnberg ca. 1730?], Signatur: M: Sf 224; Nachweise im Folgenden unter der Sigle E mit Seitenangabe direkt im Text. - Zur Autorfrage vgl. in Kap. I, bes. S. 26. 
liegt auch die transkribierte Neuedition eines anderen Exemplars vor, die im Anhang ein Ortsverzeichnis der Landkarte bietet. ${ }^{7}$

Dieser merkwürdige Medienmischling, dieses Stück kartografischer Literatur oder literarischer Kartografie, fasziniert mich immer wieder neu, sodass ich die verschiedensten Themen - wie das Verhältnis von Literatur und Luxus bzw. Ökonomie, imaginäre Raumkonzeptionen, intermediale Beziehungen oder sogar die Grundsatzfrage 'Was ist Literatur? - zum Anlass nehme, damit hervorzukommen. Das ist erklärungsbedürftig, handelt es sich doch auf den ersten Blick um einen Gegenstand jenseits jeglicher wissenschaftlicher Kerngeschäfte, abseits eines noch so salopp geweiteten Kanons behandelter Werke. Schon das Wort „Werk ‘ klingt drei Nummern zu groß und schwer für diese Spielerei auf Papier, die von der ernsthaften Forschung in der Regel höchstens en passant gestreift wird. ${ }^{8}$ Natürlich könnte man es sich leicht machen und die Abseitigkeit als solche feiern. Das wäre dem schlaraffischen Sujet gemäß, aber gleichzeitig eine faule Ausrede.

Faszinierend ist vor allem die akribische Ausführung und Ausführlichkeit der Fantasiekarte mit Begleitbuch. Die Machart, durch mehrere Auflagen mit neuen Druckplatten umso aufwendiger, steht im größtmöglichen Gegensatz zum effizienten Verfahren, Grundzüge zu skizzieren und prägnante Beispiele zu geben, bis die Idee deutlich wird, um es dann mit der Geste

7 Johann Andreas Schnebelins Erklärung der wunder-seltzamen Land-Charten Utopiae aus dem Jahr 1694, hg. von Franz Reitinger, Bad Langensalza 2004; Verweise fortan unter der Sigle S im Text. Soweit die schlaraffischen Orte im Verzeichnis mit Kartenausschnitten, das Harald Rockstuhl zur Neuausgabe beigesteuert hat (ebd., S. 227-273), aufgeführt sind, werden sie nach diesem Ortsverzeichnis nachgewiesen (unter der Sigle OV mit Seitenzahl). Im Übrigen wie auch durchgängig in der Schreibweise der Ortsnamen halte ich mich jedoch an das erwähnte Grazer Kartenexemplar.

8 Vgl. z.B. Ludwig Stockinger: Ficta respublica: gattungsgeschichtliche Untersuchungen zur utopischen Erzählung in der deutschen Literatur des frühen 18. Jabrhunderts, Tübingen 1981, S. 102f.; Dieter Richter: Schlaraffenland. Geschichte einer populären Utopie, Frankfurt a.M. 1995, S. 214 bzw. 235; Michaela Brodl (Red.): Der verbotene Blick: Erotisches aus zwei Jahrtausenden, hg. von der Österreichischen Nationalbibliothek, Klagenfurt 2002, S. 114; exemplarisch auch die Referenz im unpaginierten E-Book der Reihe Bastei Entertainment: Wolfgang Seidel: Sternstunden: Die abenteuerliche Geschichte der Entdeckung und Vermessung der Welt, Köln 2012. Der eingehendste Beitrag findet sich im Anhang zur Neuedition der Erklaerung: Franz Reitinger: »Die wunder-seltzame Land-Charten Utopiae. Ein Hauptwerk barocker Lachkultur«, in: ders. (Hg.): Schnebelins Erklärung, S. 275-336. 
von >und so weiter bewenden zu lassen. Hier mag die Idee längst überdeutlich sein, doch es wird weiterhin fröhlich über ihre Stränge geschlagen, die Örtlichkeit detailliert weiterfantasiert, das Sprachspiel zur Wortschatzkarte ausgeklügelt, wieder und wieder variiert, unersättlich, unermüdlich, unaufhörlich. Nirgendwo ist anschaulicher als in dieser ausgiebigen Utopia, dass Fiktion weit weniger in einer Idee denn in der Ausführung besteht. Und wie viel Arbeit das Spiel bedeuten kann.

Die Verbindungsmöglichkeiten mit grundlegenden Themen und Verfahren von Fiktion zeigen zudem, dass es sich nicht nur um Vorwände fürs Hervorholen der fantastischen Karte handelt. Karte und Buch stehen im Schnittpunkt einschlägiger Diskurse ihrer Zeit und setzen auf fundamentale Möglichkeiten von Fiktion. So rückt der abseitige Gegenstand in den Bereich zentraler Fragestellungen. Das Kartenlesen erfolgt auf der Basis einer Auswahl von ergiebigen Kontexten, bei der selbstverständlich auch persönliche Vorlieben mitspielen. Dabei beschränke ich mich auf einige ausgewählte Perspektiven, ohne eine erschöpfende Präsentation zu beanspruchen. Insbesondere eine systematische Untersuchung des Namensmaterials in allen Sinn- und Hintersinndimensionen wäre ein anderes (sicher lohnendes) Projekt. Im besten Fall würde das punktuelle Ausloten - nicht erschöpfend dann im positiven Sinn - zu weiteren Erkundungen anstiften und die Obsession ansteckend wirken. Nebenbei würde ich die Klärung aller Urheber- und Datierungsfragen in unverbesserlicher Neugier auch auf solche `Fakten` auf die Wunschliste setzen.

Aus der Blickrichtung auf allgemeinere Fragestellungen ergibt sich das womöglich etwas ungewöhnliche Vorgehen: Anstatt jeweils vom `Text $\iota$, von der Karte, auszugehen und im zweiten Schritt Kontexte einzublenden, beginne ich meistens umgekehrt bei Themen und Verfahren, die auch für sich genommen interessieren und in der Folge einen - beiderseits - erhellenden Kontext für den Blick auf die Karte versprechen. Anstatt Text und Kontext einfach als Vorder- und Hintergrund zu gewichten, erlaubt dies eine 'gleichberechtigte< Behandlung. Bezüglich der Accurata Utopiae Tabula ist es eine Annäherung von außen in mehreren Anläufen, ein gleichsam exzentrischer Umgang mit dem Objekt der Obsession. 
Während die Imaginationsgeschichte des Schlaraffenlandes als Bezugshorizont durchweg wichtig ist, führen die Perspektiven darüber hinaus, indem die einzelnen Kapitel zugleich andere Kontexte vorschlagen: Im ersten Kapitel werden schlaraffische Erfindungswelten mit Konzeptionen von Luxus in Verbindung gebracht, die sich um 1700 in einem für die moderne Diskussion folgenreichen Umbruch befindet: der Verstärkung von ökonomischen Argumentationen auf Kosten von theologisch-moralischen. So lässt sich die Accurata Utopiae Tabula samt Erklaerung als - allerdings keineswegs eindeutig moralisierende - Laster-Landkarte auf der Schwelle zur Moderne exemplarisch mit einer französischen Schlaraffia-Fable von Fénelon aus dem gleichen Zeitraum kontrastieren. Dass dies jedoch nichts mit Realitätsbzw. Ökonomieferne zu tun hat, führt das zweite Kapitel vor Augen. Wenn auf der fantastischen Karte ganze Regionen Realien wie Kredit und Pfand samt Kerbholz gewidmet sind, erweist sich die luxuriöse Imagination ökonomisch geerdet, d.h. erstaunlich konkret verstrickt mit dem historischen Kontext des frühneuzeitlichen Kreditwesens.

Mindestens so zentral wie der genüsslich ausgemalte Binnenraum sind bei Schlaraffia-Vorstellungen die Ränder des erdichteten Landes, was die Darstellungen für ein generelles Interesse an fiktionalen Raumkonzeptionen attraktiv macht (Kapitel III). Durch das Medium der Karte zusätzlich begünstigt, treibt die Accurata Utopiae Tabula die raffinierte Ausstaffierung der Grenzen des Landes unbegrenzter Genüsse auf die Spitze, sprengt mutwillig topologische Grundgesetze - und kostet eine allgemeine Möglichkeit von Fiktion aus: Fingieren als Grenzüberschreitung, als lustvolles Spiel mit Grenzen.

Das vierte Kapitel verfolgt schließlich einen versteckten Bezug der Erklaerung auf die Riesenwelt von Rabelais' Gargantua bzw. Fischarts Geschichtklitterung aus dem 16.Jahrhundert. Dies geschieht nicht einfach, um den anonymen Medienbastard durch den Anschluss an namhafte literarische Werke zu adeln, sondern vor allem, um wechselseitige Vergleichsperspektiven zwischen den Büchern und der Landkarte (mit Buch) zu gewinnen, die auch für mediengeschichtliche und intermediale Aspekte aufschlussreich sind. Wenn sich nun der vergleichende Blick auf Intertexte, genauer Prätexte richtet, wobei neben der Fischart'schen bzw. Rabelais'schen Textwelt offensichtlichere Bezugswerke ebenfalls ausführlicher zur Sprache kommen, dann geht es hier am Ende um Kontexte, mit denen ein weniger exzentrisches Vorgehen angefangen hätte. Wer sich in erster Linie dafür interessiert, mag deshalb 
umstandslos beim letzten Kapitel beginnen. Und wer sich - noch obsessiver - nur für den `Text « der erklärten Schlaraffenlandkarte an sich ohne vorgeschlagene Kontexte interessiert, lese hemmungslos sprunghaft. ${ }^{9}$

9 Nämlich bes. S. 22-41 (Kap. I), S. 50-63 (Kap. II), S. 73-84 (Kap. III) sowie, wegen unentwirrbarer Text-Kontext-Verstrickung, das ganze Kap. IV. Diese Publikation basiert teilweise auf meinen im Literaturverzeichnis genannten Aufsätzen zur Schlaraffenland-Thematik, die im Sinne von work in progress überarbeitet und erweitert worden sind. 


\section{Land des Luxus}

Fantasien des Überflusses im Umbruch um 1700

\section{Schlaraffia ist ein luxuriöses Land:}

Die Rebhühner und Schnepfen fliegen einem gespickt und gebraten um den Mund, und bitten demüthig daß man sie essen möchte; Fische von allen Arten schwimmen gekocht in Teichen von allen möglichen Brühen, deren Ufer immer voll Austern, Krebse, Pasteten, Schinken und Ochsenzungen liegen. Hasen und Rehböcke kommen freywillig herbey gelaufen, streifen sich das Fell über die Ohren, stecken sich an den Bratspieß, und legen sich, wenn sie gar sind, von selbst in die Schüssel. Allenthalben stehen Tische, die sich selbst decken; und weich gepolsterte Ruhebettchen laden allenthalben zum Ausruhen vom Nichtsthun und zu angenehmen Ermüdungen ein. Neben denselben rauschen kleine Bäche von Milch und Honig, von Cyprischem Wein, Citronenwasser und andern angenehmen Getränken; und über sie her wölben sich, mit Rosen und Schasmin untermengt, Stauden voller Becher und Gläser, die sich, so oft sie ausgetrunken werden, gleich von selbst wieder anfüllen. Auch giebt es da Bäume, die statt der Früchte kleine Pastetchen, Bratwürste, Mandelkrapfen und Buttersemmeln tragen; andere, die an allen Ästen mit Geigen, Harfen, Cithern, Theorben, Flöten und Waldhörnern behangen sind, welche von sich selbst das angenehmste Koncert machen, das man hören kann. Die glücklichen Menschen, nachdem sie den wärmern Theil des Tages verschlafen und den Abend vertanzt, versungen und verscherzt haben, erfrischen sich dann in kühlen marmornen Bädern, wo sie von unsichtbaren Händen sanft gerieben, mit feinem Byssus, der sich selbst gesponnen und gewebt hat, abgetrocknet, und mit den kostbarsten Essenzen, die aus den Abendwolken herunter thauen, eingebalsamt werden. Dann legen sie sich auf schwellende Polster um volle Tafeln her, und essen und trinken und lachen, singen und tändeln und küssen die ganze Nacht durch, die ein ewiger Vollmond zum sanftern Tage macht; [....$^{1}$

In der Beschreibung, die Christoph Martin Wieland unter Rückgriff auf eine lange Imaginationsgeschichte ${ }^{2}$ der Demokrit-Figur seines Romans Geschichte der Abderiten (1774/81) in den Mund legt, bietet das Schlaraffenland mit

1 Christoph Martin Wieland: Geschichte der Abderiten, in: Gesammelte Schriften, hg. von der Deutschen Kommission der Preußischen Akademie der Wissenschaften, 15 Bde., Berlin 1986f., Abt. 1, Bd. 7, S. 65f. Der Roman ist 1774 zunächst in Fortsetzungsfolgen unter dem Titel Die Abderiten. Eine sehr wahrscheinliche Geschichte im Teutschen Merkur erschienen, 1781 dann als Geschichte der Abderiten vervollständigt und ergänzt durch einen Schlüssel zur Abderitengeschichte.

2 Vgl. Wielands Anmerkung, ebd., S. 66. Zur Motiv- bzw. Utopiegeschichte vgl. bes. die Anthologien von Martin Müller: Das Schlaraffenland: Der Traum von Faulheit und Müßiggang: eine Text-Bild-Dokumentation, Wien 1984, bzw. Richter: Schlaraffenland. 
seinem Saus und Braus für alle Sinne und Gelüste zentrale Facetten von Luxus: nicht allein Angenehm-Übliches im Überfluss (z.B. Milch, gekochter Fisch, gebratener Hase, Bratwürste), sondern auch Raffiniert-Exquisites wie Austern, Marmorbadewannen, edle Stoffe und kostbare Essenzen. Beide Dimensionen betreffen neben der Sparte der Waren zugleich diejenige der Lebensstile, wenn hier die totale Freizeit ${ }^{3}$ und der permanente Kunstgenuss eines Dauerkonzerts herrschen. Den qualitativen Aspekt des >Verfeinerten', der womöglich mehr noch als der quantitative den Kern des Luxuriösen bildet, ${ }^{4}$ spricht das dümmliche bauch- und mengenfixierte Klischee dem Schlaraffenland zwar gerne ab. Doch dies zu Unrecht, denn die Fantasien von , Schlauraffenland «, ,Coquaigne (oder `Cocagne $<$ ), ,Cuccagna $<$, Lubberland oder $>$ Luilekkerland ${ }^{5}$ verwenden seit einem anonymen französischen fabliau aus dem 13. Jahrhundert ${ }^{6}$ - der als erstes Gedicht vom Schlaraffenland im heute noch bekannten Sinn gilt - oftmals viel auf die Raffinesse in der Ausstattung ihres allzu irdischen Paradieses. ${ }^{7}$ Eines der schönsten Beispiele findet sich auf einem italienischen Kupferstich (anonym, um 1650), der ein speziell auf Frauen zugeschnittenes Schlaraffenland, „CHVCAGNA DELLE DONNE«, zeigt: In der Mitte der konzentrisch aufgehäuften kulinarischen wie kosmetischen Köstlichkeiten steht als Gipfel der Annehmlichkeit ein Baum, von dem Gold tropft - zum Zwecke der Blondierung (Abb. 1 und 2). ${ }^{8}$

3 Entsprechend nimmt etwa Berry >leisure bei seiner systematischen Bestimmung unter die Zentralkategorien von Luxus auf, vgl. Christopher J. Berry: The idea of luxury. A conceptual and historical investigation, Cambridge 1994, bes. S. 5, 7. Vgl. auch bereits Thorstein Veblen: The Theory of the Leisure Class, New York 1926.

4 Vgl. Berry: The idea of luxury, S. 11, 24f.

5 So je eine deutsche, französische, italienische, englische und niederländische Namensvariante. $\mathrm{Zu}$ den verschlungenen und z.T. ungesicherten Wortgeschichten um frühneuhochdeutsch >schlauraff(e)< = >Müßiggänger, Faulenzer, Narr $<$ (mittelhochdeutsch sslur oder ssluderaffer, ev. von ssludern i.S. von schlenkern, schludern) und verwandtem Vokabular vgl. am ergiebigsten Richter: Schlaraffenland, S. 12-16. Im Deutschen taucht schlaraffenland a als Begriff zum ersten Mal in Heinrich Wittenwilers satirischem Roman Der Ring (um 1408/10) auf (vgl. dazu etwa Hans Rudolf Velten: »Das Schlaraffenland - ein europäischer Mythos? Zur historischen Semantik einer literarischen `Dekonstruktion«, in: Praktiken europäischer Traditionsbildung im Mittelalter: Wissen - Literatur - Mythos, hg. von Manfred Eikelmann u. Udo Friedrich, Berlin 2013, S. 245-268, hier S. 248).

6 Vgl. den Abdruck in: Étienne de Barbazan: Fabliaux et contes des poètes françois des XI, XII, XIII, XIV et XVe siècles. Tirés des meilleurs auteurs, 4 vols. Nouv. éd., augm. et revue par Méon, Paris 1808, vol. 4, S. 175-181; dazu zuerst Veikko Väänänen: »Le `fabliau< de Cocagne«. In: Neuphilologische Mitteilungen 48 (1947), S. 3-36. Eine deutsche Übersetzung findet sich in der Anthologie von Richter: Schlaraffenland, S. 130-135.

7 Zu dieser Dimension von Luxus im fabliau vgl. etwa Velten: Europäischer Mythos?, S. 250.

8 Eine Reproduktion dieser Darstellung findet sich etwa auch bei Müller: Schlaraffenland, S. 110 f. 


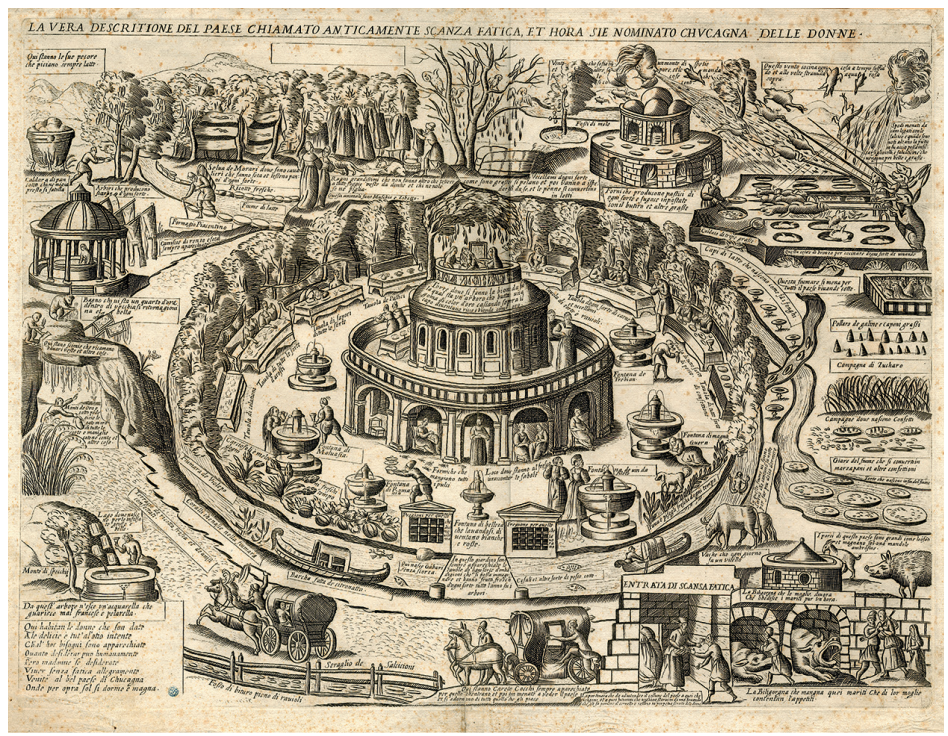

Abb. 1: Cuccagna delle Donne: Ein Schlaraffenland extra für Frauen ... (Kupferstich, Italien, ca. 1650. Civica Raccolta delle Stampe Achille Bertarelli, Castello Sforzesco, Milano)

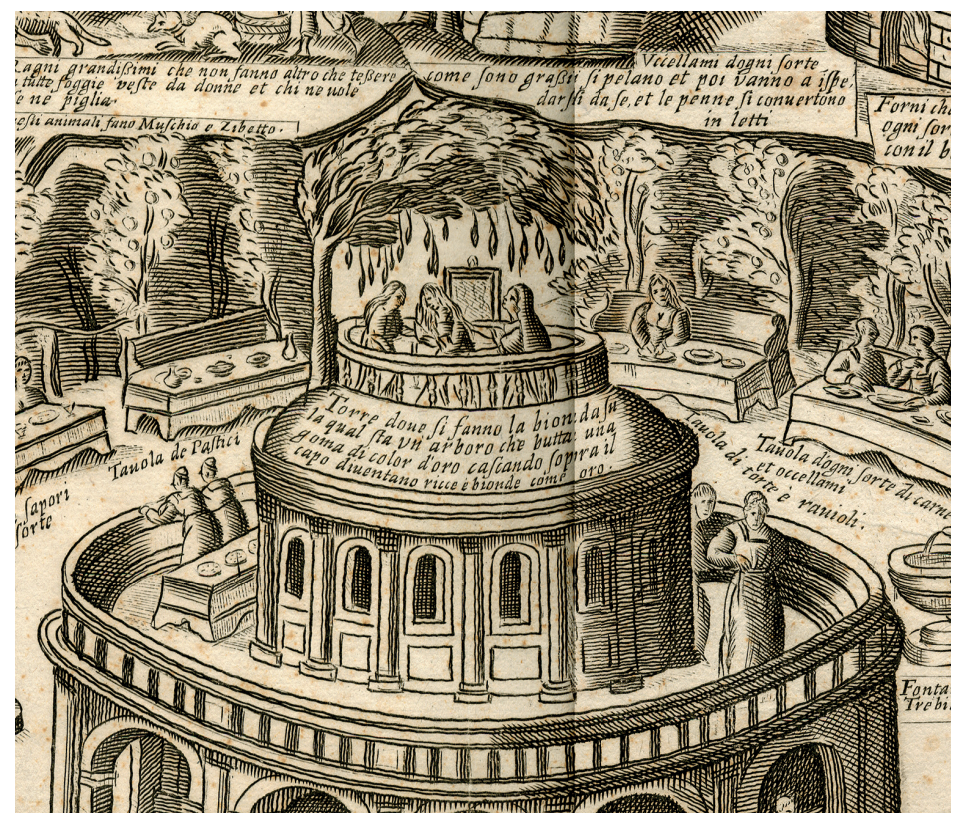

Abb. 2: ... mit Friseursalon: Goldblondes Haar dank Tropfbaum (Detail aus Abb. 1) 
Die entscheidende Differenz zum Luxus in gewöhnlichen Ländern besteht freilich in der fehlenden Exklusivität. Im Schlaraffenland gibt es den Überfluss nicht für einige wenige, die dadurch zu >feinen Leuten`würden; es gibt auch nicht bloß genug für alle, sondern Überfluss für alle. Der Luxus ist hier genauso demokratisiert wie die Befreiung von der Arbeit. ${ }^{9}$ Denn, wie es bei Wieland heißt, »die Natur« ist »so gefällig [...], neben ihren eigenen Verrichtungen auch noch die Arbeit der Menschen auf sich zu nehmen «, weshalb alles "von selbst « und mit »unsichtbaren Händen « erledigt wird. ${ }^{10}$ Mit unsichtbaren Händen: Die Formulierung klingt, als gälte es, jene harmonische Weltordnung auszufantasieren, die Adam Smith in seiner rasch bekannt gewordenen Theory of moral sentiments (1759) entworfen hatte und in der die - später in The wealth of nations (1776) erneut auftauchende »invisible hand« der Providenz die ganze Gesellschaft, namentlich auch die Armen, vom Luxus-Leben der Reichen profitieren lässt. ${ }^{11}$

Mit der fleißigen Natur, die über den elementaren Zaun zur Kultur grast und alle Kulturprodukte gleich mitfabriziert, wird der Luxus des Schlaraffenlandes umso größer, luxuriöser als in Wirklichkeit - aber zugleich umso fiktiver: Die Erfindung dieser dezidiert unnatürlichen Natur als Bedingung eines derart demokratisierten Luxus streicht den Chimärencharakter besonders deutlich hervor. Schlaraffia ist nicht nur das Land des Luxus par excellence, sondern, direkt damit verbunden, auch erklärtes Kerngebiet der luxurierenden Einbildungskraft, der Literatur als Erdichtung.

9 Demokratisierter Luxus ist freilich für Theoretiker wie Baudrillard ein Widerspruch in sich. Zu diesem Punkt vgl. Berry: The idea of luxury, S. 32f., der diese Sicht aber nicht teilt.

10 Wieland: Abderiten, S. 65f. Hervorh. im Original gesperrt.

11 Vgl. Adam Smith: The theory of moral sentiments, hg. von David D. Raphael u. Alec L. Macfie, Oxford 1976, S. 184f. Der Prominenz des Luxus-Themas in Smiths Schrift entspricht, dass darin eine eingehende Auseinandersetzung mit Mandeville stattfindet. Smith wirft Mandeville vor, er gehe bei seiner berühmten Formel der sprivate vices - public benefits (vgl. dazu weiter unten in diesem Kapitel) einseitig von bösen Motiven aus (hierzu vgl. Laurenz Volkmann: »Mandeville’s Beehive and Smith’s Invisible Hand: Conflicting Voices of Ethics and Economics in Early Industrialism «, in: Talking Forward, Talking Back: Critical Dialogues with the Enlightenment, hg. von Kevin L. Cope u. Rüdiger Ahrens, New York 2002, S. 13-42, bes. 30-33).Zu den insgesamt drei Auftritten der sinvisible hand < bei Smith vgl. J. Ronnie Davis: »Adam Smith on the providential reconciliation of individual and social interests: is man led by an invisible hand or misled by a sleight of hand? «, in: History of Political Economy 22/2 (1990), S. 341-352. Die dritte Verwendung findet sich in History of astronomy, einer Schrift, die bereits vor 1758 geschrieben, jedoch erst 1795 postum veröffentlicht wurde (vgl. ebd., S. 342). Ob es sich bei dieser Textstelle der Abderiten um eine Anspielung auf Smiths Theory of moral sentiments handelt, die Wieland durchaus gekannt haben könnte (während The wealth of nations erst zwei Jahre nach dieser Romanfolge im Teutschen Merkur 5 [1774] erschien), sei dahingestellt. 
Entsprechend häufig wird die Wahrheits- und Wahrhaftigkeitsfrage ironisierend besprochen, sodass die Texte in der Tradition der Lügengeschichte stehen, die insbesondere an Lukians Wahre Geschichten (2. Jh. n. Chr.) mit dem Reisebericht von der schlaraffischen >Insel der Seligen` anknüpft. ${ }^{12}$ Auf die doppelte, thematische wie poetologische Affinität der SchlaraffenlandLiteratur zum Luxus hebt Wieland in einer Fußnote zur zitierten Passage $\mathrm{ab}$, indem er die "ausschweifendste[ ] Einbildungskraft" als Produzentin von Schlaraffenland-»Mährchen « anspricht. ${ }^{13}$ Schlaraffengeschichten vom Überfluss sind demnach besondere Luxusprodukte der Fantasie. Am elegantesten bringt dies etwas später der Serapionsbruder Lothar bei E.T.A. Hoffmann auf den Punkt. Nachdem er seinen Freunden im Dichterclub das Märchen Nussknacker und Mausekönig (1816) erzählt hat, das von einem Schlaraffenlandabenteuer handelt, erklärt er, er habe sich erlaubt, »in fantastischem Übermut zu luxurieren $\ll .{ }^{14}$ Hier - und vielleicht überhaupt - heißt >dichten< >luxurieren<.

Obwohl oder gerade weil der Luxus im »nahrhafteste[n] Märchen des Volkes«, wie es Ernst Bloch bei seiner Auffassung als populare Utopie genannt hat, ${ }^{15}$ nichts kostet, wird er auffallend oft diskreditiert. Dies erfolgt besonders gerne durch rahmende Textelemente, etwa in hermeneutischen Ankündigungen und Fazits der Erzähler oder in Rahmenhandlungen, die den narrativ-schwelgerischen Teil zur Lügengeschichte erklären oder mit Warnungen und anderen ernsten Worten einklammern. Man könnte auch sagen, dass die Schlaraffenwelt, die in der Binnenerzählung kon-

12 Vgl. Lukian: Wahre Geschichten, in: Die Hauptwerke des Lukian, griech.-dt. hg. und übers. von Karl Mras, München 21980, S. 376-399. Vgl.z.B. die Texte, die Richter: Schlaraffenland, S. 181-202, unter dem Titel Lügenland versammelt. Die Dimension der Lügengeschichte betont etwa auch Velten: Europäischer Mythos?, bes. S.255. Ausführlicher dazu in Kap. III, S. $70 f$.

13 Wieland: Abderiten, S. 66.

14 Ernst Theodor Amadeus Hoffmann: Nussknacker und Mausekönig, in: Sämtliche Werke, hg. von Wulf Segebrecht u. Hartmut Steinecke, 6 Bde., Frankfurt a.M. 1985-2004, Bd. IV, S. 241-309, hier S. 309. Vgl. ausführlicher dazu: Christine Weder u. Maximilian Bergengruen: »Moderner Luxus« (Einleitung), in: Luxus. Die Ambivalenz des Überflüssigen in der Moderne, hg. von Christine Weder u. Maximilian Bergengruen, Göttingen 2011, S. 7-31, hier S. 25f.

15 Ernst Bloch: Freiheit und Ordnung. Abriß der Sozialutopien, Berlin 1947, S. 9. Für Kritik an dieser (zu einseitigen) Auffassung angesichts der mindestens ebenso dominanten Anknüpfung an Traditionen gelehrter Schriftlichkeit vgl. bes. Velten: Europäischer Mythos?, S. 251f., in Anknüpfung an Hans-Jörg Gilomen: »Das Schlaraffenland und andere Utopien im Mittelalter«, in: Basler Zeitschrift für Geschichte und Altertumskunde 104 (2004), S. 213-248, hier S. 221-235. 
struiert wird, in der Rahmung gleichzeitig dekonstruiert wird. ${ }^{16}$ So entsteht die Ambivalenz, die diese literarischen Behandlungen des Luxus fast programmatisch zu bestimmen scheint, oftmals entscheidend über das Textverfahren - und man verpasst viel, wenn die Rahmungen ignoriert werden, wie das in Motivgeschichten und Anthologien häufig geschieht. Ebenso einseitig ist die ebenfalls gängige Lektüre, welche die Darstellungen aufgrund der Einfassung einfach als Moraldidaxe verbucht. ${ }^{17}$ Weil es sich im Schlaraffenland so unverdient wie ungestraft schlemmen und bechern, schwelgen, spielen und faulenzen lässt, ist diese Geschichte an sich denkbar ungeeignet für Moralisierungen. Umso augenfälliger ist deshalb oft der Riss zwischen Rahmen und Gerahmtem. Die aufgezwungene Klammer einer >Moral von der Geschicht'، wirkt dann alles andere als zwingend; vielmehr wie ein Freibrief, es dazwischen umso toller zu treiben.

Besonders eklatant ist dieser Aspekt beim berühmten Meistersang Das Schlauraffen Landt (1530) von Hans Sachs, der übrigens das Motiv des Breibergs ${ }^{18}$ in die Geschichte eingeführt hat. Auf die detaillierte Beschreibung des Paradieses der Prasser und Faulpelze folgt hier eine Belehrung, die aufgepfropfter nicht sein könnte: Die »alten" hätten das Schlaraffenland zum Tadel und zur Warnung der gemeinhin faulen und gefräßigen "jugent" erdichtet. ${ }^{19}$ Wie die moralische Motivation der Jugend zustande kommen soll durch die alles andere als abschreckende Geschichte, ist aber ein Rätsel.

Auch Wielands Demokrit lässt das luxuriöse Land trotz seiner liebevollen Darstellung vor seinem abderitischen Publikum letztlich nicht gelten. Er hat allerdings andere Gründe. Ein Zuhörer, der »weise Rathsmann «, vermutet darin eine »Satire auf gewisse Filosofen«, die »das höchste Gut in der Wollust suchen $\ll^{20}$ Er spielt wohl auf Materialisten wie den Wieland bekannten La Mettrie an, der unter anderem mit L'art de jouir bzw. Die Kunst, die Wollust zu empfinden (beide 1751) Anstoß erregt und - epikureisch inspiriert - die

16 Bezüglich Lügendeklaration vgl. Velten: Europäischer Mythos?, S. 255 und 263-267.

17 So verfährt die (ältere) Forschung namentlich etwa mit Hans Sachs' Spruchgedicht vom Schlaraffenland gerne (vgl. dazu bes. Werner Wunderlich: „Das Schlaraffenland in der deutschen Sprache und Literatur«, in: Fabula 27, 1986, S. 54-75, hier S. 66, im Forschungsüberblick). Kritisch dazu vgl. etwa auch Velten: Europäischer Mythos?, bes. S. 255, der mit seinem Fokus auf Lügengeschichte und Rahmung neben der Moraldidaxe zugleich Hungerkompensation, Utopie und Rationalitätskritik als gängige Funktionsvorschläge für schlaraffische Vorstellungen verwirft.

18 Mehr dazu in Kap. III.

19 Hans Sachs: Das Schlauraffen Landt, in: Meistergesänge, Fastnachtsspiele, Schwänke, hg. von Eugen Geiger, Stuttgart 1985, S. 65-69, hier S. 68f., V. 99-108.

20 Wieland: Abderiten, S. 66. 
Wollust als umfassende Lebenshaltung propagiert hatte. ${ }^{21}$ Wieland war solchen Ideen bekanntlich selbst nicht abgeneigt, weshalb ihm ebenfalls "viehische[r] Epicuräismus « vorgeworfen worden war. ${ }^{22}$

Entsprechend ist sein Demokrit ganz gegen den sweisen< Zuhörer und eine Satire auf die Wollustsphilosophen. Er verkauft die Schlaraffenlandgeschichte für das genaue Gegenstück: Sie soll nämlich den »Abderitischen Sittenlehrer $[n]$ " und mit ihnen allen "Gesetzgeber[n], Projektmacher[n], Schulmeister[n] und Weltverbesserer[n] auf dem ganzen Erdenrund « vor Augen führen, dass sie sich mit ihren Idealen fälschlich am Schlaraffenland orientieren, was nicht funktionieren könne, weil das etwa so viel bedeuten würde, wie wenn man von Menschen ausginge, die »keinen Magen und keinen Unterleib haben ${ }^{23}$

Die Passage ist als Zentralstelle für eine diesen Roman insgesamt bestimmende Utopieskepsis interpretiert worden. ${ }^{24}$ Die Identifizierung von Schlaraffenland und Utopie mag - obschon keineswegs selbstverständ$\operatorname{lich}^{25}$ - einleuchten, zumal wenn es Wieland offensichtlich darum geht, Idealentwürfe mit >weltverbesserndem` Anspruch als SchlaraffenlandVorstellungen zu kritisieren, die auf unrealistischen Voraussetzungen (wie einer Welt des allgemeinen Überflusses) beruhen würden. Die Gleichsetzung stimmt übrigens mit der Definition im Zedler'schen Universal-Lexicon überein, wo der Begriff /Schlaraffenland k geradezu als deutsche Übersetzung von lateinisch >Utopia< präsentiert wird. ${ }^{26}$ Doch überrascht Wielands Argument, bei dem das allen Magen- und Unterleibsgelüsten ausgiebig frönende Luxusland-Leben in eins fällt mit einem Leben ohne Magen und Unterleib.

Eine solche Argumentation - so die These - wäre 100 Jahre früher kaum möglich gewesen. Dies hat mit jenem grundlegenden Umbruch in der Luxus-Diskussion um 1700 zu tun, den Christopher Berry als »de-morali-

21 Vgl.Julien Offray de La Mettrie: Die Kunst, Wollust zu empfinden, hg. und eingel.von Bernd A. Laska, Nürnberg 1987, bes. S. 71,77.Zur Berufung auf die epikureische Philosophie vgl. ebd., z.B.S. 81.

22 So in einer Anklageschrift des Augustinerpaters Jordan Simon von 1771, zitiert nach SvenAage Jørgensen u.a.: Christoph Martin Wieland. Epoche - Werk - Wirkung, München 1994, S. 76.

23 Wieland: Abderiten, S. 67f. Hervorh. im Original gesperrt.

24 Vgl. etwa Bernhard Budde: Aufklärung als Dialog. Wielands antithetische Prosa, Tübingen 2000, bes. S. 288-290.

25 Vgl. dazu in Kap. IV, S. 93f.

26 Vgl. Johann Heinrich Zedler: Großes vollständiges Universal-Lexicon [1731-1754], 68 Bde., photomech. Nachdr. Graz 1961-1964, Bd. 34 [1742], Sp. $1828 f$. 
sation of luxury« bezeichnet. ${ }^{27}$ Anders als Berry, der sich bei seiner ideengeschichtlichen Studie auf expositorische Texte zum Thema Luxus konzentriert, möchte ich der Verschiebung anhand von zwei ungefähr zeitgleichen, aber im hier interessierenden Punkt fundamental unterschiedlichen Schlaraffenland-Imaginationen nachgehen, die sich - so die Hoffnung - als spezifisch literarische Beteiligungen an der Diskussion lesen lassen. Auf die seltsame Gleichung bei Wieland ist am Schluss des Kapitels zurückzukommen.

\section{Die Accurata Utopiae Tabula als Landkarte der Laster}

Die herkömmliche Denk- und Darstellungsfigur in diesem Umbruch akzentuiert besonders anschaulich die in jener Zeit mehrfach aufgelegte Accurata Utopiae Tabula. Viel genauer als mit der weit zu verstehenden Angabe sum 1700< ist die Schlaraffenlandkarte bisher nicht schlüssig datierbar, obschon in den divergenten und bisweilen widersprüchlichen Zuschreibungen einige konkrete Jahreszahlen kursieren. Darauf ist zuerst näher einzugehen.

Die Datierungsvorschläge bezüglich der (drei?) leicht differenten, meist kolorierten Fassungen der Karte reichen vom letzten Jahrzehnt des 17. bis in die 40er-Jahre des 18. Jahrhunderts, ${ }^{28}$ wobei es aber in meinen Augen auch Hinweise auf eine mögliche frühere Ersterscheinung gibt. Dass die Karte oftmals als Beilage zu Atlanten verbreitet wurde, verspricht zunächst gute Datierungschancen. Allerdings scheint der Großteil der überlieferten Exemplare in den Bibliotheken sfreischwebend zu liegen - mithin anders als das Exemplar der Grazer Universitätsbibliothek, das einer Ausgabe von Johann Baptist Homanns Atlas novus von 1716 beigebunden ist. ${ }^{29}$

Der Titel in der Kartusche enthält bei aller barocken Ausführlichkeit keine Jahreszahl (Abb. 3): Accurata UTOPII TABULA Das ist der Neu=entdeckten SCHALCK=WELT, oder des so offt benannten, und doch nie erkannten SCHLARAFFENLANDES Neu=erfundene lächerliche Land=Tabell Worinnen all und jede Laster in besondere Königreich, Provintzien und Herrschafften abgetheilet Beyneben auch die nächst angräntzende Länder der Frommen

27 Berry: The idea of luxury, S. 101.

28 Diese Bandbreite gibt Reitinger in seiner Auseinandersetzung mit den bisherigen Datierungsansätzen an. Er selbst ermittelt drei Fassungen und datiert die erste auf >vor 1700<, die letzte auf sum 1730<. Vgl. Reitinger: Hauptwerk barocker Lachkultur, S. 302-305.

29 Wohl deshalb vermerkt der Kommentar zur digitalen Präsentation der Karte bei der UB Graz, vor 1716 sei die Karte nicht nachweisbar. 
des Zeitlichen Auff ü: Unterg. auch ewigen Verderbens Regionen samt einer Erklarung anmuthig und nutzlich vorgestelt durch Authorem Anonymum. Im Gegensatz zu diesem Kartuschentitel, wie er sich beispielsweise beim Grazer Exemplar findet, trägt derjenige (mindestens) einer anderen Fassung ${ }^{30}$ den Zusatz Prostat in Officina Homanniana (Abb. 4). Mit der Offizin wird jene Instanz genannt, die den literarischen Markt der Zeit maßgeblich gestaltet und zumal bei Landkarten weit wichtiger ist als der Author. Auch - womöglich frühere - Fassungen ohne diese Angabe könnten vom berühmten Nürnberger Kartografen stammen. So schreibt etwa Reitinger die älteste Fassung Homann (1663/64-1724) zu und datiert sie auf die 1690er-Jahre, als der Kupfer- und Landkartenstecher bereits aktiv war, bevor er 1702 seinen eigenen Verlag gründete. ${ }^{31}$ Bei der bildlichen Umrahmung der Kartusche existieren zwei ganz verschiedene Versionen, woraus indes keine genauere Datierung ableitbar ist. Während die eine die schlaraffischen Schwelgereien ins Bild einer bäuerlich-grobianischen Szenerie setzt (Abb. 4), bietet die andere eine sedlere Staffage mit adligem Personal um den mittig thronenden Bacchus (Abb. 3). ${ }^{32}$

Weitere Hoffnung auf eine präzisere Ermittlung der Entstehungszeit weckt der Umstand, dass die Accurata Utopiae Tabula und die Erklaerung in Buchform ursprünglich ein Ensemble gebildet haben dürften, weil ihre Titel gegenseitig ausdrücklich aufeinander verweisen. ${ }^{33}$ Die Angabe zum Erscheinungsjahr in der Titelei der Erklaerung führt jedoch ins Leere, d.h. ins Schlaraffenland (Abb.5): Erklaerung der Wunder=seltzamen Land=Charten

30 Reitinger bestimmt diese als die zweite Fassung (vgl. Reitinger: Hauptwerk barocker Lachkultur, S. 304).

31 Er wendet sich damit gegen eine andere prominente Zuschreibung zu Peter/Pieter Schenck (1660-1711) und dessen Atlas Contractus (zw. 1695 und 1705) durch Cornelis Koeman (vgl. ebd., bes. S. 304-306 und 323-325). Weitere Argumente für seine Zuschreibung und Datierung der Karte vgl. Franz Reitinger: »Ein Stern geht unter, der andere erhebt sich ‘. Das erste Leben des Johann Baptist Homann«, in: Franz Reitinger u. Hans Joachim Schollenberger: Johann Jakob Schollenberger (1646-1689). Nürnberg und die Bildproduktion der Kunstverlage des Barock. Werkbiographie eines Verschollenen, Regensburg 2018, S. 297318, hier S. 302f.

32 Reitinger verbindet erstere Version mit den früheren beiden Fassungen der Karte und letztere mit einer dritten Fassung, die er auf einiges später datiert (um 1730) und nicht mehr Homann, sondern dessen Schüler Matthäus oder Matthias Seutter zuschreibt (vgl. ebd., bes. S. 305 und 331). Dem widerspricht jedoch, dass das Grazer Exemplar aus dem Homann'schen Atlas von 1716 die Bacchus-Version aufweist.

33 Das unterstreicht auch Reitinger gegen die immer wieder anzutreffende Annahme, die Erklaerung sei die Textvorlage für die Karte gewesen, und führt weitere Belege des konkreten Kartenbezugs aus der Erklaerung an (ebd., S. 306-308). 


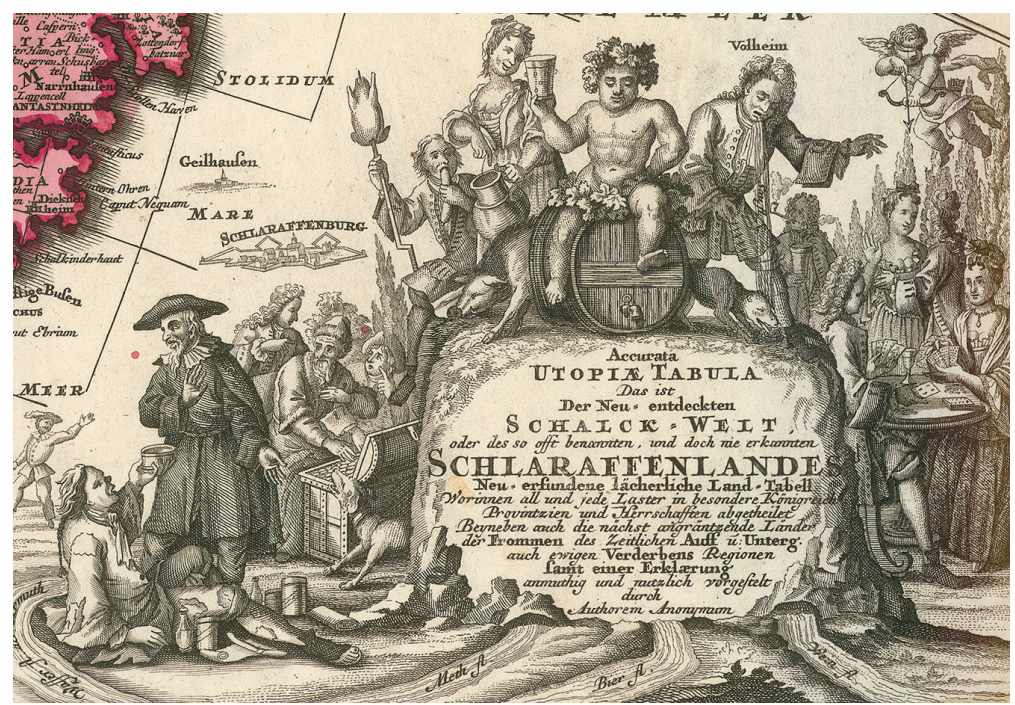

Abb. 3: Die Kartusche des Grazer Kartenexemplars, in: Johann Baptist Homann: Atlas novus terrarum orbis imperia regna et status exactis tabulis geographice demonstrans, Nürnberg 1716 (Universitätsbibliothek Graz)

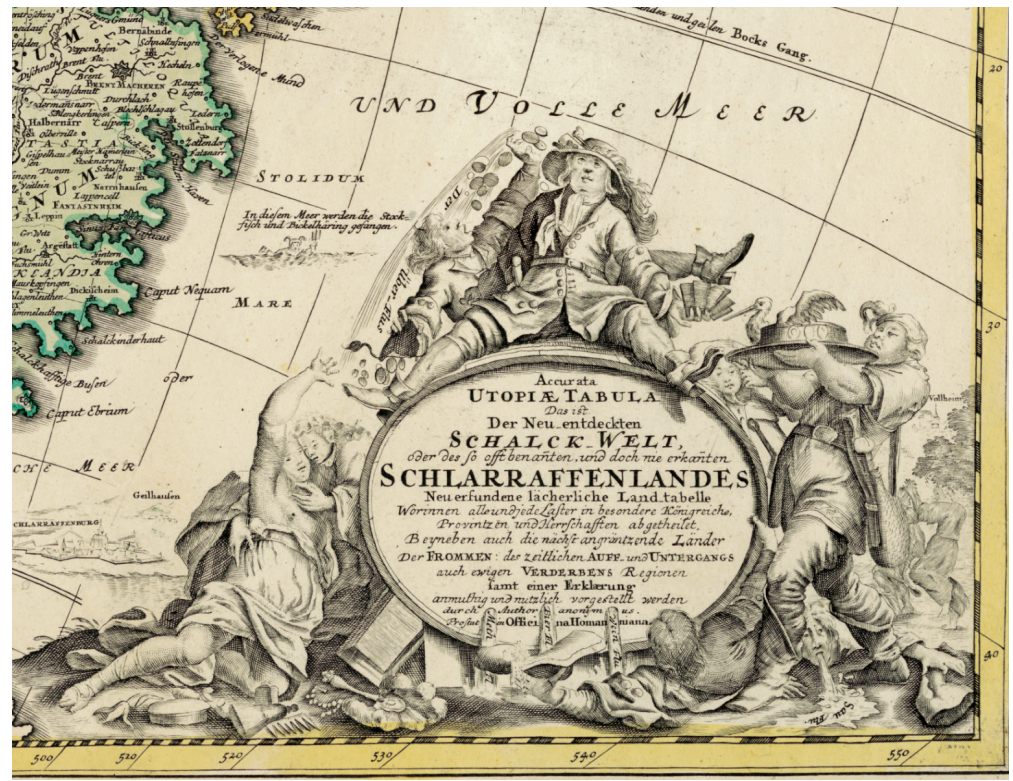

Abb. 4: Die Kartusche des Berner Kartenexemplars, Homann [Nürnberg] 1730? (Universitätsbibliothek Bern) 


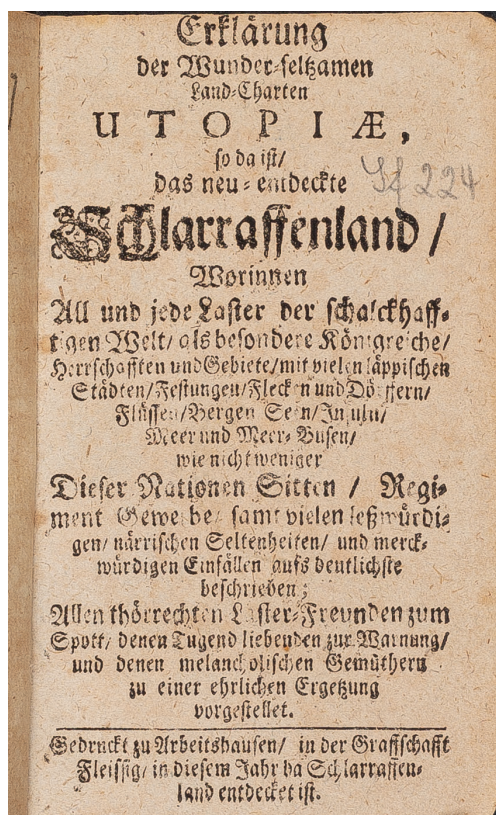

Abb. 5: Titelblatt der Erklaerung

(Exemplar von ca. 1730 der Herzog August Bibliothek Wolfenbüttel)

UTOPIÆ, so da ist/das neu=entdeckte Schlarraffenland/Worinnen All und jede Laster der schalckhafftigen Welt/ als besondere Koenigreiche/ Herrschafften und Gebiete/ [...] beschrieben; [...]. Gedruckt zu Arbeitshausen/ in der Graffschafft Fleißig/ in diesem Jahr da Schlarraffenland entdecket ist.

Reitinger hat unter den relativ wenigen überlieferten Exemplaren für die Zeit bis 1730 mindestens drei Auflagen ermittelt, darunter eine mit Frankfurt und Leipzig, die übrigen mit Nürnberg als wahrscheinlichen Druckorten. ${ }^{34}$ Für die Datierung der Erstausgabe, deren Bandbreite bis ca. 1650 zurückreicht, ${ }^{35}$ übernimmt er mit 1694 die Angabe des Erscheinungsjahrs von Hayn und Gotendorf in ihrer Bibliotheca Germanorum erotica \& curiosa

34 Vgl. ebd., S. 323-325.

35 Vgl. etwa Richter: Schlaraffenland, S. 214; Alice Stroup: „French Utopian Thought: The Culture of Criticism", in: Studies in Early Modern France, Bd. 4 = Utopia I: 16th and 17th centuries, hg. von David Lee Rubin, Charlottesville 1998, S. 1-30, hier S. 3; oder z.B. auch die Angabe mit Fragezeichen im elektronischen Katalog der Yale University Library (collection of German Baroque literature). 
(1912-1920). ${ }^{36}$ Dies geht (auch bei Hayn und Gotendorf) einher mit einer Zuschreibung der Autorschaft an einen Würzburger Offizier, nachmals kaiserlichen Feldmarschall namens Johann Andreas Schnebelin (gest. 1705) mit mehrfachen Beziehungen zur Reichsstadt Nürnberg. Schnebelin soll bisweilen auf Kosten seiner militärischen Pflichten literarischen Neigungen gefrönt haben und könnte während der jährlichen Winterquartiere in den 1690erJahren auch ausreichend Zeit dafür gehabt haben. ${ }^{37}$ Zuerst hatte Johann Georg Keyssler in seinen Reisebeschreibungen (1740-1742) den »General Schnebelin" als "Autor von der bekanten kurzweiligen und moralischen Land=Carte $[\ldots]$, welche den Titul von Tabula Utopiæ oder Schlaraffen Land führet«, vermerkt. ${ }^{38}$ Keyssler könnte aber dabei auch einem Jux aufgesessen sein und einen literarischen 'Schnäbler für eine historische Person genommen haben. ${ }^{39}$ Jedenfalls erscheint die Ermittlungslage bezüglich des Autors ebenso wie bezüglich der Datierung auf das Jahr 1694 zu dünn, um die Erklaerung umstandslos mit dem Autornamen Schnebelin und diesem Erscheinungsjahr zu versehen - und sei es `nur ‘ für eine moderne Leseausgabe des Buchs. ${ }^{40}$ Ungenaue Angaben sind da präziser, und am schönsten ist ohnehin die Originaldatierung auf das Jahr da Schlarraffenland entdecket ist.

Ungenaue Hinweise finden sich bei der Erklaerung auch textintern. Ein wichtiger Wink ist in einer heilsgeschichtlichen Bemerkung gegen Ende

36 Vgl. Bibliotheca Germanorum erotica \& curiosa, 9 Bde., hg. von Hugo Hayn u. Alfred N. Gotendorf, München 1912-1920, Bd. 7, S. 174. Beim Vermerk mit Druckort Nürnberg wird dort als Quelle auf den Jahreskatalog 1906 des berühmten Münchner Antiquariats von Ludwig Rosenthal verwiesen.

37 Vgl. Reitinger: Hauptwerk barocker Lachkultur, S. 308-312. Die Zuschreibung zu Schnebelin findet sich ebenfalls in Emil Weller: Die falschen und fingierten Druckorte. Repertorium der seit der Erfindung der Buchdruckerkunst unter falscher Firma erschienenen deutschen, lateinischen und französischen Schriften, Bd. 1, 2. vermehrte und verbesserte Aufl., Leipzig 1864, S. 183. Neben einer undatierten verzeichnet Weller eine Ausgabe mit seiner Ergänzung »Nürnberg c. 1730«, und zwar unter der Rubrik `Ohne Jahrzahl für das 18./19. Jahrhundert (nicht für das 17. Jahrhundert).

38 Johann Georg Keyssler: Fortsetzung Neuester Reisen, durch Teutschland, Böhmen, Ungarn, die Schweitz, Italien und Lothringen: worinn der Zustand und das merckwürdigste dieser Länder beschrieben wird, 2 Bde., Hannover 1740-1742, Theil 2 (1741 [ersch. 1742]), LXV. Brief, S. 538.

39 Diesen Zweifel äußert Reitinger selbst (vgl. Reitinger: Hauptwerk barocker Lachkultur, S. 311f.).

40 So steht der Titel von Reitingers Neuausgabe (Johann Andreas Schnebelins Erklärung der wunder-seltzamen Land-Charten Utopiae aus dem Jahr 1694) - folgenreich zumal als bisheriges >Monopok in den Bibliothekskatalogen - im Widerspruch mit seinen vorsichtigen Erwägungen im Nachwort und erneut im Homann-Aufsatz (Reitinger: Das erste Leben des Johann Baptist Homann, worin vom »unbekannte[n] Autor, vielleicht ein[em] General namens Schnebelin«, die Rede ist [S.302]). 
des Buchs versteckt. ${ }^{41}$ Bei der Besprechung des »TARTARISCHEN oder HOELLISCHEN REICH[S]« (E 378), eines Umlandes von Schlaraffia, heißt es: »[D]aß aber diese hoellische Gewalt schon ueber sechszehenhundert Jahr gebunden / und in etwas geschwaechet worden / haben wir der Liebe des himmlischen Vatters / und der Erloesung seines eingebornen ewigen Sohn [sic] zu dancken." (E 380) Daraus lässt sich auf 1634 als terminus post quem schließen, wenn man vom Jahr der Auferstehung Christi (33 n.Chr.) aus rechnet, wie sie Gregor der Große als Nullpunkt zur Zeitzählung angesetzt hatte. Der terminus post quem verschiebt sich noch um einige Jahre auf 1640, berücksichtigt man die gleichzeitige Berufung auf die weltliche Literaturgeschichte im Buch: Zur Positionierung seines Unternehmens bezieht sich der Autor in der Vorrede (vgl. E 19f.) namentlich auf Thomas Morus' Utopia (1516), Joseph Halls Mundus Alter et Idem (lat. ca. 1605, engl. 1608/9, dt. 1613) ${ }^{42}$ und Jakob Bidermanns Utopia (1640). Bei seiner jüngsten Referenz mag er zwar auf eine bereits über einige Zeit etablierte Bekanntheit von Bidermanns Werk gesetzt und womöglich auch erst an dessen zweite Ausgabe von 1670 angeknüpft haben, ${ }^{43}$ die im Gegensatz zur (postumen) Erstausgabe auf dem Frontispiz eine Landkarte darstellte (Abb. 24 in Kap. IV). Aber die Inspirationsbeziehung mit jener Karte könnte auch umgekehrt gelagert - und die erste Accurata Utopiae Tabula vor 1670 entstanden sein. Wenn die Erklaerung zur Accurata Utopiae Tabula erst in den letzten Jahren vor der Wende zum 18. Jahrhundert - mit 1694 also gut 1660 Jahre nach Christi Auferstehung - entstanden wäre, erschiene die heilsgeschichtliche Angabe "ueber sechszehenhundert Jahr« doch leicht untertrieben. Dies könnte, zumal zusammen mit einem Rezeptionszeugnis bei Gottfried Wilhelm Leibniz, ${ }^{44}$ für eine (etwas) frühere Entstehung sprechen.

So oder so passt die ungenaue Datierung zum unscharfen Umbruch in der Optik auf Luxus. Umso lustvoller lässt sich nun in den Luxus der Landkarte eintauchen, die nicht nur Überfluss verzeichnet, sondern dabei auch luxuriös verfährt.

41 Die bisherigen Datierungsversuche gehen nicht darauf ein.

42 Der Verfasser identifiziert hierbei allerdings den Erzähler Mercurius Britannicus mit Albericus Gentilis (zum Verwirrspiel Hall/Gentilis vgl. Derrick Moors: »Imaginary Voyages", in: The La Trobe Journal 41 (autumn 1988), S. 8-14, hier S. 9). Von einer bloßen Übersetzung oder Bearbeitung von Halls Werk, wie in vielen Bibliothekskatalogen zur Erklaerung vermerkt, kann nicht die Rede sein (mehr dazu vgl. in Kap. IV).

43 So suggeriert Reitinger: Hauptwerk barocker Lachkultur, S. 290-292.

44 Vgl. dazu S.36f. 


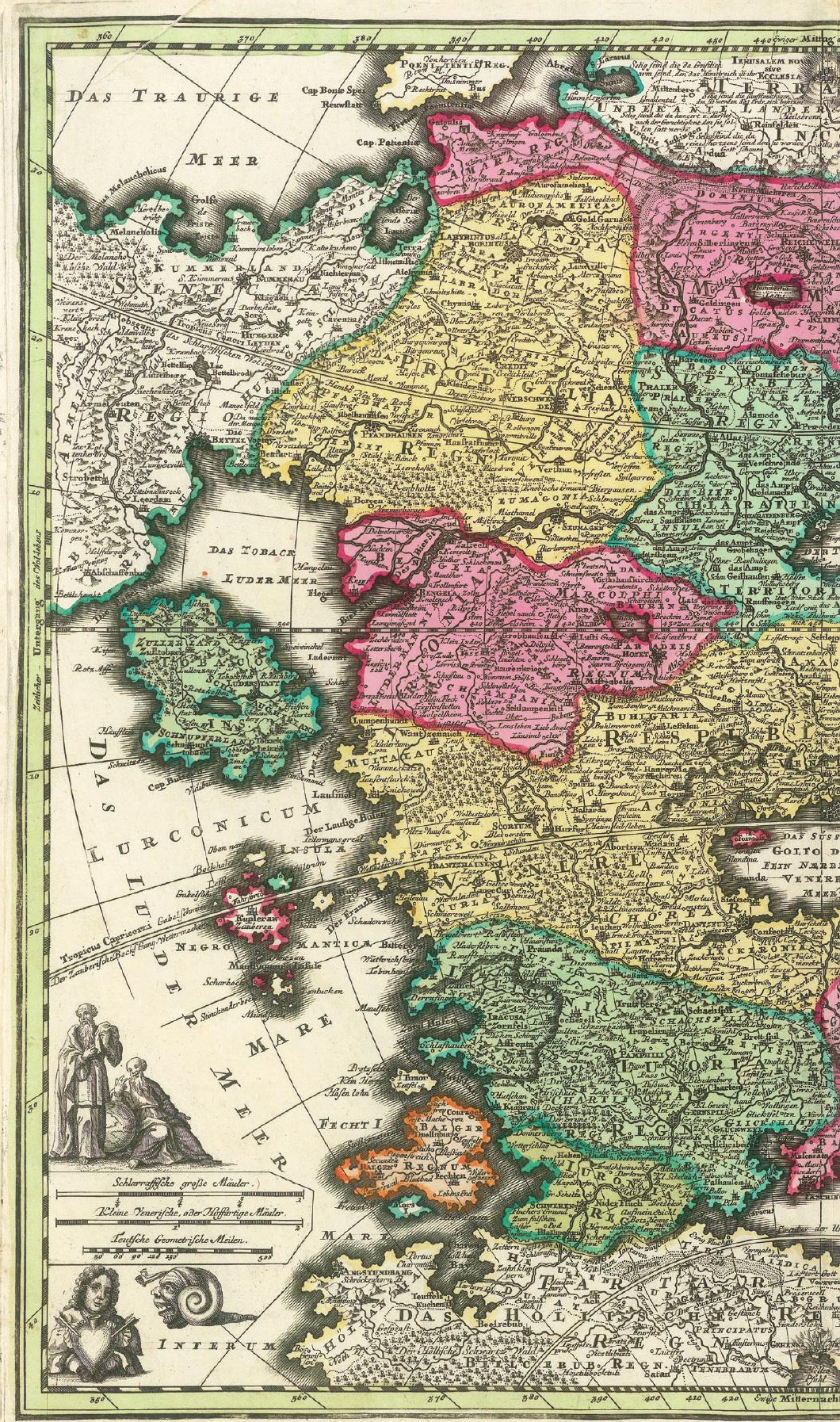


Mindestens so aufwendig und detailreich wie die Atlanten jener Zeit ihre Weltgegenden kartografiert die Accurata Utopiae Tabula das Schlaraffenland (Abb. 6). Die fiktive Örtlichkeit wird dabei immer wieder an Reales angelehnt. Die Umrisse Schlaraffias scheinen an Nordamerika orientiert, ${ }^{45}$ sodass die Neu=erfundene an die Neu=entdeckte Welt (Kartusche) par excellence erinnert und die Erfindung mit der Realgeschichte der europäischen `Entdeckung< bzw. Kolonialisierung ferner Länder verknüpft wird. Die Verknüpfung, die in der Erklaerung punktuell mit der Rede von "Colonen" oder »Pflantz-Voelcker[n] (z.B. E 319) aufgerufen wird, erscheint für eine neue Landkarte besonders sinnig, ist doch die Entwicklung der Kartografie seit jeher unauflöslich mit jener Geschichte verstrickt. ${ }^{46}$ Während Christopher Columbus zwar nicht Amerika alias >Indien<, sondern die Antillen einmal als wahres Schlaraffenland (für Sünder und Müßiggänger) beschrieben hat, passt die Amerika-Referenz außerdem zur Tradition mittelalterlicher Weltkarten, Schlaraffia, sofern (noch) nicht ausgemacht fiktiv, jeweils in Entgegensetzung zum östlichen Paradies im Westen zu verorten. ${ }^{47}$

Wenn die Karte bis zur hintersten Provinz und zum kleinsten Flüsschen mit sprechenden Namen versehen ist, als gälte es, das tendenzielle Fehlen von zeitlicher Handlungsdynamik - und Sprechaktivität - in Schlaraffenland-Darstellungen ${ }^{48}$ mit dem dafür perfekt prädestinierten räumlichen Medium auszugleichen, dann deuten diese nicht nur auf die in der jeweiligen Fantasieregion dargebotenen Verlockungen und bevorzugten Beschäftigungen der Einwohner, sondern lassen auch reale Regionen anklingen. Die Beteuerung der örtlich-orthografischen Differenz und die Entschuldigung allfälliger Koinzidenz von Schreibweisen der Namen durch die schiere Menge der `Erdichtungen im Vorwort der Erklaerung ist scheinheilig:

Wir gebrauchen uns auch in solcher erdichteten Vorstellung dieser Schlarraffenlaender / einiger / auf gewisse Weise / andern in der Welt hier und dort befindlichen Laender und Staedte / dem Klang und Pronunciation nach / ziemlich gleich= lautender Namen / welche aber nicht allerdings wie selbige geschrieben wer-

45 So bemerkt Richter: Schlaraffenland, S. 235, ohne weiteren Kommentar.

46 Vgl. z.B. Denis Wood: The power of maps, New York u.a. 1992; Jörg Dünne: Die kartographische Imagination: Erinnern, Erzählen und Fingieren in der Frühen Neuzeit, Paderborn 2011, bes. S. 35-44 und 70.

47 Vgl. dazu Gilomen: Das Schlaraffenland und andere Utopien im Mittelalter, S. 239 bzw. 248.

$48 \mathrm{Zu}$ abwesender dynamis und verbreitetem Schweigen im Schlaraffenland - dessen Personal erst im 17. Jahrhundert überhaupt zu sprechen beginnt - vgl. Velten: Europäischer Mythos?, S. 263, mit Verweis auf Müller: Schlaraffenland, S. 24. 
den / dafuer wir uns moeglichst gehuetet haben / unsern erdichteten Land= Charten ein desto besseres Ansehen zu machen; solte aber wider unser Vermuthen / in Erdichtung so vieler hundert Namen / einem oder andern Ort / Provintz / Stadt / Marckflecken / Schloß oder Dorff gantz ein gleichlautendes Wort gefunden werden / so bitte hiemit/selbiges in Argem nicht aufzunehmen / weilen solches ohn alle boese reflexion auf eine oder andere Stadt / Regierung / Herrschafft oder Familien im geringsten nicht geschehen [...]. (E 6f.)

Zum Beispiel: Die Provinzen Langedoc und Nova Francia (d.i. Louisiana) in der Respublica Venerea (OV 236) holen das Stereotyp des wollüstig-luxuriösen Frankreich inklusive dessen nordamerikanischer Kolonie ins Schlaraffenland. In der gleichen Republik der Lust befinden sich aber auch die Provinz Bublgaria (OV 237) und die Stadt Inconstantinopel (OV 237). Porcellona klingt zwar einerseits spanisch, liegt jedoch, weil andererseits das Schwein darin hörbar ist, am Senfer See in Schweinlandia (OV 232), jenem Land, das unverschämt an die Schweiz gemahnt, denn der See sieht aus wie der Genfer, und Schaffhausen ist auch nicht weit (Abb. 7; OV 230).

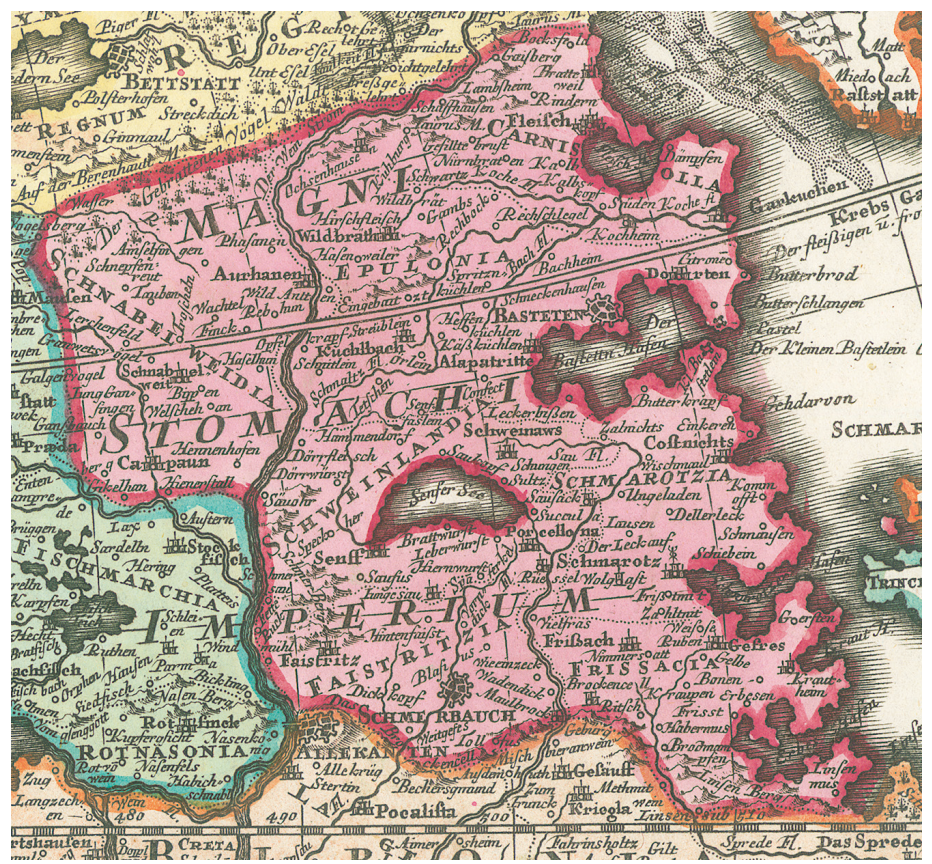

Abb. 7: Verräterisch schweizerisch: Schweinlandia

(Detail aus Abb. 6) 
Wie das Schaffhausener Beispiel in durchgängig fleischig benannter Umgebung zeigt, muss an manchem Namen aus der realen Geografie fast oder gar nichts geändert werden für die Versetzung nach Schlaraffia: Im karibischen Tobaco bzw. Tobago (Berner Kartenexemplar) etwa meldet sich ein Genussmittel, auf das die Ausstattung dieser Insel mit Schnupferland, Schmauchberg, Rotzkolben und Stinckmantl nur noch aufmerksam zu machen braucht (OV 250).

Der Hauptfluss der Zentralprovinz Schlaraffenburgi Territorium heißt programmatisch Überfluss (bzw. Uber Fl.), und der Luxus ist omnipräsent, auch außerhalb des speziellen Ampt Verschwende (Abb. 8; OV 229). Bei deutlichem Akzent auf bodenständiger Kost in Hülle und Überfülle (Schwein und Bier dominieren) ist zugleich Edles und Feinkost erhältlich: In Mammonia, dem Reich der Reichen, befinden sich Ortschaften wie Kleinod, Rubin, Granada oder Diamantstein (Abb. 11 in Kap. II; OV 258;); Leckeronia ist das Land von Marcipan, Confect und Zuckerbrod, das Land, in dem buchstäblich Cafe und Cocolate fließen, denn so heißen seine Flüsse (OV 238f.). Schlaraffia als Land von Bier und Schokolade im Überfluss: Die zwei unterschiedlichen Versionen der Karten-Kartusche (vgl.oben Abb. 3 und 4) setzen diese beiden Luxus-Dimensionen der Karte je separat genüsslich ins Bild.

Bereits nach einem ersten Eindruck von der reichen Ausstaffierung der Karte ist es keine metaphorische Überstrapazierung des Begriffs, von einem luxuriösen Verfahren zu sprechen, und zwar in jenem spezifisch rhetorischen Sinn, wie etwa noch bei Zedler der "STYLUS LUXURIANS « definiert wird: als "eine Schreib-Art, so in Tropis, Figuren, zuvörderst aber Synonymien, Exergasien, und dergleichen, keine Maasse hält und überhaupt selbst des Guten mehr thut, als die Sache leidet «. ${ }^{49}$ Zedlers Definition mit abwertendem Unterton steht in der Tradition einer Kritik an stilistisch-rhetorischem Luxus seit der Antike. In Rhetorik und Poetik trifft das Verdikt >luxuria bei Seneca, Cicero, Quintilian und Horaz vor allem die gezierte Rede, den übermäßig ausgeschmückten oder wortreichen Stil und die verlorene Einfachheit der Versform. ${ }^{50}$ Insbesondere ab dem 18. Jahrhundert wird solcher Sprachluxus häufig mit barockem Schwulst assoziiert.

49 Zedler: Universal-Lexicon, Bd. 40 [1744], Sp. 1474. Zum Gebrauch des Begriffs `Exergasie als Synonym zu >Expolitio< (Erweiterung und Variation eines Gedankens durch den Gebrauch verschiedener Worte und Redewendungen) vgl. Historisches Wörterbuch der Rhetorik, 12 Bde., hg. von Gert Ueding, Tübingen; Berlin, Boston u. New York 1992-2015, Bd. 3, Sp. 125.

50 Vgl. Heinrich Lausberg: Handbuch der literarischen Rhetorik: Eine Grundlegung der Literaturwissenschaft, Stuttgart ${ }^{4} 2008$, Verweise im Register unter sstylus luxuriosus‘; vgl. auch Joseph 


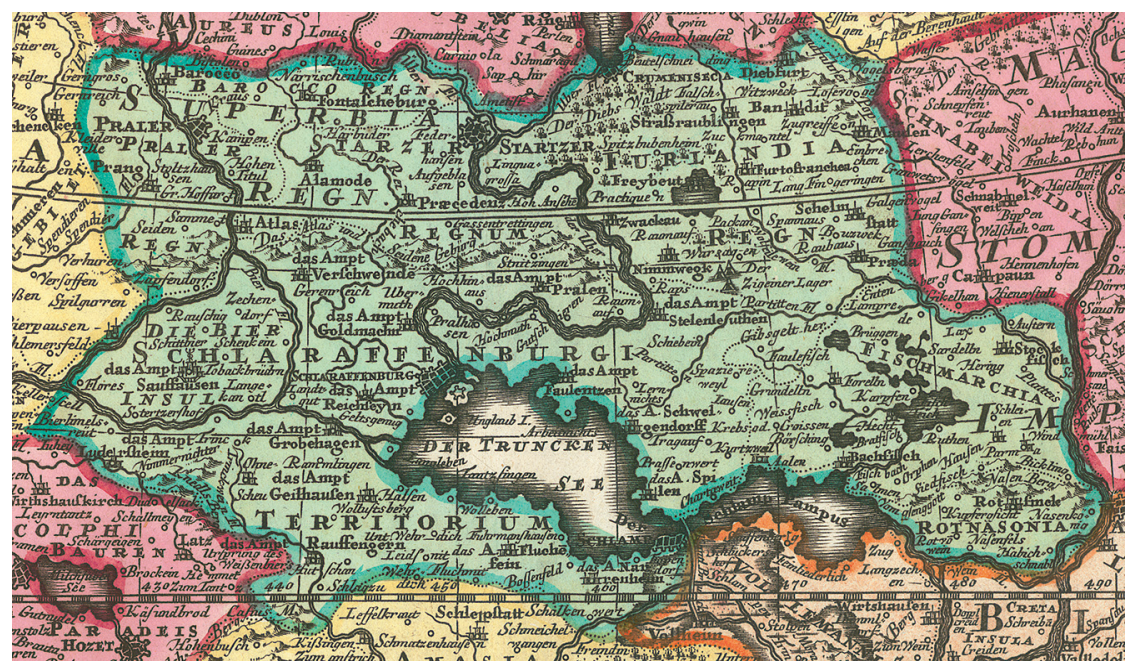

Abb. 8: Luxuriöse Landschaft: Schlaraffenburgi Territorium mit Uber Fl.

(Überfluss) und Ampt Verschwende (Detail aus Abb. 6)

Die Schlaraffenlandkarte frönt ganz ungeniert dem luxuriösen Stil, zelebriert Sprachluxus. Abgesehen davon, dass man die Darstellung von Luxusgütern und Lebensweisen als Landschaften insgesamt als tropisch, als figürlich charakterisieren kann, setzt dieses gemischte Bild-Text-Medium ${ }^{51}$ mit der obsessiven sprachlichen Ausarbeitung bis in den letzten Winkel und den unzähligen Varianten des Gleichen oder Ähnlichen - z.B. der Präsentation von Bier in allen Trinkformen oder Schwein in allen Sprachen - offensichtlich maßlos auf Verfahren aus der Sparte "Synonymie, Exergasie und dergleichen«. Das exzessive Weitertreiben eines allgemeinen Zugs von SchlaraffiaDarstellungen, die auch gerne Namen verballhornen, ${ }^{52}$ ist dabei zentral vom Medium selbst motiviert, wie generell der auf der Karte dargestellte Luxus nicht vom kartografisch luxuriösen Darstellungsverfahren ablösbar ist. Entsprechend erscheint die Lust an der Sprache mindestens so unmäßig wie die Lust an der Sache.

Vogl: Art. `Luxus‘, in: Ästhetische Grundbegriffe. Historisches Wörterbuch in sieben Bänden, hg. von Karlheinz Barck u.a., Stuttgart u. Weimar 2000-2005, Bd. III, S. 694-708, hier S. 695 und 703.

51 Zum >Medienverbundsystem $<$ Karte vgl. in Kap. IV, S. 86f.

52 Vgl. dazu z.B. Velten: Europäischer Mythos?, S. 266. 
Diese hingebungsvolle Darbietung des Schlaraffenlandes, die auf der Bildebene bis in die Umrahmung der Titelkartusche reicht, steht in Spannung zur denunziatorischen Absicht, die dagegen der Titel in der Kartusche verkündet (vgl. oben Abb. 3 und 4): [...] Neu=erfundene lächerliche Land=Tabell Worinnen all und jede Laster in besondere Königreich, Provintzien und Herrschafften abgetheilet [...]. Mit dem Etikett Laster verkauft die Schlaraffenland-Imagination all ihren Luxus als negative Utopie, Anti-Utopie oder genauer Utopie-Parodie und rückt das kartografische Unternehmen, das sich ohnehin synkretistisch bei allen möglichen Traditionen auch jenseits des Schlaraffia-Stoffes bedient, in die Nachfolge der christlichen Sündenund Lasterkataloge. ${ }^{53}$ Namentlich mit den Königreichen Superbia (Stolz, Hochmut), Invidia (Neid) und Avaritia (Geiz) übernimmt die Karte tel quel drei der sieben - oder mehr - Hauptsünden (»peccata [...] capitalia «54), wie sie im Mittelalter besonders en vogue gewesen sind. Die Todsünde des Zorns (ira) ist in Litigonia, dem Königreich der Raufer und Zanker mit Iracusa als Hafenstadt, diejenige der Trägheit (acedia) im Land der Faulen, Pigritarum Regio, variiert; die Völlerei (gula) erscheint schlaraffisch ausdifferenziert zu einem Reich des Fressens (Magni Stomachi Imperium) und einem des Saufens (Bibonia Regnum).

Obwohl der lateinische Begriff nicht vorkommt, klingt in diesem Kontext nun die Hauptsünde der >luxuria im Sinne von geistiger und vor allem körperlicher, sprich sexueller Ausschweifung ${ }^{55}$ nochmals verstärkt an. Diese wird theologisch und moralphilosophisch verurteilt, da sie gleichermaßen gegen die - im Zentrum auch der protestantischen Tugendlehre stehenden - Zehn Gebote ${ }^{56}$ wie gegen stoische Gebote der Selbstbeschränkung verstößt. Parallel dazu behauptet die frühneuzeitliche Medizin, »das kein

53 Vgl. auch Reitinger: Hauptwerk barocker Lachkultur, S. 301. Zur `Utopia-Anknüpfung vgl. Kap. IV.

54 Petrus Canisius: Der Große Katechismus - Summa doctrinae chistianae (lat.-dt.), übers. und hg. von Hubert Filser u. Stephan Leimgruber, Regensburg 2003, S. 202.

$55 \mathrm{Zu}$ diesen zwei Bedeutungsebenen vgl. Horst Mühlmann: Luxus und Komfort. Wortgeschichte und Wortvergleich, Bonn 1975, S. $22 \mathrm{ff}$.

56 Zur protestantischen wie katholischen Ablösung der Todsünden durch die Zehn Gebote im ausgehenden Mittelalter und der Frühen Neuzeit und damit zur Verschiebung der Sünden gegen den Menschen zu Sünden gegen Gott vgl. Robin Briggs: Die Hexenmacher. Geschichte der Hexenverfolgung in Europa und der Neuen Welt, übers. von Dirk Muelder, Berlin 1998, S. 123f., mit Bezug auf John Bossy: "Moral Arithmetic. Seven Sins into Ten Commandments", in: Conscience and Casuistry in Early Modern Europe, hg. von Edmund Leites, Cambridge u.a. 1988, S. 214-234. 


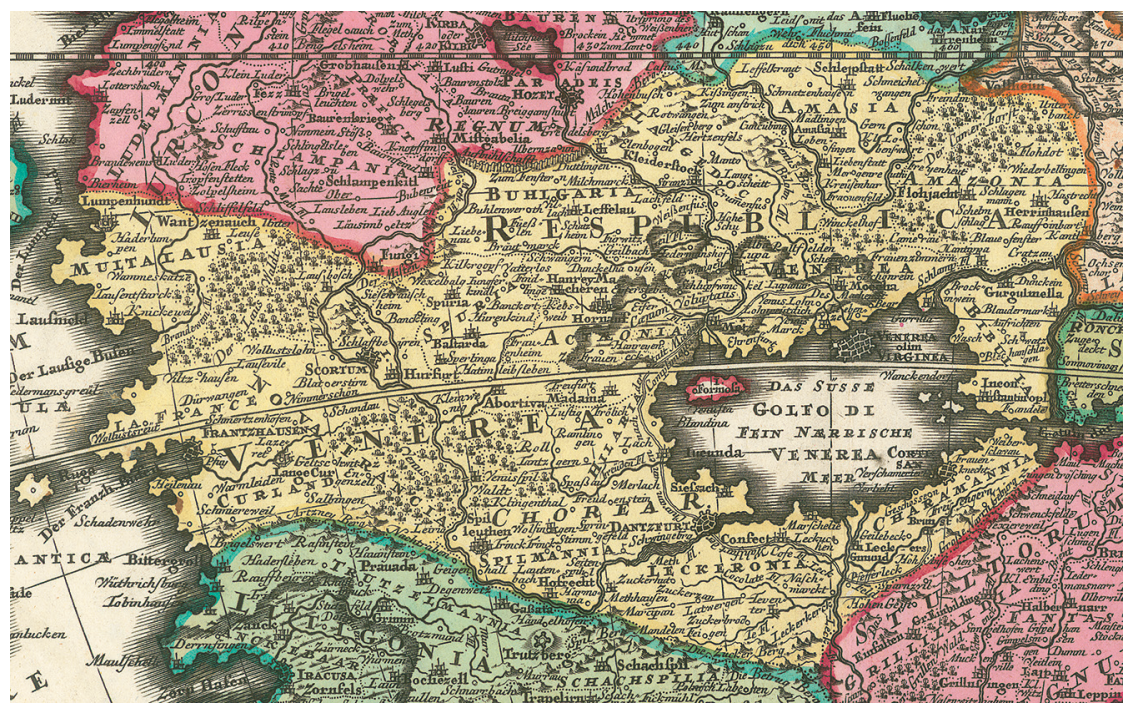

Abb. 9: Venus Berg, Geilbach, Frantzhausen, Blaterstirn, Abortiva und andere 'Luxuriar-Orte in der Respublica Venerea (Detail aus Abb. 6)

franzosen«, also keine Syphilis, »ursprünglich komen allein dan durch luxuriam $\ll_{0}^{57}$

Das Erbe dieser Bedeutungsdimension von Luxus tritt die lächerliche Laster-Karte insbesondere mit der erwähnten Respublica Venerea an (Abb.9), wo sich neben Inconstantinopel und Bublgaria etwa auch Geilbach, Hornauf und Weibersclavau, Schleppstatt, Schmeichelwangen und Schmatzenhausen, Mädlingen, Kebsweib und Abortiva finden (OV 236-239). Nicht zufällig in der hiesigen Provinz Nova Francia drohen Orte wie Frantzhausen (»an dem Frantzhœsischen Busen des grossen Luder=Meers gelegen« [E 127]) mit Syphilis und anderen Folgen wie Dürwangen, Lausevile, Schandau, Pfuy oder Iedermansgreül bzw. mit Versuchen der Schadenwehr wie Lange Cur, Artzney Berg, Salbingen oder Lazeret (OV 238). In dieser Region liegen auch der Venus Waldt und Blaterstirn recht eng beieinander - genau wie in Grimmelshausens Roman Simplicissimus (1668), als der Titelheld an den "Blattern" erkrankt, dem ersten und untrüglichen Anzeichen für die »Frantzosen«, wenige Tage

57 Paracelsus: Von Ursprung und Herkommen der Franzosen, in: Sämtliche Werke, hg. von Karl Sudhoff u.a., München 1929ff., Bd. I/7, S. 190. Vgl. als Überblick zu der vormodernen Epoche der Luxus-Kritik auch Vogl: >Luxus‘, S. $695 \mathrm{f}$. 
nachdem er der sexuellen Schwelgerei im »Venus-Berg« nachgegangen ist (wobei Simplicissimus dann `nur an den »Kinds-Blattern« erkrankt und mit einem entstellten Gesicht davonkommt). ${ }^{58}$

Die herkömmlichen Sünden- und Lasterkataloge werden jedoch nicht einfach durchdekliniert, sondern vielmehr unordentlich weitergesponnen und karnevalesk verwandelt. Überhaupt ließe sich die Schlaraffenlandkarte mit ihren zentralen Momenten des Exzessiven, Materiell-Leiblichen, der verkehrten Welt und des Satirischen als Paradefall von karnevalisierter >Literatur im Sinne Bachtins beschreiben. ${ }^{59}$ Damit führt sie zugleich in besonderer Form jene karnevalesken Strategien vor, die für die Schlaraffia-Tradition insgesamt charakteristisch - und bisher noch zu wenig beachtet worden sind. ${ }^{60}$ Diese Strategien stehen in wechselseitigem Zusammenhang mit dem vermutlich häufigen `Gebrauch`schlaraffischer Darstellungen bei Karnevalsritualen. ${ }^{61}$ Bisweilen wird der Karneval in den Darstellungen auch thematisiert. So gibt es bei genauem Hinsehen auf der Karte eine Provinz des Fastnachtstreibens zu entdecken. ${ }^{62}$

Die karnevaleske Verwandlung spielt sich nicht allein durch den karikierend-befreienden Umgang der lächerlichen Land-Tabell mit dem belastenden Thema ab, sondern auch formal und medienspezifisch durch die nichtklassifikatorische Ordnung der Karte. Während Kommentierungen der Karte die aufgehäuften Ortschaften zur Orientierung jeweils linear auflisten, was sich von der buchförmigen Erklaerung bis hin zu digitalen Präsentationen ${ }^{63}$ zeigt, bietet die Karte gerade keine Ordnung im Sinne eines Katalogs oder einer Liste und hält sich nicht an die Hierarchie der Todsünden.

Es dürfte der mit dem Begriff des Lasters verbundene didaktische Impetus gewesen sein, der Leibniz in den 1690er-Jahren dazu bewogen hat, in seiner Didaktiktheorie diese imaginäre Karte - neben weiteren Beispielen

58 Hans Jacob Christoffel von Grimmelshausen: Simplicissimus, in: Werke, hg. von Dieter Breuer, 3 Bde., Frankfurt a.M. 1989-1997, Bd. I/1, S. 355-371. Vgl. hierzu Maximilian Bergengruen: »Lässliche Todsünde oder Männerphantasie? Zur Funktion der Luxuria in der Venusberg-Episode des Simplicissimus«, in: Simpliciana 32 (2010), S. 83-100.

59 Vgl. bes. Michail Bachtin: »Der Karneval und die Karnevalisierung der Literatur«, in: ders.: Literatur und Karneval. Zur Romantheorie und Lachkultur, München 1969, S. 47-60.

60 Für diesen Befund vgl. Velten: Europäischer Mythos?, S. 255.

61 Vgl. bes. Herman Pleij: Der Traum vom Schlaraffenland. Mittelalterliche Phantasien vom vollkommenen Leben, übers. von Rainer Kersten, Frankfurt a.M. 2000, S. 87-89, 119121, 136 u.ö. Generell zum Zusammenhang von Schlaraffenland-Darstellungen und Karnevalskultur vgl. auch Richter: Schlaraffenland, S. 70-76.

62 Vgl. dazu in Kap. III, S. 78-80.

63 Bes. derjenigen der UB Graz: http://sosa2.uni-graz.at/sosa/karten/schlaraffia/index.php [letzter Zugriff 18.06.2021]. 
allegorischer Darstellungen wie Daniello Bartolis La geografia trasportata al morale (1664) - zusammen mit der berühmten Carte de Tendre (Abb. 26 in Kap. IV) aus dem ersten Teil von Madeleine de Scudérys Roman Clélie (1654-1660) als spielerisches Lehrmittel zu empfehlen. ${ }^{64}$ Dass Leibniz die Accurata Utopiae Tabula hier ohne weitere Erklärung in einer Reihe mit der französischen Landkartenallegorie und verwandten, damals allgemein bekannten Beispielen nennt, würde ebenfalls für eine frühere Datierung als 1694 (Reitinger) sprechen.

Als hätte der Erfinder der Karte seinerseits ein schlechtes Gewissen gehabt ob seiner luxuriösen Darstellung des Laster-Landes, hat er dieses in theologisch-moralisch motivierte Umländer eingefasst, deren höchstes die Unbekante Länder der Frommen im Norden und deren tiefstes das bereits genannte Tartari Regnum bzw. Höllische Reich im Süden sind (Abb. 18 in Kap. III; OV 272f.). ${ }^{65}$ Während die »blinden und wolluestigen Schlarraffen" (E 367) Ersteres überhaupt nicht kennen, treiben sie Handel mit den Bewohnern des Letzteren und haben eine Art Teufelspakt ${ }^{66}$ abgeschlossen: Um unbehelligt ihren Lebensfreuden frönen zu können, händigen sie den »hoellischen Tartarn" hernach ihre Seelen aus, denn hier müssen sie nun die »Schulden ihres Laster=Lebens « begleichen (E 379), wie es warnend in der Erklaerung heißt.

Neben der Laster-Etikettierung und der theologisch-moralischen Einfassung durch Umländer auf der Karte fungiert dieser beschreibend-erzählende Text der Erklaerung insgesamt als zentrale sflankierende Maßnahmer zur gleichzeitig erzeugten Attraktivität des Schlaraffenlandes - allerdings ohne die Ambivalenz letztlich zu beheben. Der Autor, wohl kein Kleriker, aber ein Gebildeter mit soliden theologischen Kenntnissen, gibt sich dabei überkonfessionell. ${ }^{67}$ Er baut die Schlaraffenland-Vorstellung, in der Vorrede als »gemeine Fabel der Unwissenden « bezeichnet, »welche / ausser einem lustigen Freß= oder Sauff=Discurs / wenig Witzes« habe (E 4), erklärtermaßen

64 Vgl. in den Änderungsnotaten zu Nova methodus discendae docendaeque jurisprudentiae. Ex artis Didacticae Principiis in parte Generali praemissis, Experientiaeque Luce [1667], in: Sämtliche Schriften und Briefe, Reihe 6, 6 Bde., Darmstadt u.a. 1930-1962, Bd. 1, S. 261-364, hier S. 276. Diese Änderungen hat Leibniz ungefähr 30 Jahre nach der Ersterscheinung vorgenommen (vgl. in der Einleitung zu dieser Ausgabe, S. XXII). Vgl. dazu auch Reitinger: Hauptwerk barocker Lachkultur, S. 330, der die hier genannte "Germanica Slauravoniae tabula« als besagte Karte identifiziert und Leibniz' Erwähnung als erstes Rezeptionszeugnis wertet.

65 Mehr zu den Umländern vgl. in Kap. III, bes. ab S. 73.

66 Mehr dazu vgl. Kap. II, bes. S. 55f.

67 Vgl. dazu auch Reitinger: Hauptwerk barocker Lachkultur, S. 311f. 
zu einer »durch das gantze Werck währende[n] verblühmte[n] Redens-Art / oder Allegoria« auf die Lasterhaften um (E 27). Was das Schlaraffenland zu bieten hat, wird in der Beschreibung immer wieder mit ironischen Lobreden durchsetzt. Zudem ist jedem Kapitel eine belehrende "Anweisung « (z.B. E 56, 84) oder »Application« (z.B. E 327) angehängt, die festlegt, dass die davor gebotene "possirliche Beschreibung« (z.B. E 56, 146) abschreckend zu verstehen sei. So werden wir etwa nach fast 40 Seiten Beschreibung der Respublica Venerea über deren »Worzu« belehrt: Sie "zeiget an / auf wie vielerley Weise sich das menschliche Geschlecht wider die Reinigkeit versuendige / was fuer eine grosse Pfuetze der Wollust, und gefäbrliches Meer die Suessigkeit derselben umb sich habe«, aber auch konkret, "wie nahe das Tantzen und die Seitenspiele bey dem Venus-Spiel waeren / und wie die Hurerey eine abscheuliche Kranckheit an dem Leibe verursache« (E 146) und vieles Schreckliche mehr.

Doch all diese miesmacherischen Mittel wirken nicht garantiert. Denn die Freunde des »Freß= oder Sauff-Discurs « kommen beim fantasievoll-überbordenden Tischleindeckdich des Texts derart auf ihre Rechnung, dass sie das Allegorisieren leicht vergessen, was die expliziten Applikationen mehr eingestehen denn verhindern. ${ }^{68}$ Und der Verfasser muss sich in der Vorrede richtiggehend selbst daran erinnern, dass er bei all dem Ausmalen dann jeweils »doch auch nicht vergessen" werde, »dieser Lastern [...] zu spotten« (E 6). Auch Ironie ist ein zweischneidiges Verfahren, zumal in Kombination mit einer offenkundigen Lust am Ausbau der Sprachspiele in den Benennungen der Karte. So droht das delectare das docere zu überflügeln, entgegen der Wirkabsicht, die der Autor zu Beginn mit der für das Schlaraffen-Thema passendsten Version von Horaz' Maxime formuliert: »Omne tulit punctum, qui miscuit utile dulci./ Zu Teutsch: / Den rechten Zweck gewiß erwischt / Der Nutzlichs mit dem Süssen mischt« (E 22).69 Das mutwillig riskante Doppelspiel erhellt besonders augenfällig das ambivalente Potenzial jeder (Moral-)Satire, die wie keine andere Gattung vom satirierten Objekt lebt. ${ }^{70}$ Entsprechend präsentiert sich die Darstellung von einem widersprüchlichen Standpunkt aus geschrieben, indem sie sich einerseits mit dem fingierten Druckort Arbeitshausen vom Land der Faulenzer distanziert, sich aber andererseits als erfundene schalckhafftige Welt (im Titel u.ö.) selbst zum schla-

68 Zum letzten Aspekt vgl. auch Richter: Schlaraffenland, S. 214.

69 Die Zeilen stammen aus Horaz' Ars poetica, V. 343.

$70 \mathrm{Zu}$ diesem Effekt bezüglich einer anderen Schlaraffenland-Imagination vgl. Peter Schnyder: "Satire in saturierter Zeit. Heinrich Manns Roman Im Schlaraffenland und die Poesie des Geldes«, in: Weder u. Bergengruen (Hgg.): Luxus, S. 217-232. 
raffischen Produkt - nämlich zum Erzeugnis von Schalcklandia (OV 241), einer Region innerhalb des luxuriösen Schlaraffenlandes - macht. ${ }^{71}$ Mit Schalcklandias direkter Nachbarschaft zu Fantastia samt Meerbusen Sinus fantasticus, Grillilandia samt den Ortschaften Gr. und Kl. Einbildung innerhalb des Königreichs der Narren (Stultorum Regnum; Abb. 21 in Kap. III) stellt diese Imagination zudem jene erwähnte Verbindung von Fantasie und Luxus her, die übrigens umgekehrt auch in der damaligen LuxusDiskussion eine wichtige Rolle spielt, wenn die Verfallenheit an den Luxus als Befriedigung eingebildeter Bedürfnisse verstanden wird. ${ }^{72}$

Die durchgängige Ambivalenz der Erklaerung in der Wertung der imaginierten Welt des Luxus, die noch ganz im moralisch-theologischen Vokabular von `Sünden` und >Laster beschrieben wird, zeigt, dass solche Doppelspurigkeit nicht für moderne Texte reserviert ist, die ja ihrerseits den Luxus nicht einfach aufwerten. Das gilt zumindest und speziell für das literarische Medium, denn die Lust am Laster kann und darf in der (durchaus auch belehrenden) Literatur eher ausgelebt werden als in eindeutiger didaktischen Genres, wie etwa der Vergleich mit einer Schlaraffenland-Predigt aus der gleichen Zeit besonders deutlich machen kann.

Seit Geiler von Kaisersberg 1498 einen Predigtzyklus über Sebastian Brants Narrenschiff (1494) gehalten hatte, der in gedruckter Form über Jahrhunderte hinweg wirkmächtig blieb, ist das Schlaraffia-Sujet bei Predigern beliebt. ${ }^{73}$ So verbreitet um 1700 etwa der bayerische Augustinereremit Ignatius Ertl (1645-1713) in einer seiner voluminösen Sammlungen eine lange Predigt zum Thema Wo aus gehet der Weeg vom Schlaraffen=Land? wohin kommt man durch den Muessiggang? ${ }^{74}$ Hierin holt Ertl »jedermann « beim Fernweh nach dem schlaraffischen Land des Müßigganges ab, das noch "viel lustiger zu bewohnen" scheint als das göttliche »Paradeiß ${ }^{75}$ Das geschieht freilich nur, um das Schlaraffenland als Reich des Teufels zu entlarven (»der leidige Teuffel $[\ldots]$ regieret« es, denn »Muessiggang ist des Teuffels Haupt=Kueß / Haupt=Polster und Loder=Bett; Otium puvinar Diaboli«) und es als nir-

71 Ausführlich zu diesem zweischneidigen Standpunkt vgl. Kap. III.

72 So erklärt etwa - der im moralisierenden Paradigma argumentierende - George Mackenzie, die dem Luxus Frönenden würden versuchen »to satisfy their Imaginary fantastick Necessities«, vgl. George Mackenzie: The Moral History of Frugality, London 1711, S. 291. Vgl. dazu auch Berry: The idea of luxury, S. 108, 120.

73 Vgl. Richter: Schlaraffenland, S. 207.

74 In: Ignatius Ertl: Sonn- und Feyer-Tägliches Tolle Lege, Das ist: Geist- und Lebr-reiche Predigen Auf alle Sonn- und Feyer-Täg des gantzen Jahr-Lauffs eingerichtet, 1. Dominical-Theil, Nürnberg 21708, S. 122-133.

75 Ebd., S. 122. 
gends existent - im buchstäblichen Sinn - wie zugleich überall präsent im allegorischen Sinn - zu entdecken: Während man vergeblich »alle Geographische Welt=Beschreibungen und Land=Karten durchsuchen « werde, grassiere das "Welt=gemeine[ ] Haupt=Laster der Faul= und Traegheit allerorts. ${ }^{76}$ In drastischen Bildern malt der Prediger für fleißiges Arbeiten aus, wie ein solches Laster-Leben dazu führt, dass man »zeitlich und ewig / am Leib und Seel verdirbet«, indem der Müßiggang der »Weg zu aller Armut und Noth / zu aller Boßheit und Leichtfertigkeit« sowie in der Folge zu den »Hoellen=Straffen der ewigen Verdammnuß sei. $^{77}$

Bei seiner Beschreibung der zeitlich-irdischen Konsequenzen könnte Ertl übrigens die Accurata Utopiae Tabula ganz konkret vor Augen gehabt haben, was die betonte Vergeblichkeit der Suche nach dem erdichteten Ort auf »Land=Karten « umso mehr relativieren würde: »[D]er erste und nechste Weg von dem Schlaraffen=Land des Muessiggangs fuehret Schnurgrad in das grosse Hunger= und Kummer=Land hin / in das weite Elend zu dem Bettel $=$ Stab hinaus. $\ll^{78}$ Auf der Schlaraffenlandkarte droht im Nordwesten gleich jenseits der Schlaraffia-Grenze die Region des Alters (Senectae Regio) mit dem Kummerland und dem Hungersland, wo ein Ort namens Bettelstab liegt (Abb. 13 in Kap. II; OV 269f.). Die Verbindung lässt aber gerade auch den Unterschied ins Auge stechen: Ertl, als Prediger mit einer klaren Botschaft nicht auf lustvolle Behandlung der verurteilten Laster aus, schaut auf der zweideutigen Schlaraffenlandkarte am saftig ausgeschmückten Schlaraffenland selbst vorbei auf ein elendes Umland.

Das Spezifische, in diesem Sinn Vormoderne, das die kartografische Schlaraffenland-Imagination samt Erklaerung indes mit Ertls Predigt teilt, wiewohl darstellerisch ganz anders realisiert, liegt grundsätzlich in der Art und Weise, Luxus (in materiellen wie temporalen Dimensionen) zu problematisieren. Es wird mit den Folgen des Laster-Lebens argumentiert, und zwar nicht allein mit den ewigen jenes Höllischen Reichs, sondern - typisch neuzeitlich ${ }^{79}$ - auch mit den zeitlichen. Deshalb ist das Reich von Hunger und Kummer, Armut und Krankheit ebenso signifikant, das direkt an das schlaraffische »Königreich der Verschwender« (E 316) grenzt - abgetrennt nur durch die »Credit-Berge«. ${ }^{80}$ Weil bei der Konzeptualisierung als Laster

76 Ebd., S. $123 f$.

77 Ebd., S. 124 bzw. 133.

78 Ebd., S. 125.

79 Vgl. Richter: Schlaraffenland, S. 204, in Bezug auf Brants Narrenschiff.

80 Vgl. dazu Kap. II. 
die argumentative Hauptlast ${ }^{81}$ auf der Androhung der Folgen des Luxus liegt und weil die kartografische Ordnung zeitliches Nacheinander als räumliches Nebeneinander realisiert, sind auf der Accurata Utopiae Tabula die Umländer so zentral, die das Schlaraffenland buchstäblich in den theologisch-moralischen Rahmen einfassen, einpassen - und es zugleich freihalten. Denn das Land des Luxus prangt groß und fett in der Mitte.

Entscheidend anders gestaltet sich eine Schlaraffenland-Vorstellung, die ungefähr gleichzeitig entstanden ist, jedoch unter der hier gewählten Perspektive als modern kontrastiert werden kann und so den (Rück-)Blick auf die Karte um eine wichtige Dimension erweitert.

\section{Zum Vergleich: Fénelons Voyage dans l'île des plaisirs oder Überfluss produziert Überdruss}

Die kurze, an Lukians >Insel der Seligen erinnernde »Fable« Voyage dans l'île des plaisirs des französischen Theologen, Fürstenerziehers und Schriftstellers François de Salignac de la Mothe Fénelon ist zwischen 1689 und 1692 geschrieben ${ }^{82}$ und erst postum publiziert worden. ${ }^{83}$ Zunächst wirkt alles wie gehabt. Auch der Ich-Erzähler dieses imaginären Reiseberichts ist didaktisch ambitioniert und fügt am Schluss eine Moral gegen das schlaraffische Leben an: Die sinnlichen Genüsse (»plaisirs des sens«), so abwechslungsreich und mühelos (»faciles«) sie seien, wirkten entwürdigend und machten nicht glücklich (F 204). Deshalb habe er die Gegenden solch genussreichen Anscheins verlassen und zu Hause in einem enthaltsamen Leben (»vie sobre«), maßvoller Arbeit (»travail modéré«), reinen Sitten und Verwirklichung der Tugend (»pratique de la vertu«) das Glück und die Gesundheit gefunden, die ihm die unaufhörlich guten Speisen (»la continuité de la bonne chère«) und die Mannigfaltigkeit der Genüsse nicht zu verschaffen vermochten (ebd.). Über die herkömmlichen Bezüge auf den Tugend-versus-Laster-Komplex und auf schädliche Folgen des Luxus-Lebens hinaus deutet sich hier nun aber ein neues Argumentationsfeld an, das der

81 Zugleich wird mit Schlaraffia-Ortschaften wie Kotzinhaven in Seulandia (OV 262) oder Kopfwe in Lallandia (OV 235) auch einiges zur intrinsischen Trübung des Vergnügens versucht.

82 Vgl. Alain Lanavère: »L'imagination de Fénelon dans ses premiers écrits de fiction «, in: dixseptième siècle 206 (2000), S. 11-27, hier S. 12.

83 François de Salignac de La Mothe-Fénelon: Voyage dans l'île des plaisirs, in: Euvres, hg. von Jacques Le Brun, Paris 1983-1997, Bd. I, S. 200-204. Verweise auf diese Ausgabe im Folgenden unter der Sigle F direkt im Text. 
vorangehende Bericht der Reiseerlebnisse narrativ bespielt: Die Reisenden werden zunächst von Händlern (»marchands«, ebd.) empfangen, die Appetit und Müdigkeit verkaufen, da es daran auf dieser Insel des Überflüssigen (»des choses superflues«, F 203) und der Untätigkeit oftmals mangle (vgl. F 201). Trotzdem muss der Besucher zwischendurch fasten, um sich vom Überdruss der Tafelfreuden zu erholen (»la fatigue des plaisirs de la table«, F 202); schließlich hat er genug und reist ab.

Die Händler mit der Mangelware `Appetitく sind besonders typisch für dieses neue Schlaraffenland, das weniger unter moralischem denn unter ökonomischem Blickwinkel präsentiert wird. Die literarische Neuerfindung kann in Verbindung gebracht werden mit der Tendenz zur Entmoralisierung der Luxus-Debatte um 1700, genauer: der tendenziellen Abkoppelung der ökonomischen von den theologisch-moralischen Argumentationen. Diese Ausdifferenzierung hatte gerade in Frankreich bereits früh im 17. Jahrhundert mit Autoren wie Antoine de Montchrétien, Charles de Saint-Évremond und Pierre Bayle begonnen; sie lässt sich im englischen Kontext etwa an Nicholas Barbons Discourse of Trade (1690) exemplarisch studieren und wurde von Bernard Mandeville im Untertitel seiner Fable of the Bees (1705-1732) $)^{84}$ auf die international wirkmächtige Formel Private Vices, Publick Benefits gebracht. ${ }^{85}$

Die Erzählung treibt es besonders weit mit der Verlagerung des moralisch hin zum ökonomisch bedachten Überfluss: Der Fokus liegt durchweg auf dem Verhältnis von Angebot und Nachfrage. Fénelon stellt seine Insel der grenzenlosen Genüsse weder als Sündenpfuhl noch umgekehrt als Tugendreich vor, sondern als Ort, dessen jederzeit und überall bestehendes (Gratis-)Angebot schlicht entsprechende Nachfrage erfordert. $\mathrm{Da}$ das Angebot im Schlaraffenland garantiert und geschenkt ist, entsteht Nachfrage nach der Nachfrage selbst, und es gibt Händler, die den Kreislauf des Konsums in Bewegung halten, indem sie Nachfrage verkaufen. Sie bieten Bedürfnisse bzw. Gelüste als Waren an; je reicher man ist, desto mehr Gelüste kann man sich leisten. Die Gelüste rücken demnach im

84 Die Editionsgeschichte ist kompliziert: Das Gedicht erschien schon 1705, 1714 zwei Editionen mit Anmerkungen, 1723 die erweiterte »zweite« Auflage, 1724 die »dritte« mit dem Zusatz der »Defence« und einigen stilistischen Änderungen; 1725, 1728, 1729 und 1732 weitere Auflagen mit minimalen Änderungen.

85 Vgl. dazu Berry: The idea of luxury, S. 101-125 (v.a. zu Barbon) und Vogl: ‘Luxus‘, S. 697699. Zu Mandeville im historischen Kontext vgl. Dorit Grugel-Pannier: Luxus. Eine begriffs- und ideengeschichtliche Untersuchung unter besonderer Berücksichtigung von Bernard Mandeville, Frankfurt a.M. u.a. 1996, S. 297, die auch die verschiedenen, für die Fable insgesamt relevanten Lesarten der äußerst mehrdeutigen elliptischen Formel auflistet. 
Schlaraffenland auf die Position des Exquisiten, die andernorts die Genüsse besetzen. So aktualisiert Fénelons Darstellung das in der imaginativen Tradition der Schlaraffenländer prominente Motiv der 'Verkehrten Welt‘.

Das Spiel von Angebot und Nachfrage ist dabei bis in den Körper des Individuums verlängert, mithin diätetisch gewendet, indem die Dynamik von Genüssen und Gelüsten analog funktioniert. Die Genüsse werden nicht moralisch beurteilt; vielmehr gilt es einfach dafür zu sorgen, dass die Gelüste Schritt halten können. Mit diesem Blick auf das Individuum geht die Geschichte einen entscheidenden Schritt weiter in der Ökonomisierung als die ökonomisch argumentierenden Theoretiker der Zeit: Es ist kein Zufall, dass in Mandevilles Formel Private Vices, Publick Benefits die individuelle Seite durch den Begriff ,Vices` noch mit dem moralischen Vokabular verknüpft ist, und zwar in signifikantem Gegensatz zu >Benefits` anstatt des moralischen Pendants ,Virtues auf der allgemeinen Seite. Damit wird zugleich eine andere Differenz deutlich: Während sich die Theoretiker bei der Beurteilung des Luxus für die Effekte auf das Wohl der `Nation`oder das Allgemeinwohl interessieren, das sie gerne in eine paradoxe Beziehung zur individuellen Moralität setzen, lässt Fénelons Erzähler das `Gemeinwohk völlig außer Acht und konzentriert sich - eine privilegierte Möglichkeit des Mediums Literatur nutzend - egoistisch auf die individuelle Perspektive.

Umso weniger scheint zunächst einer Aufwertung des Überflusses im Wege zu stehen, wie sie in der neuen ökonomischen Betrachtungsweise angelegt ist. Tatsächlich wirkt Fénelons Insel einerseits wundervoll: Die raffinierten Appetitverkäufer sichern den Nachschub an Nachfrage und lösen allfällige Kreislaufprobleme, noch bevor diese entstehen. Ihr Geschäft lässt zudem das Geld fließen, und zwar dank Reisenden wie dem Erzähler vor allem auch von außerhalb ins Land. Das würde jene modernen Ökonomen freuen, die den Handel mit Luxusgütern im Hinblick auf die Prosperität der Gesellschaft besonders dann - gut merkantilistisch - loben, wenn mehr Geld in den eigenen Staat als hinaus fließt. ${ }^{86}$ Überdies bemisst sich in Fénelons Geschichte der Überfluss je nach Appetit, der nicht snatürlich beschränkt ist, sondern durch Hinzukauf individuell erweitert werden kann. Entsprechend wird in der Debatte häufig betont, wie relativ der Luxus-Begriff sei, weil die fließende Abgrenzung zwischen Notwendigem und Überflüssigem nicht substanzialistisch getroffen werden könne. ${ }^{87}$

86 Vgl. z.B. Berry: The idea of luxury, bes. S. $102 \mathrm{f}$.

87 Vgl. z.B. Bernard Mandeville: The Fable of the Bees, or Private Vices, Publick Benefits, hg. von Phillip Harth, London 1970, S. 137, zusammenfassend dazu Vogl: >Luxus`, S. 699. Diese 
Allerdings und andererseits tritt der egoistische Erzähler nicht als Merkantilist auf, was bei Fénelon auch überrascht hätte, enthält doch sein Roman Les Aventures de Télémaque (1699) eine dezidierte Kritik an der merkantilistischen Wirtschaftslenkung des Königs. ${ }^{88}$ Auch hat die Erfindung des Appetithandels einen karikierenden und ad absurdum führenden Effekt. Dass außerdem die Esslust in Form von Taftsäckchen mit der Funktion künstlicher Mägen (vgl. F 202) verkauft wird, verweist doch wieder auf die snatürliche` Grenze des Magens aus Fleisch und Blut. Keinen Zweifel lässt der Erzähler folglich auch daran, dass Überfluss zu Überdruss führen muss. Nachhaltig hilft ihm nämlich nicht der Erwerb von Zusatzappetit, nicht die exzessive Aufstockung der Gelüste, sondern im Gegenteil: das Fasten - und am Ende nur noch die Abreise aus Schlaraffia. Denn das notorische Überangebot erzeugt ein Defizit an Nachfrage, das den Genuss ebenso verhindert wie der Mangel.

Analog zu diesem inhaltlichen Moment verhält sich der diätetisch umsichtige Erzähler selbst vergleichsweise enthaltsam in der Ausmalung der klassisch-kulinarischen Schlaraffenland-Motivik. Ausführlich handelt er von anderen Themen, von seinem Traum kristallener Menschen (F 201f.), vom Ausflug zu einer Marmorstadt (F 203) und vom gynokratischen Regierungssystem der Insel (F 204), als sei er bemüht, dem Überdruss des Lesers ob all der Aufzählungen und Wiederholungen vorzubeugen, welche die schlaraffischen Darstellungen insgesamt kennzeichnen.

Einer ähnlichen, ökonomisch inspirierten Denkweise wie Fénelons Imagination ist die am Anfang dieses Kapitels vorgeführte Gleichung bei Wieland verpflichtet, die freilich einen anderen Punkt vorbringt: Die Mägen und Unterleiber der Menschen zu ignorieren, ist so gut oder eben so schlecht wie Schlaraffen mit permanent befriedigten Bäuchen und Unterteilen zu fantasieren. Nicht zufällig findet sich denn in einem anderen Roman von Wieland, dem Goldnen Spiegel (1772), auch eine (Binnen-)Geschichte, die vom Überdruss am Überfluss handelt und dort explizit als literarische Antwort auf die in der Rahmenhandlung aufgeworfene und in den Abhandlungen vieldiskutierte Frage präsentiert wird, was Regenten unternehmen sollten, damit der »Luxus« einer »Nazion so wenig als möglich scha-

Relativierung sieht Berry als Hauptunterschied zur aristotelischen Luxus-Theorie, vgl. Berry: The idea of luxury, S. 115.

88 Vgl. dazu etwa Winfried Hobert: Fénelon als Denker der politischen und sozialen Reform, Braunschweig 1974, S. 189-202. 
de«, konkret: ob man eine »Polizey« mit dieser Aufgabe betrauen solle. ${ }^{89}$ Ganz im Sinne der allmählichen Abschaffung der Luxus-Gesetze und Ersetzung durch Steuern im 18. Jahrhundert ${ }^{90}$ wird diese Regulierungsfrage verneint. Dafür erzählt der Hofphilosoph dieses (Meta-)Fürstenspiegels zur normativen Orientierung die utopische Geschichte von den `Kindern der Natur $<$, die sich - wie Fénelons Reisender nach seiner Rückkehr von der île des plaisirs - dem maßvollen Leben verschrieben haben, und zwar aus keiner anderen (moralischen) Motivation heraus als derjenigen, besser genießen zu können.

Den gleichen Grund macht uns Fénelons Erzähler für sein Maßhalten weis, der ja bereits sein Fasten in Schlaraffia nicht als Verzicht, sondern als Genuss-Technik verkauft hat, nicht als asketisches, sondern als hedonistisches Fasten. Wielands `Kinder der Natur , ein »Völkchen von ausgemachten Wollüstigen «, ${ }^{91}$ die sich mäßigen, um zu genießen, sind das positive Pendant zu den armen Schlaraffen, denen der Überfluss den Genuss vergällt.

Das schlaraffische Luxus-Land, das kein Laster-Land mehr ist, erweist sich so als eine Art Mangel-Land zweiter Ordnung: Hier herrscht Mangel an Mangel. War es früher unmoralisch, ist es jetzt unökonomisch. Eine moderne bzw. (früh)aufklärerische Disqualifizierung des Schlaraffenlandes erfolgt nicht mehr nach der Formel >Luxus ist Laster<, sondern neu nach der Voraussetzung >Überfluss produziert Überdruss‘. Dahin gestellt bleibe, ob es ein milderes oder aber umso harscheres Verdikt gegen den maßlosen Genuss bedeutet, keine heteronomen Werte ins Feld zu führen neben dem Genuss selbst - was sich übrigens speziell die literarischen Texte leisten, während die theoretischen etwa mit gefährdetem Bevölkerungswachstum oder beeinträchtigter Soldatentauglichkeit argumentieren ${ }^{92}$ - und den moralisierenden Gestus eines >Du sollst nicht $<$ auf der Basis einer implizierten anthropologischen Gegebenheit durch ein apodiktisches >Du willst nicht zu ersetzen. Aber jedenfalls hält diese Verschiebung den seinerseits ambivalent agierenden Erzähler bei Fénelon so wenig ab wie den Erfinder und den Erklärer der Accurata Utopiae Tabula, sein Schlaraffenland mit aller imaginativen Raffinesse luxuriös auszustatten.

89 Christoph Martin Wieland: Der goldne Spiegel oder Die Könige von Scheschian, in: Sämmtliche Werke, 45 Bde., Leipzig 1794-1798, Reprint Hamburg 1984, Bd. 6/7, Zitate Bd. 6, S. 138 bzw. 144f. Vgl. dazu Christine Weder: »Poesie als/statt Polizei. Zum Verhältnis von Sexualität und Gesetz in Wielands Goldnem Spiegel und im polizeiwissenschaftlichen Kontext", in: Sexualität - Recht - Leben. Die Entstehung eines Dispositivs um 1800, hg. von Maximilian Bergengruen, Johannes F. Lehmann u. Hubert Thüring, München 2005, S. 217-235.

90 Vgl. dazu Vogl: >Luxus‘, S. 697, und Berry, The idea of luxury, S. 115.

91 Wieland, Goldner Spiegel, Bd. 6, S. 122.

92 Vgl. Verf.: »Poesie als/statt Polizei«. 


\section{Mangel im Überfluss \\ Kredit und Ruin in Schlaraffia und frühneuzeitlicher Ökonomie}

Schlaraffia ist das unökonomischste Land der literarischen Welt. Im Reich des Überflusses an allem und für jeden mangelt es keinem an nichts. Wo die gebratenen »Spanferkel « mit »Tranchiermesser im Rücken« herumrennen, damit man sich à discretion ein »saftiges Stück abschneiden kann" und einem aus den Brunnenröhren "Malvasier" und "Champagner" wie Wasser ins "Maul « fließen, ${ }^{1}$ ist jeglicher wirtschaftliche, haushälterische, tauschhandelnde Umgang mit Ressourcen überflüssig. Nirgends scheint die Literatur (und Kunst) weiter entfernt von realer Ökonomie, die zentral auf beschränkten Ressourcen beruht, als in den schlaraffischen Fantasien, die in der Tradition der >verkehrten Welt $<$ alle Knappheit kappen.

Gerade dieser literarische (Un-)Ort, von den erzählerischen Rahmungen der Darstellungen so oft wie unnötig als betont fiktiv präsentiert, ${ }^{2}$ weist jedoch immer wieder enge Bezüge zu den historisch-ökonomischen Verhältnissen auf - und zwar nicht nur im simplen Modus des Kontrasts, aus dem manche die (Hunger-)Kompensation als Hauptfunktion solcher Imagination abgeleitet haben. ${ }^{3}$ Die Aufmerksamkeit für solche Bezüge lohnt sich, nicht um die motiv- und literaturgeschichtlichen Perspektiven im engeren Sinn zu ersetzen, sondern um diese weiter anzureichern. Sie lohnt sich umso mehr bei einem besonders überraschenden Sujet der Wirtschaft: beim Sujet von Kredit und Verschuldung, die speziell auf materiellem Mangel basieren und deshalb - dies würde erwarten, selbst wer mit literarisch-ökonomischen Beziehungen rechnet - im Schlaraffenland des Überflusses keine Rolle spielen dürften. Doch die schlaraffischen Imaginationen, zumal die raffiniert-reichhaltigen, noch nicht zum rudimentären (Kinderbuch-) Bildkomplex abgelutschten Versionen, die bis ins 16. bzw. 17. Jahrhundert entstehen, bieten regelmäßig solche Überraschungen. So gibt es auf der auch in dieser Hinsicht ausgeklügelten Accurata Utopiae Tabula eine prominent positionierte Credit-Region, die im Folgenden nach einigen generellen

1 Ludwig Bechstein: Das Märchen vom Schlaraffenland, in: Sämtliche Märchen, hg. u. m. Anm. u. e. Nachw. von Walter Scherf, München 1971, S. 226-230, hier S. $227 f$.

2 Mehr dazu vgl. in Kap. III, bes. S. 71 .

3 So etwa Piero Camporesi: Il paese della fame, Cernusco 2000; aus historischer Sicht kritisch dazu vgl. z.B. Gilomen: Das Schlaraffenland und andere Utopien im Mittelalter, bes. S. 221. 
Überlegungen zum assoziierten Thema des Geldes in Schlaraffia näher vorgestellt und im Kontext des frühneuzeitlichen Kreditwesens verortet wird.

\section{Schlaraffisches Geld und luxuriöse Logik}

Erstaunen mag allein schon, dass es gemäß zahlreichen Schilderungen überhaupt Geld gibt im Schlaraffenland. Wo alle Gelüste augenblicklich befriedigt werden, kommt kein Tauschhandel zustande, geschweige denn in einer durch Geld potenzierten, d.h. materiell wie zeitlich flexibilisierten Form. Wo alles nichts kostet, erübrigt sich Geld; die Schlaraffia-Darstellungen könnten es konsequenterweise wegkürzen. Aber solche ökonomische Stringenz widerspricht der luxuriösen Logik dieses erdichteten Landes, ${ }^{4}$ die sich am Sujet des Geldes exemplarisch zeigt. In dieser Hinsicht repräsentativ ist bereits der erwähnte fabliau von »Coquaigne « (Cocagne) aus dem 13. Jahrhundert: Während die schlaraffische Welt als eine Art Selbstanerbietungsrestaurant ausgemalt wird, in dem niemand nach dem opulenten Mahl eine Zeche bezahle, erfährt man gleichzeitig, wie viele sous Lohn dort das Schlafen eintrage sowie dass massenhaft Geldbörsen und Goldmünzen herumliegen ganz umsonst, wie eigens betont wird, da keiner je etwas kaufe oder verkaufe. ${ }^{5}$ Dabei deutet sich an, weshalb Schlaraffenland-Darstellungen nicht auf das notwendig unnütze Geld verzichten: Es geht offenbar um den Reiz der Vorstellung vom überflüssig gewordenen, mithin >verkehrten< Geld, das vollkommen umsonst ist, weil alles umsonst zu haben ist.

Auf die Pervertierung des heiß begehrten Guts zum absolut Wertlosen setzt auch der Topos, dass es in Schlaraffia Geld gebe wie Dreck, was die Illustrationen oftmals mit Goldeseln und Konsorten wörtlich nehmen (vgl. z.B. Abb. 10).

Der Reiz solcher Perversion wäre mit einer Streichung des schlaraffischen Geldes verschenkt. Die Streichung stünde der Schlaraffia-Logik entgegen, die auf Anhäufung der Verkehrungsmomente zielt und interne Widersprüchlichkeit als Preis nicht scheut. Die Imaginationen sind nicht auf eine kohärente Verkehrungslogik aus, sondern häufen diverse, untereinander inkonsistente Verkehrungen an. Nach nichtschlaraffischer Logik ist etwa das

4 Z.T. im Anschluss an Richter spricht Velten von sausser Kraft gesetzter Logik«, >irrationaler Ökonomie und `Inkompatiblem`, worin er einen Zug des Mythischen schlaraffischer Vorstellungen sieht. Vgl. Velten: Europäischer Mythos?, bes. S. 251, 260-262, und 267.

5 Vgl. den Abdruck in: Barbazan: Fabliaux, vol. 4, S. 175-181; dt. Übersetzung in Richter: Schlaraffenland, S. 130-135. 


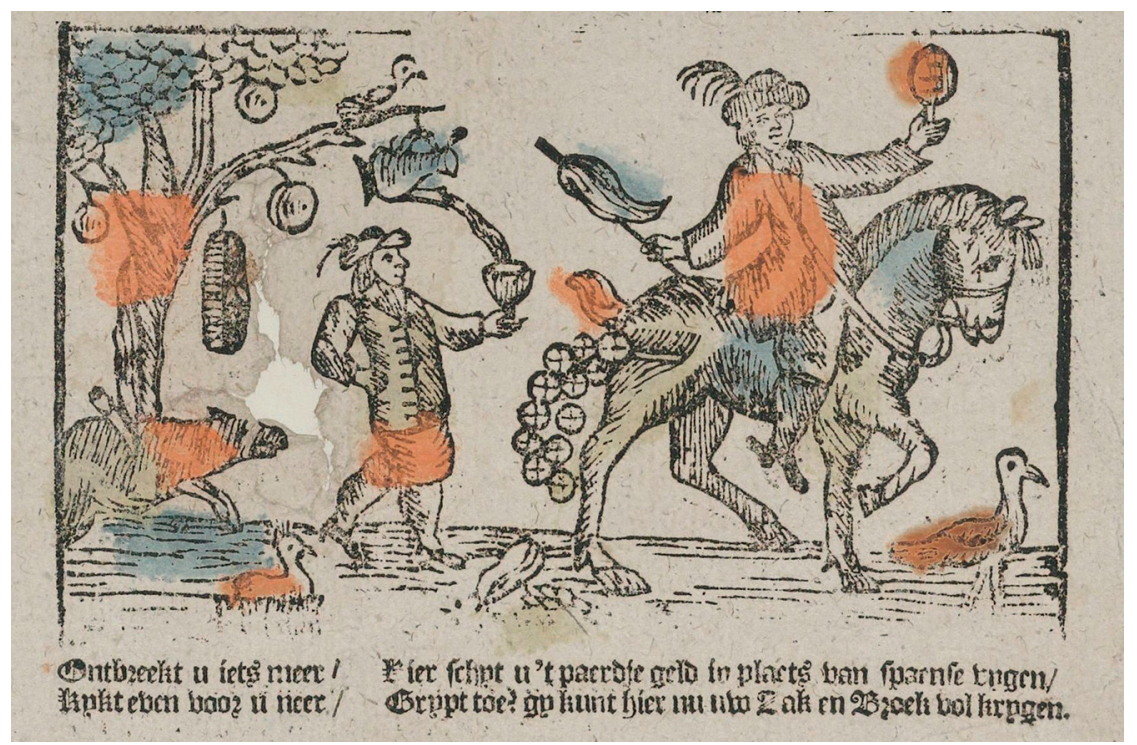

Abb. 10: Noch besser als Geld wie Heu ... Ab dem 17. Jahrhundert ist das Motiv in unterschiedlichen Varianten in populären Druckgrafiken europaweit verbreitet; hier ein Detail aus einem kolorierten Holzschnitt von Hendrik van der Putte (zwischen 1761 und 1765,

Rijksmuseum Amsterdam): »Ontbreekt u iets meer / kykt [kijkt] even voor u neer /

Hier schyt [schijt] u 't paerdje [paardje] geld in plaets [plaats] van spaense, [spaanse]

vygen [vijgen] / Grypt [Grijpt] toe! gy [gij] kunt hier nu uw Zak en Broek vol krygen [krijgen].« (»Braucht ihr noch mehr / Schaut nur vor euch nieder /

Hier scheißt euch das Pferd Geld anstatt spanische Pferdeäpfel

[’paardenvijgen`: >Pferdefeigen`] / Greift zu! Hier könnt ihr

Tasche und Hose voll kriegen.«) ${ }^{6}$

Motiv vom Geld als Dreck unverträglich mit der Schilderung, wie trefflich sich im Schlaraffenland durch Schlafen Geld verdienen lasse. Letztere Vorstellung kehrt ihrerseits topisch wieder und wird nach Belieben um die Einträglichkeit weiterer nichtsnutziger Tätigkeiten erweitert. In Ein schönes new gebachens und wolgeschmackes Honigsüsses Liede (ursprünglich auf einem Flugblatt aus der Zeit um 1600), das sich stark mit Hans Sachs' Schlauraffen Landt berührt und womöglich Ludwig Bechstein für die Prosaversion in seinem Deutschen Märchenbuch als Vorlage gedient hat, zah-

6 Vgl. auch Maurits de Meyer: Populäre Druckgraphik Europas: Niederlande, München 1970, S. 117. 
len sich zudem beispielsweise Spielen, Saufen, Foppen, Furzen und Lügen entsprechend aus. ${ }^{7}$ Die Entlöhnung des Faulenzens konterkariert die realen Arbeitsleistungsanforderungen und erlaubt in diesem Fall womöglich den historisch spezifischen Bezug auf die gegenüber dem agrarischen Feudalismus neue Zeitökonomie, welche die Arbeitsleistung nun nach der Uhr bemisst. ${ }^{8}$ Der konterkarierende Effekt entsteht nur, wenn der Lohn Wert hat, den er aber zugleich nicht hat, wenn das Geld gemäß Dreck-Topos wertlos ist.

Die Schlaraffenland-Imaginationen erzählen nicht nur auf thematischer Ebene variantenreich vom Überfluss. Sie verfahren auch nach einer unökonomischen, luxuriösen Logik der Vervielfachung und Mehrgleisigkeit, die Redundanzen und Widersprüche in Kauf nimmt. Dieses Prinzip ist am schlaraffischen Geld besonders auffällig, gilt jedoch allgemein und äußert sich analog etwa am Aspekt der Zeit, der bei aller Motivik materieller Aufhäufungen nicht zu vernachlässigen ist. Im Land des ebenso temporalen wie dinglichen Luxus sind Zeit und Geld - unter anderem über den Faulenzerlohn - speziell verquickt. Da erscheint es beinahe konsequent, dass das Zeitliche nicht weniger nach luxuriöser Logik funktioniert. Ein einschlägiges Beispiel gibt Bechsteins Märchen. Darin wird zunächst von den »Messen und Märkte[n] « Schlaraffias geschwärmt: „Wer eine alte Frau hat und mag sie nicht mehr, weil sie ihm nicht mehr jung genug und hübsch ist, der kann sie dort gegen eine junge und schöne vertauschen und bekommt noch ein Draufgeld. « ${ }^{9}$ Gleich der nächste Satz fährt nun aber zusätzlich den Jungbrunnen auf, der zur schlaraffischen Standardausstattung gehört: ${ }^{10}$ Die »alten Weiber « kommen für »drei Tage oder höchstens vier« in ein »Jungbad « und werden wieder zu »schmucke[n] Dirnlein [...] von siebzehn oder achtzehn Jahren ${ }^{11}$ - was den Tauschhandel als Verjüngungskur überflüssig werden lässt.

7 Eine Druckfassung des Liedtexts ist in digitalisierter Form bei der Universitätsbibliothek Frankfurt a.M. einsehbar (vgl. http://sammlungen.ub.uni-frankfurt.de/urn/urn:nbn: de:hebis:30-91010 [letzter Zugriff 18.06.2021]). Für das Fliegende Blatt vgl. auch die Anmerkung zum Abdruck bei Richter, S. 158-159.

8 So suggeriert Richter: Schlaraffenland, S. 40.

9 Bechstein: Das Märchen vom Schlaraffenland, S. 229.

10 Vgl. dazu z.B. Richter: Schlaraffenland, S. 49-51.

11 Bechstein: Das Märchen vom Schlaraffenland, S. 229. 
Obgleich die schlaraffischen Gegebenheiten von Geld und genereller (Un-) Logik die Leser und Leserinnen solcher Erdichtungen mit allem Möglichem bzw. Unmöglichem rechnen lassen, sind nun Kreditverhältnisse in diesem Land keineswegs erwartbar. Denn jenes Geld und jene Logik kennzeichnet durchgängig das Moment des Zuviels, während dagegen Kredite aufgrund eines zumindest zeitweiligen Zuwenigs zustande kommen. Daher ist es so erstaunlich wie erklärungsbedürftig, wenn dieses ökonomische Phänomen einmalig oder jedenfalls selten - an den unökonomischsten Ort der Literatur versetzt wird.

Buchstäblich dort verortet werden Kreditverhältnisse auf der Accurata Utopiae Tabula, die den Begriff `Credit`samt Wort(um)feld als schlaraffische Örtlichkeiten verzeichnet. Generell um Geld geht es gehäuft in Mammonia, dem Land, das nicht nur vor Perlen und Edelsteinen, Gold und Silber in fester wie flüssiger Form (u.a. als Silber Berg und Goldbach) strotzt, sondern auch eine reiche Palette an Währungen bietet mit Orten wie Batzenville, Cronenburg, Dublon, Ducat, Floren, Guines oder Louis [d'Or] (Abb. 11; OV 257f.).

Um beim genießerischen Bad in den Moneten gleichwohl den denunziatorischen Namen einer Land=Tabell der Laster (Kartusche) zu verdienen, trübt die Karte diesen materiellen Glanz pflichtschuldig mit Schmierna, Wuchersheim, Knickersgwin, Baurenschinden und anderen nach zweifelhaftem Geldumgang klingenden Ortschaften (ebd.). Hier beerbt ein ganzes Unterkönigreich der Avaritia die Position des Geizes in den Sündenkatalogen - wobei das üblich-üble Stereotyp nicht ausgespart wird mit der Beimischung von Gaza, Schachertz oder Iudenburg. Zusätzlich ins Zwielicht rückt Mammonia durch dubiose Nachbarn, die ebenso aufs Geld aus sind, namentlich Irrlandia Chymica, wo man offenbar an der künstlichen Goldmacherei laboriert (OV 259), und nebst dem hoffärtigen Superbia das diebische Furlandia Regnum mit Lang Fingeringen, Spitzbubenheim, Falschspilerau und Furtofranchea als sinnig verkehrtem Frankfurt (OV 253).

Da liegt denn ein Credit Gebiet schon fast nah, nämlich direkt neben dem Laboratorium der Goldmacher (Abb. 12; OV 260f.). Es befindet sich im Königreich der Verschwender oder Prodigalia Regnum und verzeichnet Orte wie Ober Bürg, Bürgstatt, Trauweil, Credit, Creditreut oder Auffn Pump (ebd.). Letzteres klingt ganz nach umgangssprachlichem AlltagskreditVokabular von heute, doch das Verb spumpen< in dieser Bedeutung, ursprünglich aus dem Rotwelschen stammend, ist bereits im 17. Jahrhundert 


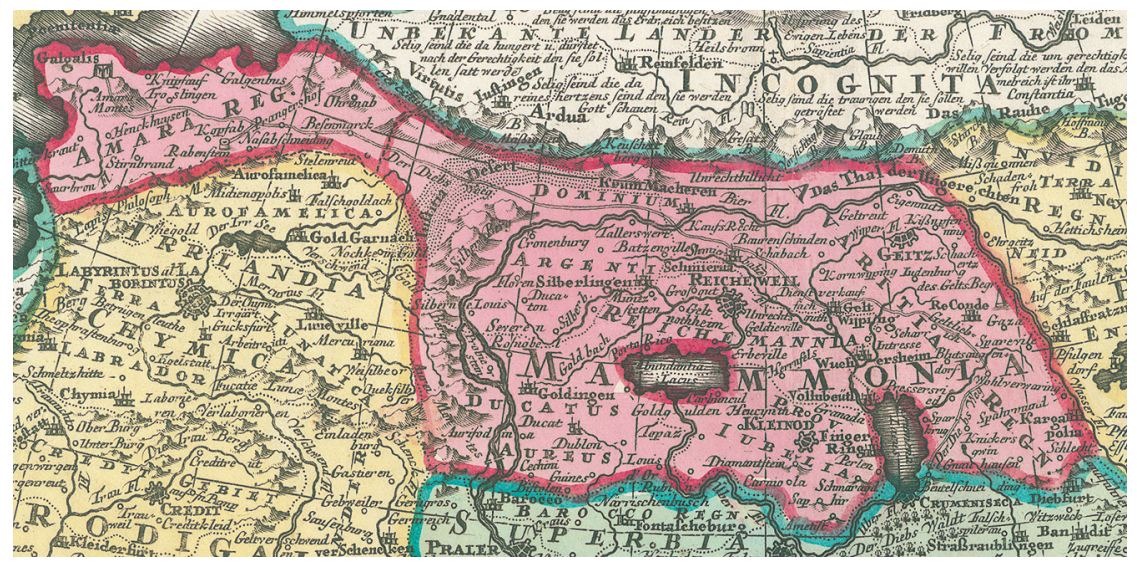

Abb. 11: (Über-)Flüssiges in Schlaraffia: Mammonia oder das Reich des Geldes mit Nachbarn Irrlandia Chymica, Superbia und Furlandia Regnum

(Detail aus Abb. 6)

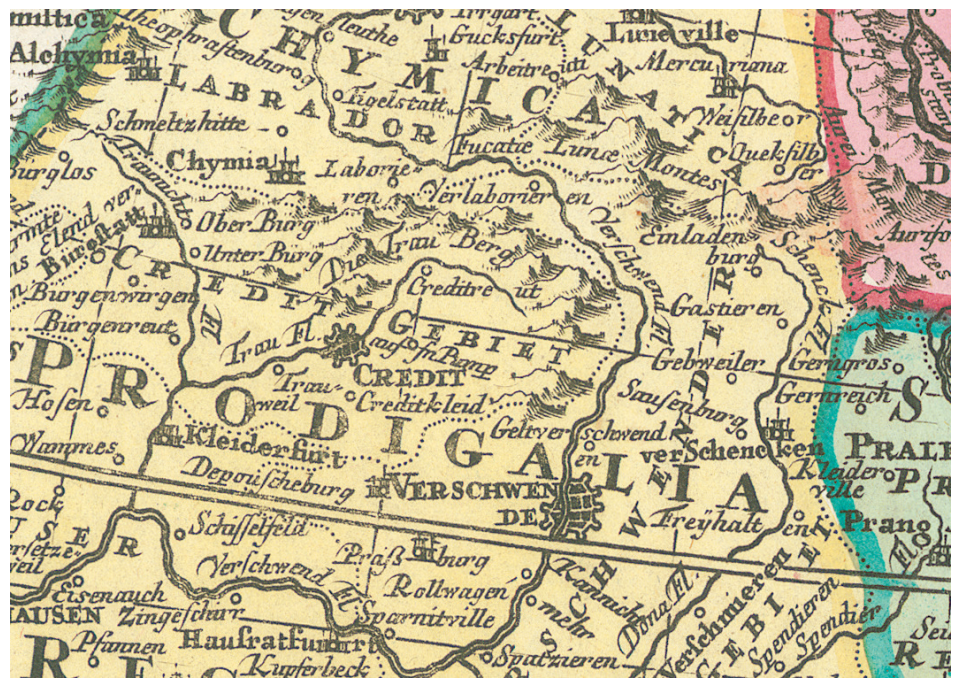

Abb. 12: Schlaraffenleben auf Pump: Das Credit Gebiet

(Detail aus Abb. 6) 
in der Studentensprache und dann im 18. Jahrhundert allgemein gebräuchlich geworden. ${ }^{12}$ Zwei weitere Gebiete gehören zum gleichen Königreich: Im Pfandhauser Gebiet reichen die Konkretisierungen von Hausbrief und Versetzeweil über Hausratfurt und Bettfurt bis zu Leerekasten, Kleiderfurt und Barock, das durch diesen Kontext den Sinn sbar / ohne Rockı erhält. Das Verschwender Gebiet bietet neben Verfreßen, Verhuren und Verthun etwa ein Praßburg, Sausenburg und Einladenburg, ein Borgen, Spendieren, Gebweiler und ein Sparnitville mit deutsch-französischer Doppeldeutigkeit (>vi[e]k / >la ville‘; OV 261).

Das Königreich Prodigalia mit seinem reichen Kreditwortschatz, der den sstylus luxurians ‘ der Karte - schlaraffische Anhäufungslogik sprachlich realisiert als exzessiv-unökonomische Benamsung - am Werk zeigt, liegt am nordwestlichen Rand des Schlaraffenlandes. Es ist indes wegen der speziellen Topologie dieser Fiktion alles andere als marginal. Zur Erklärung muss etwas ausgeholt werden: Gemäß dem Narrativ der Karte, das regelmäßig den Zeitfaktor in die räumliche Darstellung einbringt, werden verarmte Schlaraffen vom Credit Gebiet durch das Verzichtstor (Porta Carentia) ins Hungerland [...] verwiesen, wie uns die dort auf der Karte eingetragene Miniaturerzählung wissen lässt. Allen zu lange in Schlaraffia Verweilenden droht dieses Schicksal der Ausweisung in die Altersregion von Armelandia, Hunger- und Kummerland am Golfo de Triste (Abb. 13; OV 269f.).

Das Ausgangstor ist eingelassen ins Gebirge, das hier die Grenze bildet und seinerseits Pfand Berg bzw. Credit Berg heißt, sodass sich Kredit zugleich anschaulich als Grenzfall entpuppt. ${ }^{13}$ In der kartierten Überblendung von Geografie mit Biografie verläuft die Grenze des Schlaraffenlandes, das Ende des Schlaraffenlebens zwischen dem Credit mit Verschwendung diesseits und dem Schulden Berg mit Armut, Hunger und Kummer jenseits des Schlaraffenlandes. Das nur allzu irdische Jenseits schreckt mit Orten wie dem - natürlich hier alles andere als hedonistischen - Langfasten, Leerdam, Hunger Leyden, Melancholia, Klagach, Schuldenville, Bettelstab oder Bettlehembt.

Das kreditlastige Grenzreich Prodigalia erweist sich in der Ordnung der Karte als eine oder sogar die Kernregion Schlaraffias. Denn die Erklaerung

12 Vgl. Friedrich Kluge: Etymologisches Wörterbuch der deutschen Sprache, bearb. v. Elmar Seebold. 25., durchges. u. erw. Aufl. Berlin u. Boston 2011, S. 731f.; Jacob und Wilhelm Grimm: Deutsches Wörterbuch, 16 Bde. in 32 Teilbänden, Leipzig 1854-1961, Bd. 13, Sp. 2229, allerdings mit Nachweisen erst aus dem 19. Jahrhundert.

13 Gut sichtbar etwa auf dem Berner Digitalisat, während im Ortsregister von Reitingers Ausgabe die Beschriftung Credit Berg fälschlich bloß als Credit der Schlaraffenland-externen Region zugeordnet ist (OV 270). 


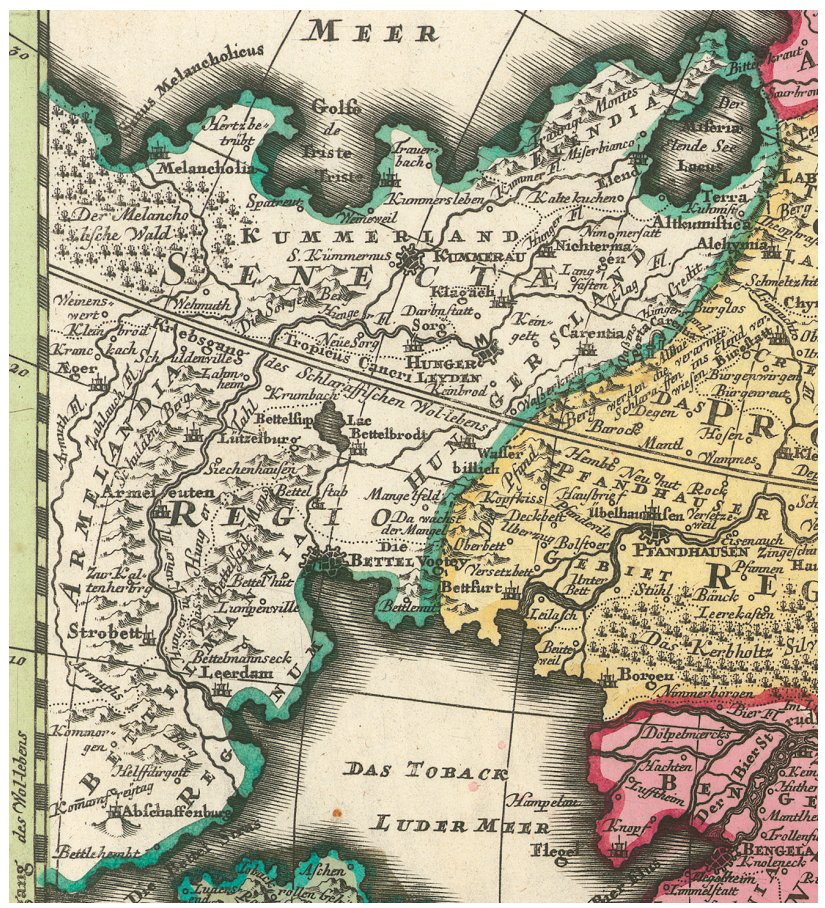

Abb. 13: Keine Altersresidenz für Schlaraffen:

Die Senectae Regio (Detail aus Abb. 6)

der Wunder=seltzamen Land=Charten UTOPIÆ deklariert die Verschwendung zum schlaraffischen Kardinallaster und folglich Prodigalia zum Zentrum. Die Erklaerung, welche die bildliche Imagination der Karte aus- bzw. weitererzählt und deren Topologie wesentlich mitkreiert, verweist im betreffenden Kapitel auf den biblischen "Fili[us] Prodig[us]« als Namenspatron der Region (E 316). Der »verlohrne[ ] Sohn« wird jedoch zugleich als (Anti-) Held der ganzen Erfindung vorgestellt: »Dieser gottlose und ungerathene Sohn« sei nämlich

derjenige gewesen / welcher alle diese erdichte Laender des gantzen Schlarraffenlandes in der Warheit durchwandert / all sein Haab und Gut in solcher Reise verzehret / sonderlich aber diesem Prodagalischen [sic] Reich / allwo er sich als ein Ertz=Verschwender etwan laenger aufgehalten / seinen Namen mitgetheilet hat. (Ebd.) 
Der Akzent entspricht einer wörtlichen Übersetzung von >filius prodigus als sverschwenderischer Sohn «. Die deutsche Betitelung des Gleichnisses vom sverlorenen Sohn nimmt dagegen - im Sprachenvergleich exzeptionell eine andere Perspektivierung vor. ${ }^{14}$ In der "Application und Anweisung « (E 327), die diesem wie jedem Kapitel nachgestellt ist, kehrt das »bewegliche Exempel« dieses »ungerathenen Sohn[s]« wieder, wenn abschließend ausgemalt wird, wie jener »in solches Elend / Armuth und Hunger gerathen " sei, dass »er die Kleyen / so denen Schweinen gewoehnliche Speise seynd / nicht genug zu essen hatte / welches der Ausgang seines Ubermuths / und Frucht seines verschwendischen Lebens gewesen« sei (E 330). Das ist bekanntlich keineswegs der beelendende "Ausgang « der Geschichte im LukasEvangelium (Luk. 15, 11-32). Deren Pointe besteht vielmehr im Happy End für den ruinierten Sohn, der alles Geld des Vaters vergeudet hat, ohne aber seinen Kredit im übertragenen Sinn bei ihm verspielt zu haben. Deshalb erscheint die abschreckende Wirkung des zum Oberschlaraffen erklärten biblischen Filius immerhin zweifelhaft. ${ }^{15}$

In der moralisierenden Klammer einschließlich ihrer fraglichen Wirksamkeit äußert sich jene Ambivalenz, die das Karten-Text-Ensemble der Accurata Utopiae Tabula wie viele andere Schlaraffenland-Darstellungen als Kluft zwischen Rahmen und Gerahmtem kennzeichnet, indem sich keine effiziente Herleitung der pro- bzw. epimythischen Momente aus der schlaraffischen Fabel ergibt. ${ }^{16}$ Die Diskrepanz lässt sich nicht einfach wegrationalisieren und erweist sich von hier aus gesehen als eine weitere Manifestation der skizzierten luxuriösen Logik.

Die Kluft betrifft auch die literarisch-kartografische Darstellung des Themas Kredit. Die detailverliebte Beschreibung wird mit der bereits angedeuteten doppelten Drohung flankiert: Strukturell analog zur warnenden "Application « im Text gibt die Karte den schlaraffischen Freuden einen zunächst ganz unmetaphorisch zu verstehenden - Rahmen mit Umländern, die zeitliche wie ewige Konsequenzen des Schlaraffenlebens geltend machen. Während das Armutsreich in direkter Nachbarschaft zur Kredit-Region

14 Die lateinische Formel dient dem moraldidaktischen Interesse der Erklaerung besser als die deutsche Bezeichnung, die übrigens spätestens seit der Biblia germanica von 1490 >erhältlich war.

15 Entsprechend betonen dagegen effizientere moralisierende Auslegungen die Reue bzw. Buße des Sohnes als Bedingung seiner Wiederaufnahme beim Vater. Dieses Moment ist in der biblischen Geschichte angelegt, die zum Sondergut des - im Vergleich zu den anderen Evangelisten generell stärker moralisierenden - Lukas gehört.

16 Vgl. dazu in Kap. I, bes. S. $19 f$. 
vor den irdischen Folgen warnt, erfüllt jenes südlich angrenzende Tartari Regnum oder Höllische Reich (Abb. 18 in Kap. III; OV 272f.) die Aufgabe der Drohgebärde hinsichtlich des ewigen Lebens. Dieses Reich passt allein schon wegen seiner Herkunft von `Tartaros‘, einem Gott (Bruder von Gaia, Eros und anderen Göttern aus dem Chaos) wie zugleich Ort (Strafraum in der Unterwelt) der griechischen Mythologie, in die Machart der Karte. Zudem wurden die sTataren prägte Turkvölker - namentlich die Mongolen unter Dschingis Khan - in Europa mindestens bis ins 16. Jahrhundert verballhornend als höllenassoziierte >Tartaren< bezeichnet.

Mit den »hoellischen Tartarn « treiben die Schlaraffen »nicht geringe Handelschafft« über die Grenze hinweg (E 379). Sie haben als »Tribut und Contribution « für ihr Schlaraffendasein die Einhändigung ihrer Seelen nach vollendetem Leben mit ihnen »verglichen« oder vereinbart (ebd.). Von »diesen bösen Creditoribus« wollen die Schlaraffen natürlich am liebsten gar nichts »hoeren ", obschon sie wissen, dass »lange geborgt nicht geschenckt « ist und »die Schulden ihres Laster=Lebens « am Ende »nolens volens « zu bezahlen sind (ebd.). Es handelt sich offenbar um einen Teufelspakt, der als Kreditvereinbarung gedacht wird.

Mit dieser Konzeptualisierung lässt sich die literarisch so produktive Vertragsart des Teufelspakts generell näher beschreiben, bei dem stets der Zeitaufschub der Zahlung entscheidend ist. Die Schlaraffen haben den Höllenbewohnern für den Genuss der irdischen Freuden ihre Seele verkauft, aber nicht per Sofortzahlung, sondern auf Kredit. Daher sind sie als Schuldner den teuflischen Gläubigern verpflichtet und leben sauf Pump<, bis die aufgeschobene Bezahlung eingefordert wird. Dies erklärt nochmals von einer anderen Seite, weshalb das Kredit-Gebiet schlaraffische Zentralprovinz ist. Außerdem zeigt sich, wie wechselseitig hier gerade über den Begriff des Kredits das weltliche (Miss-)Wirtschaften mit der metaphysischen Dimension verquickt wird: Während die weltlichen Schuldenberge im Höllischen Reich zu »Suenden-Berge $[n]$ « (E 381; vgl. OV 272) mutieren, erscheint umgekehrt der Teufel in Gestalt der »Tartaren« als Kreditgeber, und die missliche Lage der schließlich im höllischen Reich angelangten Schlaraffen heißt »ewige[r] Ruin« (S 389). Die Darstellung lädt nicht nur Weltlich-Wirtschaftliches metaphysisch auf, sondern verwirtschaftlicht zugleich Metaphysisches.

Eine solche Ökonomisierung von Theologie, konkret von Theologemen des Teufelsgeschehens, orientiert sich auffallend prominent am Modell von Kreditbeziehungen. Dies kann historisch zunächst allgemein mit 
der überragenden Rolle des Kredits für alle Bevölkerungsschichten der Frühen Neuzeit in Verbindung gebracht werden. Die neuere Forschung zur Geschichte des Kreditwesens hat für jene Zeit insgesamt eine Omnipräsenz von Kreditverhältnissen und eine dramatische Zunahme der Kreditvergaben speziell seit Mitte des 16. Jahrhunderts ermittelt. ${ }^{17}$ Im historischen Kontext seiner eminenten Bedeutung wird erklärbar, weshalb der Kredit hier nicht einmal vor der fantastischen Ökonomie des Schlaraffenlandes Halt macht - ja, sich sogar als deren Herz entpuppt. Dass der Teufelspakt in dieser Imagination nach einem Kreditverhältnis modelliert ist, mag zusätzlich spezifisch durch den Zeithorizont der historischen Kreditpraxis motiviert sein: Aufgrund der oftmals über Generationen hinweg vererbten Schulden und einer intensiven Schuldenzirkulation, bei der Schuldscheine wie Banknoten kursierten, dominierte die Langzeit-Perspektive. ${ }^{18}$ An Kreditverhältnisse, die durch derartigen Aufschub der Rück- bzw. Bezahlung gekennzeichnet waren, ließ sich die Geschichte vom Teufel und seinen Forderungen für unsere Sünden und Laster am Ende der Zeit besonders gut anknüpfen.

Die gängige Denunzierung Schlaraffias erfolgt in dieser Version dadurch, dass das Schlaraffenlandleben als Genuss von Überfluss auf Pump, als exzessive Verausgabung auf Kredit akzentuiert wird und dass unter Einsatz des theologisch-ökonomischen Narrativs der Umländer (Hölle, Armut) mit den nur aufgeschobenen Kosten im irdischen wie ewigen Leben gedroht wird. Doch die Diskreditierung als Kredit-Land ist wieder nur die eine Seite der ambivalenten Darstellung. Denn die Warnungen halten den Erzähler der Erklaerung ebenso wenig wie den Verfertiger der Karte von größter Hingabe bei der Schilderung des Schlaraffenlandes ab. Der Erzähler gibt diesen Zwiespalt im Grunde selbst zu. Gerade das letzte Kapitel zum »Hoellischen Reich « beginnt er wehmütig: »Gleichwie alle weltliche Suessigkeit / Kurtzweil / Freud und Wollust gemeiniglich ein trauriges Ende gewinnen / so muß auch gleichfalls unsere kurtzweilig angefangene Beschreibung des Schlarraffenlands / mit der Erklaerung des hoellischen Reichs / ihren traurigen

17 Vgl. im Forschungsüberblick von Mark Häberlein: »Kreditbeziehungen und Kapitalmärkte vom 16. bis zum 19. Jahrhundert«, in: Soziale Praxis des Kredits. 16.-20. Jahrhundert, hg. von Jürgen Schlumbohm, Hannover 2007, S. 37-51, hier bes. S. 37-43; für die spezifische Zunahme verweist er (ebd., S. 39) v.a. auf die maßgebliche Studie von Craig Muldrew: The economy of obligation. The culture of credit and social relations in early modern England, Basingstoke 1998, bes. Kap. 3 und 4.

18 Vgl. dazu bes. die Beiträge von Laurence Fontaine, z.B.»Die Bauern und die Mechanismen der Kreditvergabe« [im frühneuzeitlichen Westeuropa - C.W.], in: Schuldenlast und Schuldenwert. Kreditnetzwerke in der europäischen Geschichte 1300-1900, hg. von Gabriele B. Clemens, Trier 2008, S. 109-130. 
Abschied nehmen.« (E 378f.) Indem er das »kurtzweilig«-wollüstige Schlaraffenleben direkt mit seinem »kurtzweiligen« Erzählen kurzschließt, von dem Abschied zu nehmen er sich zwingen muss, sympathisiert er gleichzeitig mit dem Land von Verschwendung und exzessivem Kredit. Das Erzählen von Schlaraffia präsentiert sich selbst als schlaraffisches Erzählen, folglich als verschwenderisches Erzählen auf Kredit unter Aufschub der (Rück-) Zahlung, die zuletzt als Erzählen vom »Hoellischen Reich« erfolgen muss.

\section{Gutgläubige Gläubiger und das Risiko des Ruins}

Diese poetologische Relevanz lässt es umso lohnender erscheinen, die konkrete Ausstattung der schlaraffischen Kredit-Region näher zu erkunden. Zumal die Vorstellung eine Perspektive bietet, die (auch) im Kontext des früher Ausgeführten überrascht. Wenn namentlich durch die vorgeführten sflankierenden Maßnahmen Schlaraffia in moralsatirischer Tradition zum Sünden- und Laster-Land erklärt wird, ${ }^{19}$ ist für das Kredit-Gebiet ein Fokus auf den Schulden und den Schuldnern zu erwarten.

Doch die Optik ist konträr. Bei der Verschwendung des Königreichs Prodigalia mit Orten wie Einladenburg, Freyhalten, Spendieren, Verschencken oder Gebweiler (OV 260f.) liegt die Betonung auf der Freigebigkeit oder - mit Bertolt Brechts einschlägiger Formel aus Der gute Mensch von Sezuan gesagt auf der »Wollust « zu »schenken « ${ }^{20}$ Erzählerisch motiviert wird dies durch den Gegensatz zum Geiz: »Die Einwohner« von Prodigalia sind nämlich "mehre theils junge Leute von 18. biß etlich und 20. Jahren / rechtmaessige Colonen oder«, verdeutscht, »Pflantz=Voelcker der Reichen und Geitzigen Mamoniten" (E 319). Die Lebensweise der jugendlichen Abkömmlinge Mammonias besteht darin, »das Gut / so ihre Eltern erschunden und erscharret haben / mit verschwendischem Leben / freygebigen Haenden und offener Gurgel durch[zu]jagen und [zu] verzehren « (ebd.).

Entsprechend wird das Kreditwesen nicht in erster Linie auf die Schuldner, sondern auf die Gläubiger hin perspektiviert und in dieser Hinsicht problematisiert. Zugleich fällt der dezidiert irdisch-ökonomische Blickwinkel auf: Die »Credit-Berge« der Region sind kein verlässliches Gelände, weil sie "auf den grundlosen Boden des betrueglichen Ansehens einiger daher startzend und pralenden Leute gesetzet" sind (E 319). Am "gefaehrlichste[n]«

19 Vgl. oben bes. S. 34-38.

20 Bertolt Brecht: Der gute Mensch von Sezuan, Berlin 1964, S. 140. 
ist das »Trau-Gebürg«, denn hier ist schon »mancher gutwilliger Mensch [...] mit Erdschollen der Untreu ueberschuettet / und in denen frembden SchuldenGruben [...] / elendiglich begraben worden« (E 318). Nicht besser ergeht es dem satirisch porträtierten Regenten dieses Königreiches, dem »Groß Debauchier (E 320) oder »Grand Debauchier« (E 321). Sein Name gemahnt ans französische >débauche für >Ausschweifung bzw. >(se) débaucher ' für >von der Arbeit abhalten', dessen Ableitungen auch im Deutschen mindestens bis ins 18. Jahrhundert als Lehnwörter gebräuchlich waren..$^{21}$ Indem er gleichzeitig den deutschen >Bauch bedient, eignet sich der Begriff ideal für die Sprachspielereien dieser Darstellung. Der »Groß Debauchier « ist »ein Herr von wenig Jahren / schlechten [sic] Verstand und geringer Erfahrung«; er hält hier »seine Hoffstadt / und wird mit vielen Schmarotzern / Dellerleckern und Fuchsschwaentzlern praechtig bedienet «, wie es ironisch heißt (E 320f.). Jene sind ihm "getreu«, solange er "geben / und dieselbige freyhalten kan«; sobald »aber das Guetlein zerronnen / wischen die Schmarotzer das Maul / nehmen hinter der Thuer Abschied / und lassen den Herren Urian ${ }^{22}$ alleine in Armelandiam reisen« (E 321).

Die Perspektive der Kreditgeber setzt sich bis in die detailgenaue Schilderung der materiellen Utensilien und Dokumentationsmedien von Kreditverhältnissen fort. Der Wald in dieser Provinz heißt Kerbholtz, »erstrekket sich / seinem Gebrauch nach / weit und breit in die Welt", besteht aus "zweyen gleichen Truemmern / welche sich guetlich zusammen fuegen«, und dient dazu, "gemeine Bauren=Zahlen daran zu schneiden / und den geborgten Wein / Bier / Fleisch / Brod / Liechter und dergleichen / damit sorgfaeltig zu bemercken« (E 319f.). Hier wird auf das `Kerbholz« oder den `Kerbstock«,

21 Manche Ausgaben des Duden, darunter die Onlineversion, verzeichnen >debauchieren noch aktuell für rausschweifend leben< (vgl. https://www.duden.de/rechtschreibung/debauchieren [letzter Zugriff 18.06.2021]).

22 Vgl. dazu die Ausführungen in: Johann Christoph Adelung: Grammatisch-kritisches Wörterbuch der hochdeutschen Mundart. 4 Bde, Wien 1811, Bd. 4, Sp. 962: „Urian, ein in den gemeinen Sprecharten als ein eigenthümlicher Nahme übliches Wort, welches man mit dem Ehrenworte Herr, als eine Art eines scherzhaften Schimpfwortes, von einem Manne gebraucht, vor welchem man wenig Achtung an den Tag legen will [...]. Das Wort, welches auch im Niederdeutschen gangbar ist, ist von unbekannter Bedeutung und Abkunft. Des ehemahligen Bremischen Archivarii Post Ableitung, der es, dem BremischNieders[ächsischen] Wörterbuche zu Folge, von Urhahn, genitale viri, ableitete, ist so gezwungen als möglich, und noch dazu unanständig. Allem Ansehen nach ist es ursprünglich ein eigenthümlicher Nahme eines Mannes gewesen, der sich irgend etwa durch eine possierlich-verächtliche Handlung verewigt hat; dergleichen Nahmen in den gemeinen Sprecharten sehr viele vorkommen. Denn an den Urias der Bibel ist wohl nicht zu gedenken.« 


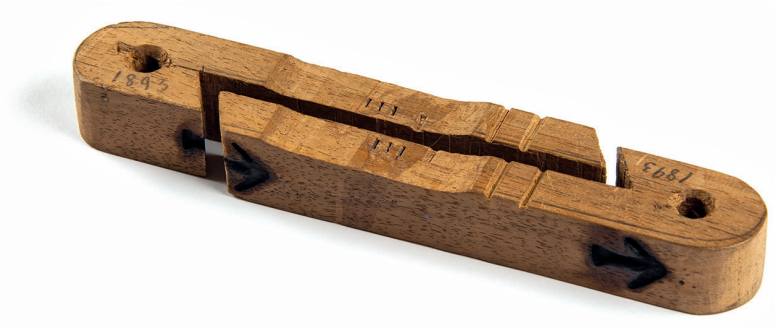

Abb. 14: Doppeltessel, eine Schweizer Art des Kerbholzes (von der Alp Blümatt, spätes 19. Jahrhundert;

Alpines Museum der Schweiz)

ein (nicht nur) im ländlichen Raum verbreitetes Buchhaltungsinstrument jener Zeit, Bezug genommen (Abb. 14). Mit diesem in Mittelalter und Früher Neuzeit gängigen, mancherorts bis ins 19. Jahrhundert und darüber hinaus verwendeten Instrument wurden vornehmlich Kreditvereinbarungen fälschungssicher festgehalten: Zählsymbole verzeichneten das Geliehene bzw. Geschuldete auf dem Holz, das in zwei Teile gespalten wurde. Die beiden "Trümmer « mussten später bei der Abrechnung aufeinanderpassen zum Beweis, dass keines der Stücke manipuliert worden war. ${ }^{23}$

Bis dahin könnte die Referenz auf das Kerbholz noch die Perspektive von Schuldner und Gläubiger zu gleichen Teilen suggerieren. Beim Weitererzählen wird indes der Blickwinkel wieder ganz parteiisch: Dieses Holz sei »nun sehr theuer / wanns allenthalben mit solchen Zahlen ueberschnitten ist / und der ein Meß oder Klaffter kauffen wollte / [...] der mueste viel 100. in 1000.fl. ${ }^{24}$ darzu haben« (E 320). Ausgemalt wird an dieser Stelle nicht etwa, wie teuer die hölzerne Rechnung den Schuldner am unausweichlichen Zahlungstermin zu stehen kommen werde. Vielmehr wird evoziert, wie das (stückweise) Weiterverkaufen des robusten Schuldscheines vor sich geht, mithin wie er als eine Art /Wertpapier`von Gläubiger zu Gläubiger die Hand wechselt. So dominiert auch bei diesem Bezug auf die damals zeitgenössische Praxis die Sicht des Kreditgebers - im Kontrast übrigens zur

23 Zusammenfassend zum Einsatz von Kerbstöcken in Kreditverhältnissen vgl. etwa Carola Lipp: "Aspekte der mikrohistorischen und kulturanthropologischen Kreditforschung", in: Schlumbohm: Soziale Praxis des Kredits, S. 15-36, hier S. 16, mit Verweis auf die Forschungen von Michael North: Das Geld und seine Geschichte vom Mittelalter bis in die Gegenwart, München 1994, bes. S. 114-115, sowie den Artikel `Kerbholz‘ bei Lutz Röhrich: Lexikon der sprichwörtlichen Redensarten, Freiburg i.Br. 2009, Bd. 2, S. 831-833.

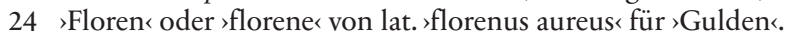


Schuldner-Perspektive der davon herrührenden Redewendung retwas auf dem Kerbholz haben<.

Die Sicht der Gläubiger dominiert selbst in der »Application« (E 327) am Ende des Kredit-Kapitels, obwohl der Erzähler hier genrebedingt auf das Thema der Schuld(en) einbiegen muss. Für diese Kurve findet er freilich einen halbwegs eleganten Kniff, wenn er das Bild der »Verschwender" abschließend abschreckend resümiert:

Sie trauen leichtlich / Creditiren andern Leuten / stehen fuer selbige Buerg / je lieber sie nun vielen Schmeichlern trauen / je leichter sie von denen selbigen betrogen / und in das zeitliche Verderben gestuertzet werden. Von diesem allen aber werden sie zu keiner Warnung witzig / sie glauben nicht / daß ihr Gut alles zerrinnen koenne / derowegen sie in Ermanglung des baaren Geldes auf ander Geld Mittel bedacht / ihre beste Mobilien und Sachen anfangen Pfandweiß zu versetzen / auf die Borge zunehmen / und an das Kerbholtz zu schneiden [...]. (E 328f.)

Die Schuldner kommen buchstäblich sekundär in den Blick, waren sie doch einst und in erster Linie Kreditgeber, die sich aber als solche selber verschuldet haben und nun vor dem endgültigen Ruin ihren Sachbesitz verpfänden, von anderen Geld oder Waren borgen sowie ihre Schulden auf dem Kerbholz anschreiben lassen müssen.

Die Gläubiger-Perspektive, mit der zumal im Rahmen des moraltheologischen Sündendiskurses nicht zu rechnen ist, dürfte - so meine Hypothese den konkreten Bedingungen der Kreditverhältnisse jener Zeit geschuldet sein, wie sich diese für den Adressatenkreis der Schlaraffenlandkarte mit zugehörigem Buch darstellten. Die Adressaten, die dank entsprechendem (Sprach-)Bildungshintergrund ihre Freude an der luxuriösen Darstellung haben konnten, kamen primär für die Rolle der Gläubiger infrage. In den frühneuzeitlichen `Kreditnetzwerken ( (im Sinn der damals dominierenden personalisierten, nicht bzw. kaum institutionalisierten Kreditbeziehungen jenseits der Beteiligung durch Banken) traten in den Städten mehrheitlich die Ober- und Mittelschichten, in den Kleinstädten und auf dem Land die Notabeln und lokalen Eliten als Geldgeber auf. ${ }^{25} \mathrm{Ab}$ dem 17. Jahrhundert

25 Vgl. dazu bes. Laurence Fontaine: "Espaces, usages et dynamiques de la dette dans les hautes vallées dauphinoises (XVIIe-XVIIIe siècles) «, in: Annales, Histoire, Sciences Sociales 49/6 (1994), S. 1375-1391, den Sammelband Des personnes aux institutions. Réseaux et culture du crédit du XVIe au XXe siècle en Europe, hg. von Laurence Fontaine u.a., Louvain-leNeuve 1997, sowie Priceless markets. The political economy of credit in Paris, 1660-1870, hg. von Philip T. Hoffman, Gilles Postel-Vinay und Jean-Laurent Rosenthal, Chicago 2000; zusammenfassend und verallgemeinernd vgl. Lipp: Kreditforschung, bes. S. 25 und 27. 
ist dabei eine sukzessive Verschiebung vom Adel zum Bürgertum und kleingewerblichen Mittelstand als Tendenz zu beobachten, die bis ins 19. Jahrhundert anhielt. ${ }^{26}$ Solche Kredite waren häufig zinsfrei oder jedenfalls günstig; sie wurden oftmals langfristig vergeben und die Schulden bei Säumigkeit nicht eingetrieben oder gänzlich erlassen. ${ }^{27}$ So machten die Gläubiger mit den Krediten in der Regel keinen oder nur wenig direkt-ökonomischen Profit. Stattdessen suchten sie damit die politische Loyalität und Gefolgschaft ihrer Debitoren zu gewinnen und sich die Chance zu sichern, im Bedarfsfall von jenen mit Gegenleistungen unterstützt zu werden. ${ }^{28}$ Für den Gewinn solcher >Reziprozität` nahmen die Gläubiger im resultierenden Klientelsystem ein ökonomisches Risiko in Kauf. Denn die materiellen Folgen der Verschuldung konnten nicht nur für den Schuldner, sondern ebenso für den - oft seinerseits verschuldeten - Gläubiger verheerend, ja ruinös sein. ${ }^{29}$ Manch ein Kreditgeber kam so »umb das Seinige und an den Bettelstab ${ }^{30}{ }^{30}$

Bei der Fokussierung auf die Gläubiger bringt die Accurata Utopiae Tabula samt Erklaerung dieses ökonomische Risiko der aktuellen Kreditpraxis satirisch in Anschlag. Deshalb verlautet kein Wort von Zins - obwohl sich das Thema aufgrund der langen Tradition theologischer Problematisierung und der mindestens auf dem Papier bestehenden kirchlichen Zinsverbote ${ }^{31}$ bestens in den moralisierenden Rahmen gefügt hätte: Zumal im Anschluss an eine mittelalterliche Verbindung von Ökonomie und Religion ${ }^{32}$ wäre zu erwarten, dass den Gläubigern ihr Verlangen von (Wucher-)Zinsen als Sünde angekreidet würde.

26 Vgl. Lipp, ebd., S. 27.

27 Vgl. Lipp, ebd., die den Befund von Fontaine referiert: »Das Abschreiben oder In-AbgangStellen von Krediten war ein üblicher Teil der Kreditpraxis in der paternalistischen moralischen Ökonomie der frühen Neuzeit.«

28 Vgl. Lipp, ebd., S. 27-30.

29 Vgl. dazu z.B. Beate Sturm: »Borg macht Sorg؛: Schuldkonflikte im frühneuzeitlichen Hannover«. In: Schlumbohm: Soziale Praxis des Kredits, S. 53-79, hier bes. S. 71.

30 So die exemplarische Formulierung in einem Dokument der Hannoveraner Regierung (um 1704), zitiert bei Sturm, ebd.

31 Vgl. dazu etwa den Sammelband Shylock? Zinsverbot und Geldverleih in jüdischer und christlicher Tradition, hg. von Johannes Heil u. Bernd Wacker, München 1997, darin bes. den Überblicksbeitrag von Matthias Theodor Kloft: »Das christliche Zinsverbot in der Entwicklung von der Alten Kirche zum Barock. Eine Skizze«, S. 21-34.

32 Vgl. Jacques Le Goff: Wucherzins und Höllenqualen. Ökonomie und Religion im Mittelalter, aus dem Franz. von Matthias Rüb. 2., überarb. u. erw. Aufl. Stuttgart 2008, und darin bes. die Einführung von Johannes Fried, S. 134-174. 
Diese Perspektive istrepräsentativ für einezentraleProblematisierungsweise von Kredit in den Texten jener Zeit. Sentenzenhafte Sprüche in der Art von »Borg macht Sorg«, wie es beispielsweise auf einem illustrierten Flugblatt (nach 1637) mit einer allegorischen Darstellung des gestorbenen »Herrn Credits « im Sinn der zu jener Zeit international verbreiteten Metapher von ’Tod des Kredits` heißt, sind häufig auf den Ruin von Gläubigern gemünzt (Abb. 15).33

In den moraltheologischen Rahmen des Karten-Text-Ensembles ist die Perspektivierung jedoch zum Preis - oder unter Gewinn - einer sichtlichen Spannung integriert. Weil die Kreditthematik poetologisch aufgeladen ist, prägt die Spannung auch diesen Aspekt: Während sich dieses Erfinden einerseits, wie vorgeführt, selbstreflexiv als verschwenderisches Erzählen auf Kredit aus der Position des Schuldners ausgibt, präsentiert es sich andererseits hier mit der Gläubiger-Position umgekehrt als verschwenderisches Vergeben von Krediten an die nicht unbedingt vertrauenswürdigen Leser, an uns »Schmarotzer / Dellerlecker und Fuchsschwaentzler«.

Die Accurata Utopiae Tabula hat sich bei aller Anknüpfung an literarische und theologische Traditionen zugleich der Veranschlagung konkreter ökonomischer Verhältnisse ihrer Zeit verschrieben. Die Mehrgleisigkeit wird selbst dort durchgehalten, wo sich die verschiedenen Dimensionen schwerlich miteinander vereinbaren lassen. Besonders deutlich ist dies beim Thema des Kredits, dessen Perspektivierung für die Gläubiger die real-ökonomischen Bedingungen des Adressatenkreises in die Imagination einbringt, aber nicht zum moraltheologischen Aufruf gegen Sünden und Laster passt - und als >Mangelerscheinung $<$ im Schlaraffenland ja ohnehin nichts verloren hätte. Aber das ist womöglich eine weitere Variante luxuriöser Logik.

$33 \mathrm{Zu}$ diesem Flugblatt und zur allgemein gängigen Metapher vgl. die Einleitung des Herausgebers im Band von Schlumbohm: Soziale Praxis des Kredits, S. 7-14, hier bes. S. 7, sowie im gleichen Band die Beiträge von Lipp: Kreditforschung, bes. S. 20f., und Sturm: Schuldkonflikte, bes. S. 53 . 


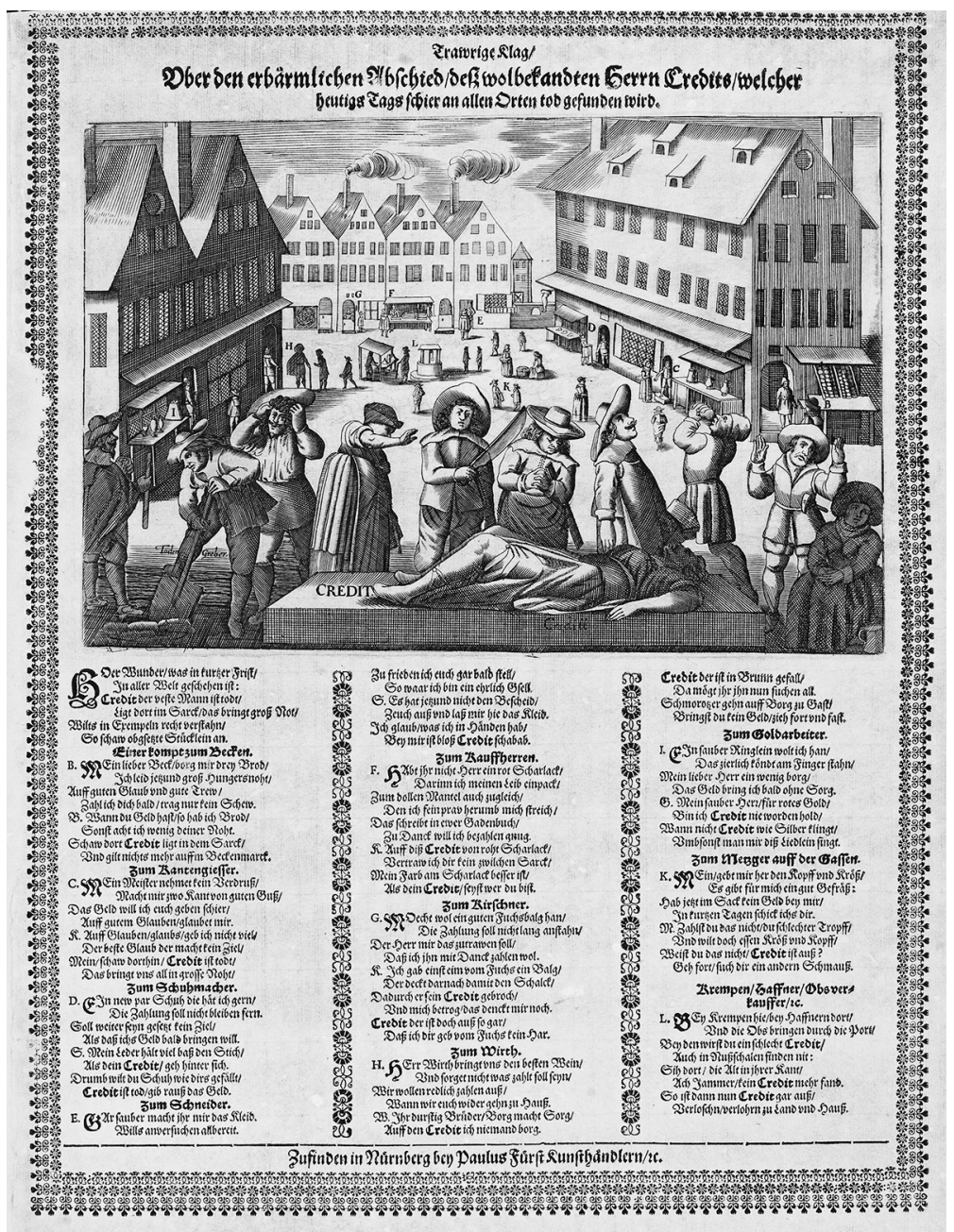

Abb. 15: »Traurige Klag / Ober den erbärmlichen Abschied deß wolbekandten Herrn

Credits / welcher heutigs Tags schier an allen Orten tod gefunden wird«, o.O. nach 1637 (Herzog August Bibliothek Wolfenbüttel) 


\section{Hüben und drüben zugleich \\ Fantastische Raumlogik und die Grenzen des Schlaraffenlandes}

In kaum einem anderen Vorstellungskomplex ist die Grenze so zentral wie in den Erfindungen des Schlaraffenlandes. Das mag überraschen, scheint doch paradox, dass ausgerechnet Ausmalungen von Gefilden grenzenloser Genüsse erzählerisch viel auf Gebietsbegrenzung verwenden. Entsprechend dürfte die (Lektüre-)Erinnerung beim Stichwort 'Schlaraffia bereitwillig zum Verzehr herbeieilende Ferkel mit Messer und Gabel bespicken, Weinbäche zum Fließen bringen, Tortentürme und alles andere aufhäufen, was es in diesem annehmlichen Land geben soll, während leicht vergessen geht, dass das Erzählen vom Übergang ins Land der ewigen Müßiggänger - und allenfalls wieder hinaus - für solche Geschichten mindestens so essenziell ist. Und wer sich immerhin an die plastischste aller Grenzen, den berühmten Breiberg, erinnert, wird fragen, was denn interessant sein könnte an den Rändern eines fantasierten Landes, das heute vornehmlich in der banal-harmlosen Kinderecke der Schublade `Motivgeschichte lagert. $^{1}$

In diesem Kapitel möchte ich am besonderen Beispiel der Accurata Utopiae Tabula, aber auch (und zuerst) an einer Reihe anderer SchlaraffenlandDarstellungen aus verschiedensten Zeiten zeigen, dass und weshalb die Grenze Schlaraffias kein randständiges Phänomen ist, obwohl es sie nirgends gibt außer in der Fiktion. ${ }^{2}$ Solche Grenzfantasien ergeben nämlich erzählerische Pointen, die historisch spezifisch und zugleich allgemein relevant sind für Verfahren von Literatur und Kunst. Die Geschichten um die schlaraffischen Landesgrenzen vermessen Möglichkeiten von Fiktion, eigene Räume zu erfinden, die nicht nur anders ausgestattet sind, sondern auch grundlegend anders funktionieren als in einer Geografie mit Realitätsanspruch. So entstehen fiktionale Räume, die topografische Konventionen und, mehr noch, topologische Grundvoraussetzungen sprengen. Weil die Imaginationen Schlaraffia dabei gerne ausdrücklich als >bloße Erdichtung verraten, hat die obsessive Behandlung der Grenze und ihrer Überschreitung Konsequenzen für ein Verständnis von Fiktion als Grenzüberschreitung.

1 Zur Geschichte des Verdikts einer einfältigen Kinderfabel vgl. Richter: Schlaraffenland, S. 94-104.

2 Die Literaturwissenschaft interessiert sich mit Vorliebe für Erzählungen von real-geografischen und -politischen Grenzen. Vgl. z.B. Dieter Lamping: Über Grenzen. Eine literarische Topographie, Göttingen 2001, oder den Sammelband Literatur der Grenze - Theorie der Grenze, hg. von Richard Faber u. Barbara Naumann, Würzburg 1995. 
Literatur erweist sich aus dieser Perspektive gerade nicht als grenzenloses Spiel jenseits von Beschränkungen aller Art, sondern vielmehr als Spiel mit Grenzen.

Daher werden im Folgenden - nach einer Bestandsaufnahme von besonders aufschlussreichen Grenz-Fällen - topografische wie topologische Aspekte fokussiert und schließlich poetologische Konsequenzen diskutiert.

\section{Schlaraffischer Grenzverkehr}

Wie gelangt man ins Schlaraffenland? Die poetisch-konkreteste Antwort gibt ein Wortgebilde von Ernst Jandl, das alles Gewicht auf die Grenze legt: ${ }^{3}$

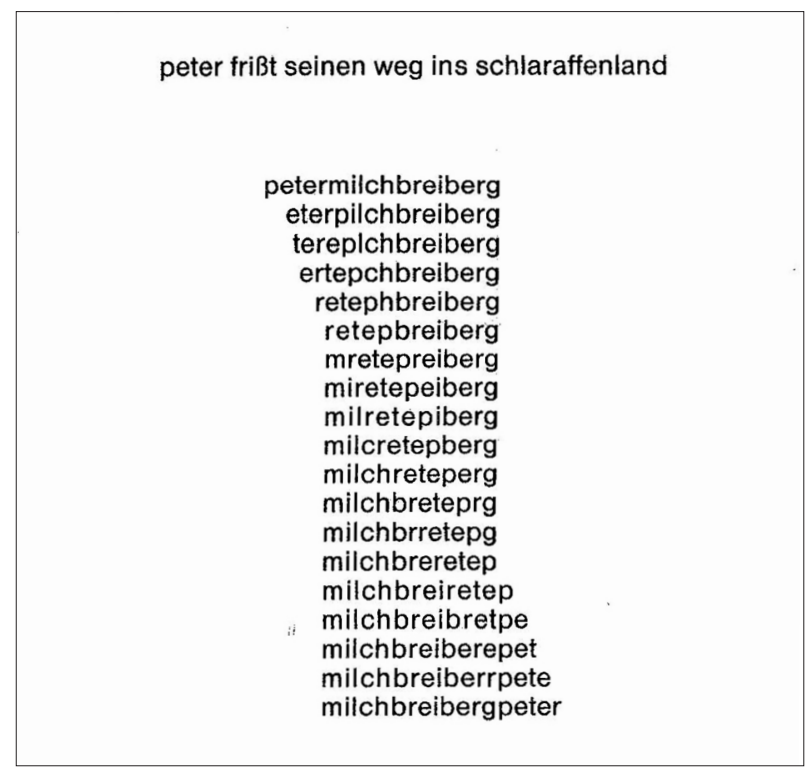

Abb. 16: Konkrete Poesie der Grenzüberschreitung: Schlaraffia-Gedicht von Ernst Jandl

3 Ernst Jandl: peter frißt seinen weg ins schlaraffenland, in: ders.: Poetische Werke, hg. von Klaus Siblewski, Bd. 6, München 1997, S. 129. 
Transformationsregeln folgend, die optisch so unmittelbar einleuchten wie sie sprachlich nur schwerfällig zu beschreiben wären, ${ }^{4}$ wird hier Peters Hindurchfressen durch den Breiberg vor dem Schlaraffenland als Mutation der ursprünglichen Buchstabenfolge von "peter « vor »milchbreiberg « Zeile für Zeile realisiert. Das im Titel angesprochene Schlaraffenland selbst kommt mit keinem Wort vor, genauso wenig wie das Diesseits, aus dem Peter aufbricht. Sogar in der ersten und letzten Zeile, die Ausgangslage (Peter befindet sich noch im Diesseits) und Zielsituation (Peter ist nun im Schlaraffenland) darstellen, dominiert der dazwischen liegende Milchbreiberg dermaßen, dass die sLänder ' ganz von der Grenze her perspektiviert sind: Sie erscheinen unter Überblendung von zeitlicher und räumlicher Dimension, wobei nicht nur der Raum dynamisiert, ${ }^{5}$ sondern zugleich die Dynamik verräumlicht wird - als Davor und Danach, als Diesseits und Jenseits der Grenze, anstatt dass umgekehrt die Grenze als ihr Dazwischen in den Blick käme.

Im Gegensatz zu gewöhnlichen Landesgrenzen, die idealtypisch als Linien ohne Flächenausdehnung gedacht werden, handelt es sich hier zudem um eine betont >dicke< Grenze. Sie erfordert einen dreistufigen Überwindungsprozess, der in der grafischen Gestaltung des Buchstabenblocks erkennbar ist und einen vollkommen von der Grenze bestimmten Plot ergibt: Peter frisst sich in den Breiberg hinein, bis er vollständig darin verschwindet (Z.1-6); dann arbeitet er sich weiter fressend innerhalb des sich offenbar hinter ihm wieder schließenden Berges vor, bis er hindurch stößt ( $Z$. 7-14); schließlich frisst er sich auf der anderen Seite daraus hervor, bis er ganz draußen ist (Z. 15-19). Augenfälliger als durch diese Konzentration auf den Milchbreiberg und dessen Durchtunnelung kann die Grenze des Schlaraffenlandes kaum ins Zentrum gerückt werden. Das lässt sich als konkret-poetischer Kommentar zur langen Tradition schlaraffischer Präsentatio-

4 Ein Beschrieb nähme leicht die Ausmaße eines langweiligen Romans an und könnte etwa so beginnen: Für die Zeilen 1 bis 6 gilt, dass im Fortgang von einer Zeile zur nächsten jeweils der erste (verbleibende) Buchstabe des ursprünglichen Wortes "milchbreiberg « entfällt und der erste (verbleibende) Buchstabe des ursprünglichen Wortes "peter « auf den Platz rechts der vertikalen Grenzlinie verschoben wird, die auf der Position der ursprünglichen Grenze zwischen den beiden Wörtern bestehen bleibt. Gemäß den drei Phasen des Hindurchfressens (vgl.im Weiteren) dürften den Mutationen insgesamt drei Algorithmen zugrunde liegen.

5 Bes. Lotman betont die Bedeutung der Grenzüberschreitung des >Helden für die Dynamisierung einer (literarischen) Raumstruktur mit Teilräumen (vgl. Jurij L. Lotman: Die Struktur literarischer Texte, aus d. Russischen von Rolf-Dietrich Keil, München 1989, S. 300-346). 
nen lesen: Der entscheidende >Punkt in den Schlaraffenland-Vorstellungen ist die Grenze, deren populärste Gestaltung hier aufgerufen wird.

Der Breiberg taucht erstmals prominent bei Hans Sachs auf, der ihm zu Beginn des Meistersangs Das Schlauraffen Landt (1530) einen breiten Platz einräumt, auch wenn er ihm nur vier Verse widmet:
Ain gegent haist Schlauraffen land,
Den faulen leuten wol bekant,
Das ligt drey meyl hinder Weyhnachten.
Vnd welcher darein wölle trachten,
Der muß sich grosser ding vermessn
Vnd durch ein Berg mit Hirßbrey essn,
Der ist wol dreyer Meylen dick.
Als dann ist er im augenblick
Inn den selbing Schlauraffen Landt,
Da aller Reychthumb ist bekant. ${ }^{6}$

Die Anfangspassage des Gedichts, gefolgt von einer langen Aufzählung des schlaraffischen »Reychthumbs« (von Fladen-gedeckten Häusern mit »Leckuchen«-Türen und -Fensterläden, »Speckuchen«-Böden und -Wänden über den Zaun, »Geflochten von Bratwürsten braun«, »Krapffen« an den Tannen und "Weyntrauben inn Dorenheckn" bis hin zu Pferden, die einen jeden machen zum »reychen Mayer, / Wann sie legen gantz körb vol Ayer «), ${ }^{7}$ erhellt vorbildlich drei generelle Grundfunktionen solcher Grenzen. Sie sollen im Verlauf dieses ersten Abschnitts skizziert werden.

Mit seiner Fresshelden herausfordernden Beschaffenheit bindet der Breiberg bei Sachs wie in vielen anderen Versionen ${ }^{8}$ erstens die ausführliche Beschreibung des Schlaraffenlandes in eine abenteuerliche Reisegeschichte ein. Während allgemein die Attraktivität von Grenzen für das erzählende Medium (auch) darin gründen mag, dass Grenzen in besonderer Weise Geschichten ihrer Überquerung evozieren, gilt dies speziell für den Übergang ins Schlaraffenland: Eine ausgedehnte, nicht reibungslos passierbare Grenze vor dem Land, in dem alles nur allzu leicht zu haben ist und bei der Aufzählung der Köstlichkeiten darbieterische Langeweile droht, bringt erzählerischen Gewinn.

6 Sachs: Das Schlauraffen Landt, S. 65, V. 1-10. Sachs gilt als Erfinder des Breiberg-Motivs (vgl. z.B. Richter: Schlaraffenland, S. 28; Martin Müller: Schlaraffenland, S. 57).

7 Ebd., S. 65-67, Zitate V. 12f., 16, 19, 24, 47f.

8 Für Beispiele vgl. Richter: Schlaraffenland, S. 28. 
Es dürfte nicht zuletzt diesem Gewinn geschuldet sein, dass ein Roman wie Heinrich Manns Gesellschaftssatire Im Schlaraffenland (1900) entgegen seinem Titel keineswegs nur berichtet, wie es da im metaphorisch als Schlaraffenland vorgestellten Kreis der 'feinen Leuter zu und her geht, sondern vielmehr die ganze Geschichte als - höchstens kurzzeitig glükkenden - Versuch eines provinziellen Emporkömmlings anlegt, ins städtische Schlaraffenland zu gelangen, "wo das Geld unter den Möbeln umherrollt[ ] ${ }^{9}$ Dabei ist der Protagonist Andreas Zumsee allein schon insofern ein diskreditierter Abenteurer, als sich abzeichnet, dass er nur den Part des Versuchskaninchens im soziologischen Experiment seines Mentors Köpf spielt. ${ }^{10}$ Heinrich Mann betreibt in diesem Roman insgesamt eine raffiniert transformierende Adaptation schlaraffischer Motive, die vor allem in der Verschmelzung mit zeitgenössischen (Dekadenz-)Diskursen besteht. So lässt er in seinem dystopisch bebilderten Land etwa den "sanguinischen" Protagonisten die Hoffnung der »[m]üde[n] Rasse« der Bewohner auf den obligaten Jungbrunnen des Schlaraffenlandes wecken. ${ }^{11}$ Es erscheint nicht überzogen, auch den herkömmlichen Breiberg in einer konkreten, entsprechend veränderten Gestalt zu sehen: Andreas Zumsees Weg ins Schlaraffenland, hier als sozialer Aufstieg in die oligarchisch organisierten Kreise umgesetzt, erfolgt hauptsächlich über seine Liebesdienste an der Ehefrau des Schlaraffia-Königs Türkheimer, deren »Fleisch" ihm, sobald er es "gekostet « hat, »Appetit" macht und in der »riesenhaften Fülle« eine »bäuerische Freude « bereitet, ihn beim Liebesmarathon aber auch erschöpft. ${ }^{12}$ Ähnlich wie sich Sachs' Breiberg-Bezwinger an der breiten Grenze durch Ausdauer im Verspeisen schlaraffisch qualifizieren muss, beweist bei Mann der »Eroberer « Andreas dergestalt seine Eignung für eine Sphäre, in der solche Liebesmühen die einzige 'Arbeit ${ }^{13}$ sind. Bloß handelt es sich bei dieser in einem anderen Sinn dicken Grenze nicht um vegetarische Kost, sondern gleichsam um eine fleischig-fleischliche Variante des Breibergs, weshalb sich Andreas hinterher folglich »wie ein triumphierender Kannibale« nach dem »Sieg« fühlt. ${ }^{14}$ Der satirisch-parodistischen Darstellung gemäß deutet sich in

9 Heinrich Mann: Im Schlaraffenland. Ein Roman unter feinen Leuten, Frankfurt a. M. 62006, die wiederkehrende Formel z.B.S. 199.

10 Vgl. ebd., bes. S. 96 und 292f.

11 Ebd., S. 67 und 81. Der Jungbrunnen findet sich selbstverständlich schon bei Sachs: Das Schlauraffen Landt, S. 67, V. 57.

12 Mann: Im Schlaraffenland, S. 118f., 154, vgl. 164.

13 Für die mehrfach wiederkehrende Thematisierung dieser schlaraffischen Arbeitsanforderung vgl. bes. ebd., S. 203 und 339.

14 Ebd., S. 118 bzw. 159. 
diesem Verdienstmoment auf der Negativfolie zugleich eine zweite kardinale Funktion der beschwerlichen Schlaraffenland-Grenze an, wie sie bereits der Breiberg bei Sachs erfüllt.

Mit derartigen Grenzen wird nämlich - je nach Blickrichtung - eine Art Schadensbegrenzung oder Besitzstandwahrung in moralischen Dingen und weiteren gegen das Schlaraffenland ausgespielten Werten betrieben. So zeigt sich ein Zusammenhang zwischen den wuchtig-betonten Grenzen Schlaraffias und jenen bereits beschriebenen Textstrategien, die widerspenstigen, weil an sich amoralischen Geschichten vom Land des unlimitierten Luxus in jedem sinnlichen Sinn ${ }^{15}$ mit moralisierenden Rahmungen einzuzäunen. ${ }^{16}$ Den rahmenden Elementen auf der Ebene des discours entsprechen auf der der histoire-Ebene die aufwendig ausstaffierten Landesgrenzen. Es scheint deshalb kein Zufall, dass gerade Sachs das Schlaraffenland mit einem Berg aus Brei begrenzt, charakterisiert doch sein Gedicht, wie vorgeführt, eine besonders große Spannung zwischen der schwelgerischen Schilderung und der beflissenen Behauptung, die ganze Geschichte diene dem Tadel und der Warnung der (jungen) Faulen und Gefräßigen. ${ }^{17}$

Auch die Erfindung des Breibergs löst zwar die Spannung nicht auf, kompensiert jedoch das radikal amoralische Potenzial der SchlaraffenlandVorstellung fernab jeglicher Verdienstethik immerhin dadurch, dass sie jener Sphäre das manifeste Leistungsprinzip als Grenze vorlagert. Wer als Schlaraffe unverdient will genießen dürfen, muss sich dies wenigstens mit einer Eintrittsleistung verdienen. Anders beschrieben (und angesichts der kulinarischen Niederungen zu hoch gestochen): Am Berg aus Brei spitzt sich die vielbeschworene >Dialektik der Grenze`, die gleichzeitig trennt und verbindet, ${ }^{18} \mathrm{zu}$ einem ebenso problematisierenden wie legitimierenden Doppeleffekt zu, indem die Grenze im Kontrast zu ihrem Jenseits besondere Leistungsbereitschaft erfordert und damit den Aufenthalt im Land der Leistungslosen rechtfertigt. Dieser Zweischneidigkeit entspricht ihre Breibeschaffenheit. Anders als seltenere Varianten - etwa eine Grenze aus Schweinemist, die man sieben Jahre bis zum Kinn eingesunken durchwaten muss, oder eine meilendicke Drecksgrenze, die es zu durchfressen gilt ${ }^{19}$ - stimmt der Breiberg das diesseitige Leistungsprinzip bereits jensei-

15 Vgl. bes. die breite Palette kulinarischer, musikalischer, kosmetischer und erotischer Genüsse in Wielands Version (Wieland: Abderiten, S. 65f.; dazu in Kap. I, S. $15 f$.

16 Vgl. dazu in Kap. I, bes. S. $19 f$.

17 Vgl. ebd., bes. S. 20.

18 Vgl. z.B. Lamping: Über Grenzen, S. 15, unter Anknüpfung an Georg Simmel.

19 Vgl. dazu Richter: Schlaraffenland, S. 28. 
tig-schlaraffisch ein. Die Anforderung hebt sich damit grundlegend von Verdienstformen ab, wie sie für die Erlangung von religiös-theologisch versprochenen Paradiesen üblich sind: Als Vorgeschmack auf das Schlaraffenland, wo in Affinität zu Verkehrte-Welt-Motiven Faulenzen entlohnt und Arbeiten im diesseitigen Sinn bestraft wird, ${ }^{20}$ heißt Arbeiten schon an der Grenze Fressen, das hier allerdings noch auf profanen Brei anstelle schlaraffischer Delikatessen beschränkt ist. Präzis gemäß ihrer Funktion als Übergang ist die Breigrenze demnach als `Zwischending ` von Hüben und Drüben konzipiert.

Zugleich ist im dicken Wall aus Hirsebrei mit dem implizierten Problem der limitierten Fresskapazität oder Übersättigung jene Schwierigkeit vorgespurt, die in modernen Schlaraffia-Versionen seit der Zeit um 1700 verstärkt auftaucht und mit dem Umbruch in der Luxus-Diskussion in Verbindung gebracht werden kann. ${ }^{21}$ Wenn, wie skizziert, Fénelons fabelhafte Erzählung Voyage dans l'île des plaisirs im ausgehenden 17.Jahrhundert die schlaraffische Problematik nicht moralisch, sondern diätetisch-ökonomisch fasst als Überdruss am Überfluss und Mangel an Nachfrage im ständigen Überangebot, lohnt sich hier ein zweiter Blick auf die Geschichte. Denn erneut nicht zufällig gehören jene Händler mit schlaraffisch begehrten Gütern - Appetit und Müdigkeit - zur Grenze des Schlaraffenlandes: Sie treiben Geschäfte mit den Ankömmlingen am Strand, der in dieser Inselreisegeschichte in Lukian'scher Tradition die Grenze zum Reich der grenzenlosen Genüsse bildet. Passend zur Akzentverschiebung von moralischer zu ökonomisch-diätetischer Problematisierung handelt es sich nicht um kontrollierende Grenzwächter, sondern um `Grenzhändler`. Da der Grenzverkehr zudem auf Geldwirtschaft basiert, muss sich der Ankömmling, anders als noch beim Grenztypus Breiberg, nicht einmal mehr durch schlaraffisch-verkehrte Arbeitsleistung qualifizieren. Ohne Fresstest als Stresstest kommt er allein mit Kaufkraft ins Schlaraffenland und die Entmoralisierung zugunsten einer Ökonomisierung der Perspektive auf den Überfluss zum Abschluss.

So einmalig und historisch spezifisch Fénelons Gelüstehändler sind, welche die schlaraffische Mangelware Esslust in Form von Taftsäckchen mit der Funktion künstlicher Mägen verkaufen, so typisch ist zugleich diese fantasiereiche Ausstaffierung der Grenze zum Schlaraffenland. Damit ist die dritte Grundfunktion der Schlaraffia-Grenzen verknüpft, die sich

20 Bei Sachs: Das Schlauraffen Landt, vgl. S. 67f., V. 63f. und V. 81f. Weitere Beispiele in Kap. II.

21 Vgl. Kap. I; zu Fénelons Fable ab S. 41. 
ebenfalls bereits bei Sachs zeigt: Die Landesgrenze aus drei Meilen dickem Hirsebrei erscheint betont fantastisch, und zwar weniger, weil so etwas in Wirklichkeit nicht existiert, denn vielmehr, weil sie in den Versen die Lokalisierung Schlaraffias »drey meyl hinder Weyhnachten " fortführt. ${ }^{22}$ Diese Ortsbezeichnung, die sich schon in einem deutschen Flugblatt aus dem 15. Jahrhundert findet, ${ }^{23}$ gibt sich ihrerseits nicht im Vergleich zu irgendeiner erfahrbaren Wirklichkeit, sondern durch die Vermischung von lokaler und temporaler Kategorie als reines Fantasieprodukt zu erkennen. ${ }^{24}$ Zumal in mutwillig widersprüchlichem Verbund mit dem verheiBenen Zeitbedarf für die Durchquerung (»Als dann ist er im augenblick / Inn den selbing Schlauraffen Landt $\star^{25}$ ) gehört die dicke Breigrenze zu jenen wiederkehrenden Elementen, mit denen die Schlaraffenland-Erzählungen sich selbst immer wieder zu freien Erfindungen erklären. Offenkundige Unstimmigkeiten, ironische Wahrhaftigkeitsbeteuerungen oder freimütige Fabulierbekenntnisse gehören zum Sprachspiel dieser Texte und rücken sie in die Tradition der Lügengeschichte, für die insbesondere die erwähnten Wabren Geschichten Lukians stehen. ${ }^{26}$ So unterbricht sich beispielsweise der Erzähler im Märchen vom Schlauraffenland (1815), das die Gebrüder Grimm nach einer mittelhochdeutschen Lügenmäre adaptiert haben, in seiner überbordenden Aufzählung von - wie Grimms Kommentar etikettiert - »unmöglichen Dingen« plötzlich mit der rhetorischen Frage: »Ist das nicht gelogen genug?«, um dann fröhlich weiter zu erfinden, bis sein »Märchen [...] ausverzählt « ist. ${ }^{27}$ Generell unterscheiden die Grimms bei der Schlaraffen-Fabel zwei Vorstellungstraditionen: zum einen diejenige von "Zuckerhäuschen« und Konsorten in der Nachfolge der "Mythen von dem verlorenen Paradies der Unschuld, worin Milch und Honig strömen «, zum anderen eben diesen Märchentypus im Anschluss an die »vielen Sagen von den unmöglichen Dingen ${ }^{28}{ }^{28}$ Wie in Sachs' Version sind allerdings die beiden Formen in den real existierenden Fabeln zumeist kombiniert.

22 Sachs: Das Schlauraffen Landt, S. 65, V. 3.

23 Vgl. dazu Velten: Europäischer Mythos?, S. 256.

24 Entsprechend verwende ich den Begriff des Fantastischen mit Bezug auf eine fiktionsintern konstituierte Spannung zwischen einer als wirklich und einer als erfunden gesetzten Sphäre. Für eine ähnliche Verwendung vgl. z.B. Uwe Durst: Theorie der phantastischen Literatur, Tübingen u. Basel 2001, bes. S. 87 und 101.

25 Sachs: Das Schlauraffen Landt, S. 65, V. 8f.

26 Vgl. in Kap. I, S. 19.

27 Grimm, Jacob und Wilhelm: Kinder- und Hausmärchen, Bd. 2, Berlin 1812/15, S. 294-296. Die mittelhochdeutsche Vorlage ist abgedruckt bei Richter: Schlaraffenland, S. 181f.

28 Grimm: Kinder- und Hausmärchen, Kommentar-Bd., S. 49f. 
Wenn es die Erzähler offenbar lieben, das Schlaraffenland als Paradefall von Erdichtung und sich selbst als unzuverlässige, d.h. fantasierende >Berichterstatter vorzuführen, dann erscheint die Ausgestaltung der Schlaraffenland-Grenze besonders prädestiniert zu diesem Spiel. Sie erlaubt es, die Differenz zu einer diesseitig suggerierten Wirklichkeit in die Erzählung hinein zu nehmen, mithin die schlaraffische Erfindung als solche hervorzukehren. Dies führt freilich nicht einfach zu einer Begrenzung der deklarierten Erfindung auf das Territorium Schlaraffias. Vor allem dort, wo die Grenze ihrerseits deutlich als fantasiert markiert ist, dehnt ja der Erzähler sein Lügengebiet mindestens bis auf die dem Schlaraffenland vorgelagerte dicke Grenze aus und lässt Zweifel aufkommen, ob es überhaupt irgendwo einen zuverlässigen Boden gibt. Deshalb hört das lustvoll betriebene Spiel mit dem Unterschied von Wirklichkeit und Fiktion an der Grenze nicht auf, sondern potenziert sich hier. Das ist topologisch wie poetologisch bedeutsam.

\section{Hüben und drüben: Fiktive Topologie}

Nicht von ungefähr spielt die Grenze die Hauptrolle bei der Erzeugung des unmöglichen Standortes, auf dem sich die Erzähler der SchlaraffenlandDarstellungen so gerne positionieren. An ihr lässt sich der gewollte Selbstwiderspruch eines Berichtenden räumlich realisieren, der einerseits die Erfindung von Schlaraffia beteuert und andererseits dieses Land minutiös beschreibt: Er nimmt im Wortsinn einen doppelten Standpunkt ein, indem er etwa erklärt, die Grenze zum Schlaraffenland sei nicht zu überwinden, sich aber durch seine (Reise-)Schilderungen gleichzeitig aufspielt als einer, der die Grenze überquert haben muss.

So benimmt sich zum Beispiel der Erzähler im Kinderlied Vom Schlaraffenlande (1853) von August Heinrich Hoffmann von Fallersleben. Er stellt seinen Ausmalungen des kulinarischen Paradieses eine einladende Mitreiseaufforderung voran: "Kommt, wir wollen uns begeben / Jetzo ins Schlaraffenland! « ${ }^{29}$ Nachdem er uns ausführlich den Speck durchs Maul gezogen hat, endet er jedoch mit der Enttäuschung:

29 August Heinrich Hoffmann von Fallersleben: Kinderlieder, hg. von Lionel von Donop, Hildesheim u. New York 1976, S. 245f., hier S. 245, V. 1f. 

Ja, das mag ein schönes Leben
Und ein herrlich Ländchen sein!
Mancher hat sich hinbegeben,
Aber Keiner kam hinein.
Ja, und habt ihr keine Flügel,
Nie gelangt ihr bis ans Thor,
Denn es liegt ein breiter Hügel
Ganz von Pflaumenmus davor. ${ }^{30}$

Dieses Bild steigert die behauptete Unüberwindlichkeit der Grenze dadurch, dass es den Pflaumenmushügel selbst noch der Anwendung unseres Lektürewissens entzieht, derartige Berge verlangten Weltmeisterleistungen im Verspeisen. Der Hügel aus Mus erinnert zwar an den Berg aus Brei, doch anstatt gigantischer Fresskapazitäten wie bei Sachs sind hier fabelhafte Flügel vonnöten. Umso exklusiver ist der Bericht aus dem Innern des Schlaraffenreiches, der dabei offenkundig dem ernüchternden Fazit aller bisherigen Eindringensversuche widerspricht. »Keiner kam hinein «- außer dem Erzähler selbst? Schlaraffia-Geschichten beschränken sich nicht darauf, von Unmöglichem zu erzählen, sondern haben es weit grundsätzlicher auf unmögliches Erzählen abgesehen. Denn ihre unzuverlässigen Erzähler kosten oft jene Möglichkeit von Fiktion speziell aus, sich nicht um den Satz des Widerspruchs zu kümmern: ১Die Grenze zu Schlaraffia wird vom Erzähler entweder passiert oder nicht. « Wie langweilig wäre das fürs Erzählen!

Ausgerechnet die Accurata Utopiae Tabula, die sich als atlasartige Landkarte besonders eng an die nichtfiktionale Darstellungweise der Kartografie anlehnt, treibt nun diesen entschieden fiktiven, da >unlogischen Standpunkt räumlich anschaulich auf die Spitze.

Bevor dies deutlich werden kann, ist die komplizierte Grenzlandschaft im Ganzen näher vorzustellen. Ebenso aufwendig wie die Schlaraffenländereien selbst werden hier die Grenzen und Umländer kartografisch gestaltet. Bereits der Kartuschentitel kündigt ihre Bedeutung im doppelten Sinn an:Beyneben auch die nächst angräntzende Länder der Frommen des Zeitlichen Auff ü: Unterg. auch ewigen Verderbens Regionen (Abb. 3 und 4 in Kap. I), und im Vorwort der Erklaerung werden sie überproportional ausführlich behandelt (vgl.E 7-10). In der ausgeklügelten allegorischen Geografie gibt es insgesamt »vier nachdenckliche[ ] Gräntz=Länder« (E 331) mit unterschiedlichen Übergängen und Beziehungen zum Schlaraffenland. Im Juventae Regnum oder »Land der

30 Ebd., S. 246, V. 33-40. 
Jugend « (Abb. 17; OV 267f.) tritt jeder Mensch seine Lebensreise an, über die hier Geografie mit Biografie verschaltet wird (E 333).

In diesem höchst zweischneidigen Königreich, geprägt von Orten wie Unschuld oder Tugendheim ebenso wie von Betnitville oder Nitscrupulos, entscheidet man sich - nicht nur in der darauf spezialisierten Stadt Erwehle entweder für den steinigen »Tugend=Weg«, der am Schlaraffenland vorbei zum »ewigen Leben « im nördlichsten Land der Frommen führt, oder aber für den mühelosen »Verführungs Weg«, das ist der Seeweg über die Insel Issland zum »zeitlichen Wolleben" im Schlaraffenland (E 339). Wie auf der Karte ersichtlich, ist mit der von den »Berge $[n]$ des Fleisses und der Arbeit « gebildeten Grenze zu Schlaraffia auch noch ein (beschwerlicher) Landweg dahin, genauer gesagt in die Faulenzerregion (Pigritarum Regio), angelegt (E 335). Doch der Erklärer der Land=Charten schreibt bei Erwähnung dieser Berge kein Wort davon.

Wer sich ins Schlaraffenland begeben und dort ausgiebig genossen hat, gelangt noch leichter wieder hinaus, und zwar in jenes hunger- und kum-

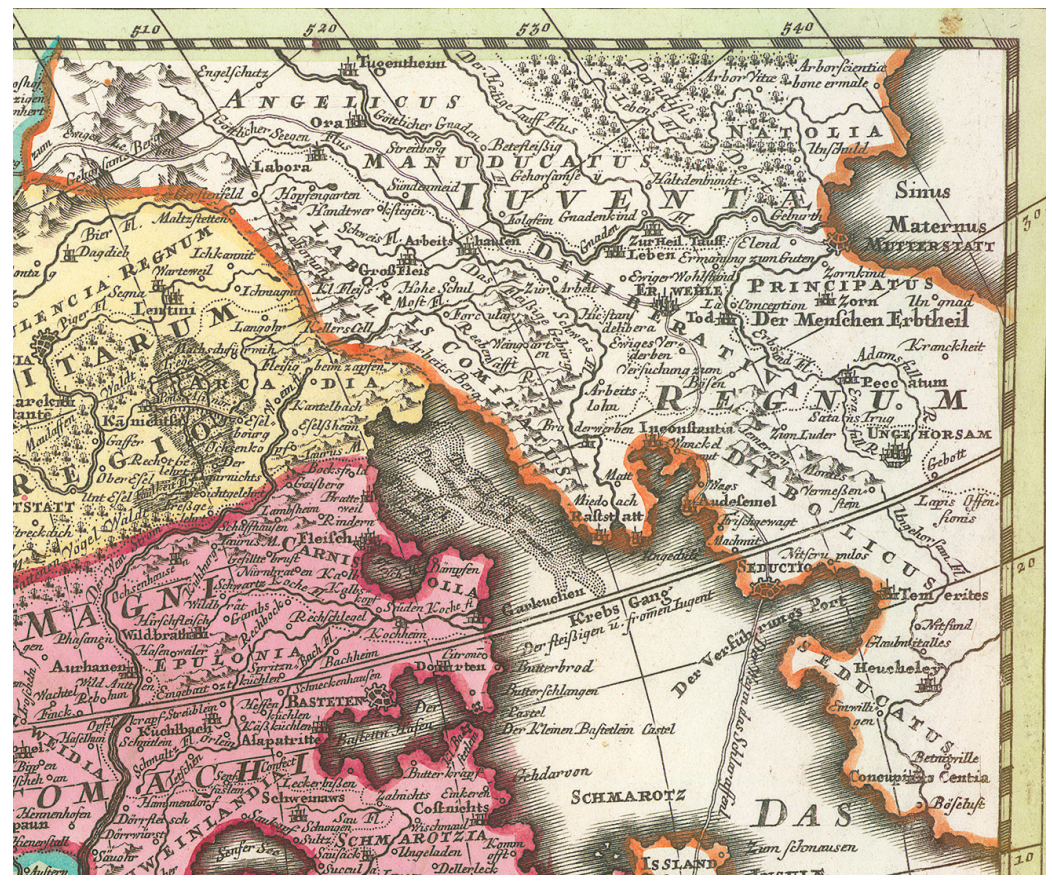

Abb. 17: Entscheidung des Lebens: Das Reich der Jugend vor der nordöstlichen Grenze zu Schlaraffia (Detail aus Abb. 6) 


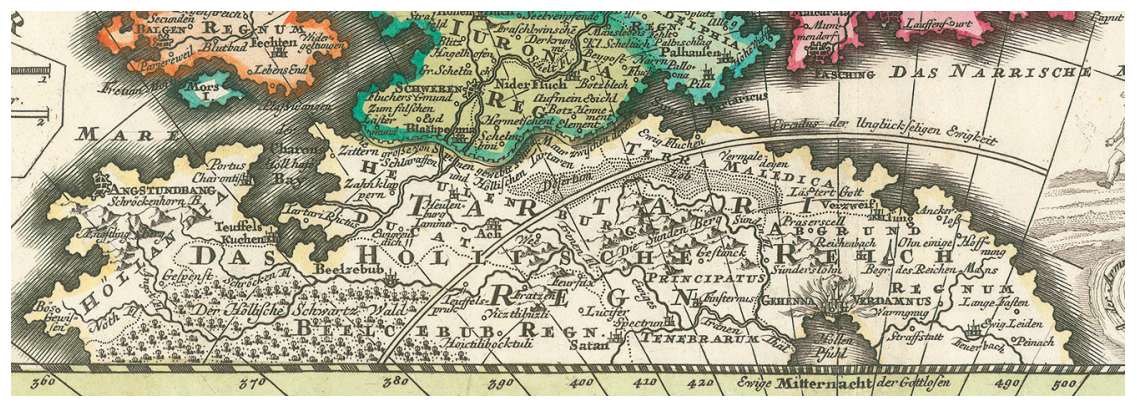

Abb. 18: Bloß Staffage: Eine Grenzmauer aus Papier oder Spinnweben trennt das Land der schlaraffischen Flucher vom Höllischen Reich im Süden (Detail aus Abb. 6)

mervolle »Land[ ] des elenden Alters" (Abb. 13 in Kap. II; OV 269f.), das »des zeitlichen Wollebens gewoehnliches Ende" und daher an Schlaraffia "graentzend[ ] « ist (E 350-352). Entsprechend unsicher ist, wie gesehen, die Abgrenzung durch die »Credit-Berge« (E 319) zwischen dem schlaraffischen Königreich der Verschwender (Abb. 12 in Kap. II; OV 260f.) und diesem zweiten Umland. ${ }^{31}$

Noch trügerischer ist die Absicherung gegenüber dem dritten Nachbarland, dem besagten Höllischen Reich oder Tartari Regnum (Abb. 18; OV 272f.). Diese Grenze besteht aus einer »Mauer der Sicherheit«, nur »von Papier erbauet / oder / wie andere dafuer halten / von Spinnen gewebet", welche die Schlaraffen und konkret die Bewohner des südlichsten schlaraffischen Königreichs Iuronia Regnum, nämlich die »Flucher«, lediglich vor dem Anblick ihres künftigen "gewissen Untergang[s]« bewahrt (E 193).

Das genaue Gegenstück zu dieser südlich-windigen Abgrenzung ist schließlich die Grenze im Norden, natürlich befestigt durch das "rauhe Tugent=Gebuerg « (E 367). Selbstredend ist jenes Gebirge absolut unüberwindlich für die lasterhaften Schlaraffen. Deshalb heißt (ihnen) das vierte Umland, das himmlisch inspirierte Reich der Frommen oder die Terra Sancta, zugleich Incognita (Abb. 19; OV 271). Die paradiesischen Gegenden der "wahren Glueckseeligkeit« - auf der Karte mit biblischen Seligpreisungen ausgeschmückt - sind den irdisch-glücklichen Bewohnern Schlaraffias »lauter Spannische Doerffer [...] / von welchen sie weder etwas wissen / noch wissen wollen« (E 367f.).

31 Vgl. in Kap. II, S. 57 f. 


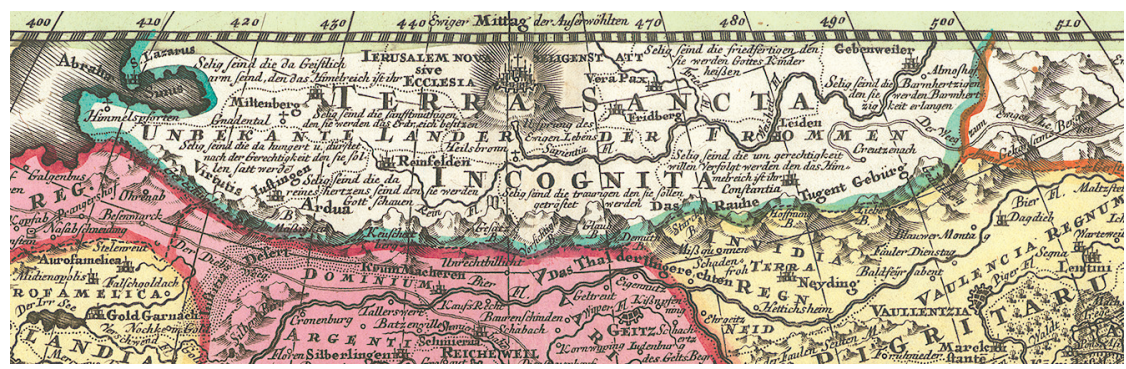

Abb. 19: Unüberwindlich für Schlaraffen: Die natürliche Grenze (»Tugent=Gebuerg«) zur paradiesischen Terra Sancta Incognita (Detail aus Abb. 6)

Wie die Grenzfantasien in anderen Schlaraffenland-Vorstellungen bringen auch die ausgreifend fantasierten Grenzlandschaften der Accurata Utopiae Tabula zunächst eine erzählerische Dynamik ein, die jedoch für das Medium der Landkarte ein spezielles Surplus ist: Mit den Grenzen, welche die Schlaraffen einst überschritten haben, künftig überschreiten werden oder aber nie bezwingen können, wird die statische Darstellung um die zeitliche Dimension von (Lebens-)Geschichten erweitert, Kartografie mit Literatur verknüpft. Diese Verbindung erfolgt auf sprachlicher Ebene, indem etwa die >Grenze des Schlaraffenlandes regelmäßig mit dem `Ende des Schlaraffenlebens überblendet wird (z.B. E 350-352 in der erwähnten Beschreibung der Altersregion). Und sie geschieht nicht erst in der Erklaerung, sondern ansatzweise bereits auf der beschrifteten Karte selbst, genauso wie umgekehrt die Erklaerung mit der Aufzählung von Örtlichkeiten ihrerseits auch kartografisch verfährt. Das Zusammenspiel von Tabula und Erklaerung ist keine simple Arbeitsteilung - ebenso wenig wie dasjenige der beiden Medien insgesamt.

Dieses Wechselspiel lässt sich mit Bezug auf die von Michel de Certeau eingeführte Unterscheidung von carte und parcours verdeutlichen..$^{32}$ Certeau verwendet das Begriffspaar einerseits allgemein topologisch für jegliche sprachlichen Äußerungen mit Raumbezug: Wenn die Äußerung auf ein deskriptives Nebeneinander verweist, das im Prinzip unabhängig ist von der Erfahrung einer Personeninstanz, spricht er von der Struktur einer carte. Beschreibt bzw. erzählt hingegen die Äußerung den sukzessiven Weg ei-

32 Vgl. Michel de Certeau: L'invention du quotidien, vol. 1, Paris 21990, bes. S. 175-180; zusammenfassend und zugleich differenzierend dazu vgl. Dünne: Die kartographische Imagination, v.a. S. 62f., 180-182. 
nes beweglichen Handlungsträgers von A nach B, nimmt sie die Gestalt eines parcours an. Im vorliegenden Fall zeigt das Ensemble von Tabula und Erklaerung konkret, wie sehr die beiden Dimensionen gegenseitig verschränkt sind: Während die Karte in ihr dominierendes Verfahren à la carte insbesondere mit den Grenzlandschaften gleichzeitig Erzählungen im Sinn von parcours integriert, ist das zumindest streckenweise vermehrt erzählende Begleitbuch gerade als Erklaerung zur Karte stark vom beschreibenden Modus der carte geprägt.

Die systematische Perspektive aufdas (intern verschränkte) Zusammenspiel der Medien ist um einen medienhistorischen Aspekt ergänzbar. Certeau setzt die Begriffe carte und parcours andererseits nämlich spezifisch kartografiegeschichtlich ein. Im Übergang vom Spätmittelalter zur Frühen Neuzeit und vor allem mit der Standardisierung von Karten in den ersten Atlanten beobachtet er eine zunehmende Verdrängung des Modells von individuellen parcours durch totalisierende cartes. Zwar handelt es sich nicht um eine einsinnige Verdrängung des parcours durch die carte, wie Certeau meint, denn Karten erzeugen in einer Art positiven Rückkoppelung stets mögliche parcours wie jene umgekehrt zur Erstellung von Karten führen. ${ }^{33}$ So gehört es weiterhin zentral (und mit der zunehmenden Verbreitung von gedruckten Gradnetzkarten sowie Kartensammlungen sogar noch verstärkt) zur Kartografie, namentlich zu Atlanten, bei denen das Reisen auch durch Blättern simuliert wird, dass mögliche parcours auf bestehenden Karten erfunden bzw. zu erfundenen Orten Karten geliefert werden. ${ }^{34}$ Doch zugleich können hier die vornehmlich per Grenzregionen erzeugten parcours der Schlaraffenlandkarte - neben ihrem intermedialen Bezug auf SchlaraffiaErzählungen mit notorischen Grenzüberschreitungsgeschichten - innermedial, d.h. innerhalb der Kartografiegeschichte in der Nachfolge einer besonderen parcours-Dimension mittelalterlicher Karten gesehen werden: in der Tradition der heilsgeschichtlich organisierten Mappae mundi. ${ }^{35}$

Im Kontext von Schlaraffia-Darstellungen liegt das auffälligste Kennzeichen dieser Imagination in der soffenen< Grenze im Nordosten: Ganz im Gegensatz zur dominanten Breiberg-Tradition ist der Übertritt ins Schlaraffenreich hier nicht schwierig, sondern nur allzu einfach. Zwar gibt

33 So betont Dünne, ebd., S. 181, zu Recht.

34 Vgl. ebd., S. 58. Letzteres unternimmt etwa Abraham Ortelius mit seiner Karte (Utopiae typus, 1596) von Morus' Utopia (vgl. dazu ebd., inkl. Abbildung S. 59) - ganz analog zum Erfinder der Accurata Utopiae Tabula.

35 Vgl. dazu auch S. 102. 
es - gemäß der luxuriösen Logik vieler Darstellungen ${ }^{36}$ - gleichzeitig jenen Weg über die Fleißberge in direkter Anknüpfung an diese Tradition. Aber er wird zugunsten des verführerisch zugänglichen Seewegs beinahe unterschlagen. Das hängt mit der unterschiedlichen moralischen Strategie zusammen: Anders als Präsentationen, die Schlaraffia als Land des unverdienten Lohns akzentuieren und dafür in den Grenzübertritt ein Verdienstmoment einbauen, soll hier erklärtermaßen vor dem Land der 'Laster ' gewarnt werden, in dem der Mensch gleichsam immer schon mit einem Bein steht. Dieser immer wieder beteuerten Absicht dient die Erzählung von den Umländern und Grenzen in der moralisch-theologisch aufgeladenen Geografie.

Freilich ist dies nur die eine Hälfte des vorgeführten Doppelspiels von hehrer Absichtserklärung gegen das Laster-Land und darstellerischem Schwärmen für die Schlaraffereien. Die allegorische Topografie der Umländer verschafft Schlaraffia ja gerade mit der disqualifizierenden Rahmung zugleich breiten (Frei-)Raum.

Dieses Doppelspiel gipfelt nun im raffiniert fingierten Ort des Erzählens diesseits und jenseits der Grenze: Auf dem Titelblatt der Erklaerung (Abb. 5 in Kap. I) steht als Druckort Arbeitshausen / in der Graffschafft Fleißig, eine Gegend, die gemäß Text wie Karte zum »Land der Jugend «(Juventae Regnum) gehört und demnach außerhalb des Schlaraffenlandes liegt (Abb. 20; OV 268; E 333).

Im Einklang mit der moraldidaktischen Absichtserklärung gibt sich die Perspektive also demonstrativ distanziert - auf der einen Seite. Doch auf der anderen Seite findet sich innerhalb des durchgängig als SCHALCK=WELT (Kartusche; Abb. 3 und 4 in Kap. I) betitelten Schlaraffenreiches selbst wiederum eine »Landschafft" namens Schalcklandia, die zusammen mit Fantastia, Grillilandia sowie Bacchanalia als Provinz der »Faßnacht=Butzen und Fasching=Gesichte«, auch »Nigriten Land benamet «, das ehrbare »Koenigreich aller Narren « (Stultorum Regnum) bildet (Abb. 21; OV 240f.; E 148-167).

In dieser südlichen, d.h. höllennahen Region leben und wirken die "Schalcken «, die dank "Witz und Arglistigkeit [...] allen andern Narren in der Welt am Verstand ueberlegen sind « (E 156). Die gescheiten Narren studieren und produzieren an der »Universitaet alldort " allerhand schalkhafte "Stuecklein / Raenck und Schwenck" (E 157) - offenbar einschließlich dieser ganzen Imagination des Schlaraffenlandes oder Schalck=Welt« (z.B. E 23). Mit solcher mise en abyme verortet sich diese Erfindung selbst mitten in ihrem Land der Laster.

36 Vgl. bes. den ersten Abschnitt in Kap. II. 


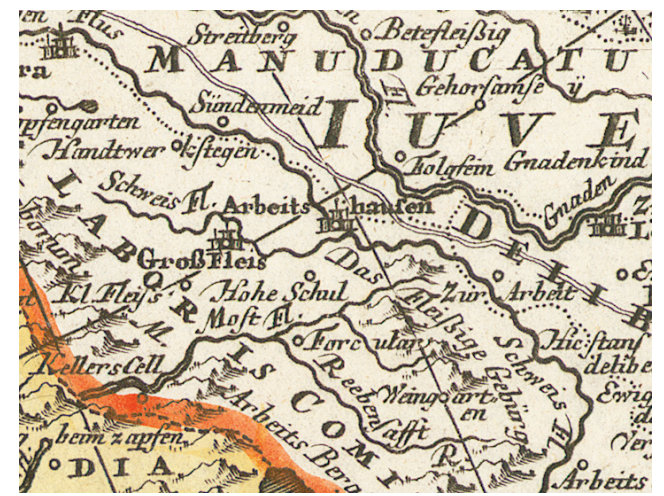

Abb. 20: Distanzierter Druckort der Erklaerung: Arbeitshausen jenseits der Schlaraffenlandgrenze (Detail aus Abb. 6)

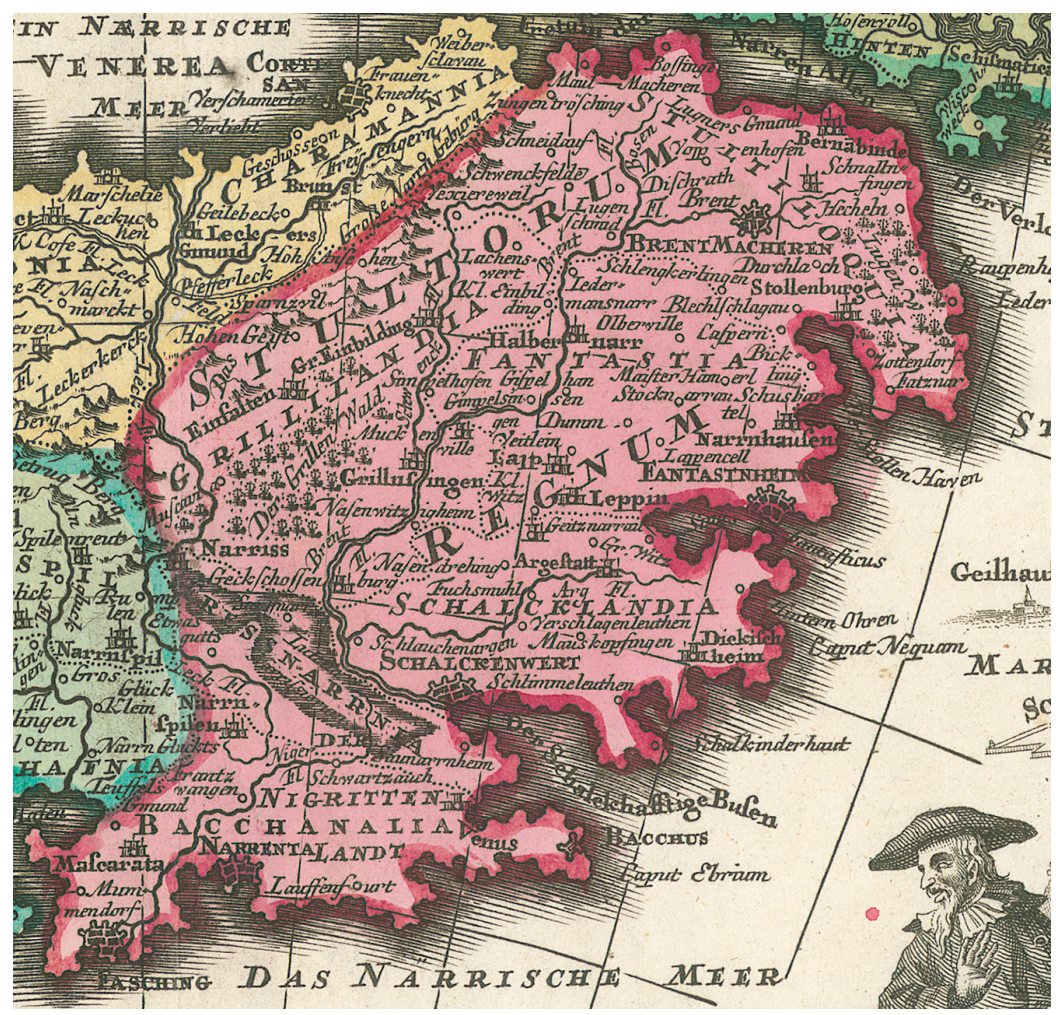

Abb. 21: Produktionsstätte der SCHALCK=WELT-Karte samt Erklaerung: Schalcklandia im Schlaraffenreich der Narren (Detail aus Abb. 6) 
Dabei spricht sie auf ihre kartografisch-literarische Art auch den karnevalistischen Grundzug dieser schalkhafftigen Welt eigens an: Die gewitzten Schalcken stehen in engem Verbund mit den bacchantischen Fastnächtlern und deren Befreiung oder "freudige[n] Entbindung" von der »beschwerliche[n] Fesselung " durch die »Ketten und Bande[n] der Erbarkeit« ihres gewöhnlichen Lebens »in guter Ordnung« (E 159). Sie - wie der Berichterstatter - sympathisieren unverhohlen mit der fastnächtlichen Verkehrung der Ordnungen, nicht nur der Stände-, sondern auch der Geschlechterordnung und der Schwarz-Weiß-Ordnung der Hautfarben (vgl. E 160). Nach dem sichtlichen Vergnügen an der Entgrenzung (zumindest auf begrenzte Zeit) klingt denn am Ende des Kapitels die abgrenzende »Anweisung / Worauf dieser kurtzweilige Discurs[ ] von dem Kuenigreich aller Narren« aus sei, umso zweideutiger - oder sogar eindeutig selbstironisch:

Gleichwie die Thorheit der Menschen aus dem schalckhafftigen Hertzen der Arglistigen entspringet / in die Fantasey sich eindringet / mit vielen Einbildungen und mannigfaeltigen Grillen sich vergroessert / durch einen verlogenen und thoerechten Mund sich offenbaret / in der geilen Weiber-Liebe sich aeussert / und endlich durch die rasend und tobende Unsinnigkeit der Fastnachts-Narren, sich allen Fromm $=$ u. Erbaren zu einem abscheulichen Greuel hervorthut / als hat diese mannigfaltige Thorheit zu verschiedenen seltzamen Provintzen [...] nachdenckliche Ursachen und kraefftige Anleitungen gegeben / aller dieser Thorheiten zu hoehnen / und selbige zu verspotten und zu verlachen. (E 166f.)

Die Provinzen des dichterisch produktiven Narrenreiches erzählen demnach mit ihren sprechenden Namen gerade auch, wie "Thorheiten" von der Art dieser Schlaraffia-Vorstellung entstehen und wie nah ihr Spaß mit anderer Sinnenlust verwandt ist. Die kunstvoll fabrizierte »Thorheit« soll dabei - welch' kluger Zweck - die menschliche »Thorheit« austreiben. Die Methode spottet aber mit Absicht jeglicher Sicherheit, kippt doch solcher Tadel leicht und gerne in ein Lob der Torheit.

Das Doppelspiel ist folgenreich. Weil in Fiktionen die Positionierung des Erzählers oder Präsentators im Raum noch weniger von der Konstruktion des Raumes trennbar ist als in Darstellungen, die einer Wirklichkeit zu entsprechen beanspruchen, hat ein derart doppelter, in sich widersprüchlicher Standpunkt direkte Konsequenzen für die Logik des Raumes, die entscheidend durch die Grenze bestimmt ist. Die Accurata Utopiae Tabula übernimmt die kartografischen Darstellungskonventionen nicht einfach, um den Raum im Sinne ihrer allegorischen Topografie lediglich anders zu ‘füllen`, sondern bietet in diesem Aspekt zudem eine fundamental andere Topologie: Die schlaraffische Grenze bringt kein entschiedenes Diesseits und Jenseits 
hervor bzw. lässt diese Differenz einbrechen. Das liegt nicht daran, dass sie etwa ein allmählicher oder unscharfer Übergang wäre, und auch nicht an einer Dialektik der gleichzeitig trennenden und verbindenden Grenze. Dass der Präsentationsstandpunkt gleichzeitig hüben und drüben vorgestellt wird, untergräbt in radikalerer Weise die Unterscheidung von Diesseits und Jenseits, in deren Etablierung die Minimalfunktion einer Grenze gewöhnlich besteht. ${ }^{37}$ Die Grenze des Schlaraffenlandes verstößt so gegen die gängige topologische Ordnung von territorialen Räumen als Semiosphären, die generell durch Abgrenzung bedingt sind. ${ }^{38}$ Diese dezidiert fiktive Topologie erweist sich als räumliche Konkretisierung der durchweg ambivalenten Wertung in der Präsentation, bei der im wörtlichen Sinn unentschieden bleibt, ob sie auf der Seite Schlaraffias steht oder nicht.

Die kommentierte Karte enthält noch eine weitere eigenartige Grenzfantasie, die zugleich einen allgemeinen Hinweis auf die Funktion der obsessiv behandelten Grenzen (nicht nur) von Schlaraffia-Imaginationen verspricht.

\section{Fiktion als Grenzüberschreitung: Ein Spiel mit Grenzen}

Die fantastische Topologie der Utopiae Tabula erlaubt nicht allein, sich zur gleichen Zeit innerhalb und außerhalb des Schlaraffenlandes aufzuhalten, sondern auch, auf zwei gänzlich verschiedenen Wegen dahin zu gelangen. Nach geografischer Raumkonzeption schließen die beiden Wege einander aus, sodass erneut eine im Kern inkohärente Grenzlogik sichtbar wird. Der erwähnte Zugang aus dem angrenzenden Jugendreich ist nämlich nur eine - dank der verschwiegenen Fleißberge eigentlich doppelte Möglichkeit. Auf die andere Möglichkeit deuten die zunächst rätselhaften Meridiannummerierungen am Kartenrand ab 360 Längengraden aufwärts.

37 Für vergleichbare literarische Untergrabungen der Grenze in anderen Zeiten und Räumen vgl. etwa Brigitte Kaute: "Paradoxien der Grenzüberschreitung in E.T.A. Hoffmanns Märchen Der goldene Topf«, in: Zeitschrift für Deutsche Philologie, Sonderheft zum Band 129 (2010): Grenzen im Raum - Grenzen in der Literatur, hg. von Eva Geulen u. Stephan Kraft, S. 93-108; Stephan Kraft: "Nicht mitten hindurch, sondern darüber hinweg und auf beiden Seiten zugleich. Zur deutsch-deutschen Grenze in Arno Schmidts Roman Das steinerne Herz«, in: ebd., S. 127-146.

38 Zum Begriff der Semiosphäre und deren Konstituente einer ’Getrenntheit von Äußerem durch die Grenze vgl. Jurij M. Lotman: »Über die Semiosphäre«, aus d. Russischen v. Wolfgang Eismann, Roland Posner, in: Zeitschrift für Semiotik 12 (1990/4), S. 287-305, hier bes. S. 290-294. 
In der Erklaerung erfährt man, welche Bewandtnis es damit hat für die Lokalisierung des Schlaraffenlandes: Wie er im zweiten Kapitel unter gleichzeitiger Anlehnung und Abgrenzung von der »ordentlich[n] Geographi« (E 27f.) erläutert, hat es der Erfinder des Landes, das bloß »ein lauteres Gedicht" und »In rerum natura nicht anzutreffen« sei, »fuer gut befunden / den ersten Meridian dieser Schalck=Welt nach demjenigen Grad zu setzen / welcher der letzte unserer allgemeinen Erd=Kugel zu seyn pfleget / nemlich den 360. Grad / und dieselbige biß in den 540. Grad / nach welchem sich unser erdichtetes Erdreich endiget / zu continuiren" (E 22f.). Daraus folge, »daß diese weiter prosequirte Schalck=Welt eine rechte Nebel=Kappen und Uberzug unsers eigenen Erdbodens seyn muesse / aus welcher in diese Schalck=Kappen / durch einen einigen Laster=Text / ein jedes leichtlich gelangen kann« (E 23f.).

Während die Grenze einerseits von der Umrisslinie Schlaraffias repräsentiert wird, verläuft sie gemäß diesen Ausführungen andererseits parallel zum kartografisch als Ebene dargestellten Schlaraffenland. Sie trennt »unsern eigenen Erdboden" von jener "Schalck=Welt«, die sich so als eine Art zweite Dimension oder eben Überzug um die westliche Hemisphäre ${ }^{39}$ wölbt, dass man bereits mit einer einzigen lästerlichen Äußerung (»Laster=Text«) in die Parallelwelt geraten kann.

Die Beschreibung verrät mit der beispielhaften Verbindung von betont frei »erdichteter « und zugleich in Beziehung zu »unserer « Welt befindlicher »Schalck=Welt«, weshalb das Erzählen von der Grenze für SchlaraffenlandDarbietungen so essenziell sein kann: Obwohl oder gerade weil dieses Reich Inbegriff des Erfundenen ist, liegt alles daran, es ins Verhältnis zu setzen mit sunserer Wirklichkeit, die nicht einfach außerhalb der Darstellung vorausgesetzt, sondern in die Präsentation mithineingezogen wird. Anders gewendet: Das Gewicht der Grenze gründet darin, dass solche Schlaraffia-Texte und -Bilder nicht nur von einem deklariert erfundenen Fantasiereich erzählen, sondern immer auch von dessen Beziehung zu einer als solchen präsentierten Wirklichkeit. Es sind Geschichten vom komplizierten Verhältnis zwischen realer und fiktiver Sphäre, zwischen Wirklichkeit und Fantasie. Deshalb sind ihre erdichteten Raumausstattungen (Topografien) und Raumordnungen (Topologien) mit Reflexion über Fiktion aufgeladen.

39 Diese begann damals bei Ferro (heute El Hierro), der westlichsten Kanarischen Insel, wo die Karten bis zur internationalen Festlegung von Greenwich als Bezugspunkt für den Nullmeridian im Jahr 1884 und z. T. noch darüber hinaus die Nullgradlinie ansetzten. Zur Geschichte des Nullmeridians vgl.z.B. Gustav Forstner: Längenfehler und Ausgangsmeridiane in alten Landkarten und Positionstabellen, Neubiberg 2005, bes. S. 23-28. 
Abgesehen von den speziellen Pointen, die darin liegen, wie das Verhältnis von Wirklichkeit und Erdichtung in den Präsentationen jeweils erfunden wird - etwa als Verkehrung wie bei Sachs oder als satirische Zuspitzung wie in der Accurata Utopiae Tabula -, erscheint poetologisch schon bedeutsam, dass für diese Räume die Grenze und mit ihr ein >wirkliches< Diesseits genauso wichtig ist wie das Schlaraffenland selbst. Denn daraus lässt sich ein konkretes Verständnis der Grenzmetapher gewinnen, die für Literatur so häufig (und oft vage) verwendet wird, wenn es um deren Grenzgänge und Grenzbeobachtungen, Grenzziehungen und -aufhebungen, Be- und Entgrenzungen jeglicher Art geht. ${ }^{40}$

Indem Schlaraffia als Erdichtung par excellence präsentiert wird, gleichzeitig aber die Grenzen und Grenzübergänge zu dieser Sphäre darstellerisch derart entscheidend sind, wird hier Fiktion nicht einfach als Spielwiese der Erfindung jenseits der Grenzen irgendwelcher Wirklichkeiten, Regeln oder Konventionen vorgestellt. Vielmehr gehört die Grenzüberschreitung selbst, samt des mitfingierten Diesseits, fundamental zur Erfindung. Entsprechend verstehen lässt sich die beliebte metaphorische Bestimmung von Fiktion (i.S. des Akts wie Produkts) als »Grenzüberschreitung«, als »Überschreiten gesetzter Begrenzungen « 41 aller Art: Was auch immer überschritten wird - und gleichgültig, ob man es in einer bestimmten Wirklichkeit, in Sprachkonventionen oder anderen Regeln sehen möchte -, ist nicht außerhalb der Darstellung zu verorten, sondern seinerseits in ihr. Die Grenze verläuft nicht zwischen der erfundenen Welt und einer Außenwelt, sondern inmitten der Fiktion. Solche Fiktion positioniert sich nicht in einfacher Opposition zu einem Überschrittenen. Sie gibt sich nicht als ein Jenseits, sondern nimmt die zwei Welten mit dem Etikett swirklich den ( (als Re-entry) in sich auf und spielt ein doppeltes Spiel, das von der fortwährenden Dynamik der inneren Grenzen und Übergänge zwischen den Welten lebt. Die schlaraffische Grenzfantasie bietet eine Auslegung der Formel `Fiktion = Grenzüberschreitung`: Fiktion ist kein durch eine vollzogene Grenzüberschreitung hervorgebrachtes Jenseits zu irgendeinem nicht-

40 Zur Konjunktur der svagierenden Grenzmetapher in den Literatur- und Kulturwissenschaften vgl. bes. Eva Geulen und Stephan Kraft im Vorwort des genannten ZfdPhSonderhefts zu Grenzen im Raum - Grenzen in der Literatur (2010).

41 Besonders prominent und in mehrfacher Bedeutung etwa bei Wolfgang Iser: Das Fiktive und das Imaginäre. Perspektiven literarischer Anthropologie, Frankfurt a.M. 1991, z.B. S. 11, 21-23, 55, 96, 130. Für einen Überblick über die »erstaunliche Karriere« des Begriffs der Grenzüberschreitung in der Literaturwissenschaft vgl. Lamping: Über Grenzen, S. 13-15, Zitat S. 13. 
fingierten Diesseits; sie besteht vielmehr in der Darstellung und Erzählung von Grenzüberschreitungen innerhalb der eigens fabrizierten doppelten Welt diesseits und jenseits, die - wie vorgeführt - ihre eigene Raumordnung hat und zwiespältige Standpunkte erlaubt.

Dieses Bild von Fiktion, das Schlaraffenland-Darstellungen zeichnen, trifft zugleich ein Grundverfahren der Kunst, setzen doch ganze Genres wie die Fantastik ${ }^{42}$ oder der Schäferroman ${ }^{43}$ auf doppelte Welten und deren interne Übergänge. Auch deshalb sind thematisierte und imaginierte Grenzen neuralgische Punkte bzw. Linien der Literatur. Dass sie dabei nicht bloß als zu vernachlässigende Trennlinien zwischen (mindestens) zwei Welten stehen, deren Verhältnis allein interessiert, ${ }^{44}$ sondern den Fokus um ihrer selbst willen lohnen, wird an den mit dickem Brei, Pflaumenmus, Schweinemist, Appetithändlern, Kreditbergen, Tugendgebirgen, Papiermauern und anderen Fantastereien befrachteten Grenzen des Schlaraffenlandes besonders anschaulich. Selbst Darstellungen, die einer betont freien Erfindung wie Schlaraffia gewidmet sind, erweisen sich in diesem Sinn gerade nicht als »Spiel ohne Grenzen «. ${ }^{45}$ Und angesichts der zahllosen erzählten Grenzen in literarischen Texten gilt generell: Literatur ist ein Spiel mit Grenzen.

42 Etwa zu Grenzübergängen und -gängern in romantischen Texten vgl. Kaute: Paradoxien der Grenzüberschreitung.

43 Vgl. Iser: Das Fiktive und das Imaginäre, S. 92-129, der seine Bestimmung von literarischer Fiktionalität als Grenzüberschreitung in diesen Romanen veranschaulicht sieht.

44 Die allgemeine Tendenz, sich mehr auf die (Beziehungen der) zwei Welten denn auf die Grenze selbst und den Akt ihrer Überschreitung zu konzentrieren, zeigt sich auch bei Iser, wo sie umso mehr überrascht, als er den $A k t$ des Fingierens als Grenzüberschreitung fasst.

45 Ebd., S. 153, freilich mit Bezug auf das "Ausfächern" von "gegenläufigen Bewegungen" durch Fiktionen. 


\section{Medienwechsel Literatur - Landkarte Die schlaraffische Utopia als heimliche Heimat der Riesen Rabelais'/Fischarts}

Landkarten lagern in Bibliotheken gewöhnlich getrennt von Literatur. Ihre Aufbewahrung in separaten Kartensammlungen dürfte dazu beigetragen haben, dass die Accurata Utopiae Tabula, sofern sich überhaupt jemand für die Kuriosität interessiert hat, über weite Strecken der Geschichte nicht im Wechselspiel mit der Erklaerung als ihrer Buchpartnerin gesehen worden ist. Umgekehrt begünstigt heute die Auffindbarkeit im sgleichmacherischen digitalen Medium, dass dieses mediengemischte Doppel in der Wahrnehmung wieder zusammenspielt.

Beim schielenden Blick auf den Medienmischling - mit einem Auge auf der Karte, einem Auge auf dem Buch - kann man nun auch ein weiterreichendes Spiel zwischen den Medien Literatur und Landkarte entdecken. Denn in der Erklaerung der Wunder=seltzamen Land=Charten UTOPI/E findet sich ein diskreter, aber deutlicher Bezug zur literarischen Welt der Riesen von François Rabelais' Roman-Pentalogie um Gargantua und Pantagruel (1531/32-1564) bzw. deren deutschen Abkömmlingen in Johann Fischarts Geschichtklitterung (1575). ${ }^{1}$ Anders als offensichtlichere Verbindungen vor allem zu in der Erklaerung ausdrücklich erwähnten Texten, namentlich Utopia (1516) von Thomas Morus, Mundus Alter et Idem (ca. 1605) von Joseph Hall und Utopia Didaci Bemardini (1640) von Jakob Bidermann, ${ }^{2}$ ist diese Beziehung bisher niemandem (auch mir nicht) aufgefallen.

Die Verbindung - eine Fernbeziehung über die Distanz von mehr als einem Jahrhundert Literatur- und Kulturgeschichte - erscheint nicht nur aufschlussreich, weil sie die anonym-abseitige Fantasiekarte, für die sich die Literaturwissenschaft kaum zuständig fühlt, ans mittlerweile kanonisch beackerte Textterritorium großer Namen anschließt. Entscheidender ist, dass diese Beziehung einen Vergleich zwischen der Accurata Utopiae Tabula samt

1 Verwendete Ausgaben: François Rabelais: Euvres complètes, édition établie, annoteé et préfacée par Guy Demerson, 2., korrigierte Aufl., Paris 1995 (im Folgenden unter der Sigle $\mathrm{R}$ direkt im Text); Johann Fischart: Geschichtklitterung (Gargantua), Text der Ausgabe letzter Hand von 1590 mit einem Glossar hg. von Ute Nyssen, Düsseldorf 1963 (im Folgenden unter der Sigle F im Text).

2 Am ausführlichsten zu diesen Bezügen vgl. Reitinger: Hauptwerk barocker Lachkultur, bes. S. 284, 286f., 288-292, 296f., der überdies Wahrmund Jacoserius' Wol-geschliffenen NarrenSpiegel (mit zahlreichen Kupferstichen) ins Spiel bringt. 
Erklaerung und den Rabelais'schen bzw. Fischart'schen Textwelten provoziert, der für beide Seiten ergiebig ist: nicht nur für die Kartenimagination, sondern ebenso umgekehrt, gleichsam aus dem Rückspiegel, für Fischarts und Rabelais' Texte.

Daher geht es im Folgenden weniger um den Nachweis der Verbindung zum Selbstzweck denn um vergleichende Perspektiven über die Grenze verschiedener Sprachen und traditioneller Epocheneinteilungen, vor allem aber unterschiedlicher Medien hinweg. Die mediale Differenz zwischen Rabelais' bzw. Fischarts Texten und der erklärten Landkarte lässt sich als Medienwechsel verstehen, wobei der Transfer nicht einfach vollzogen und vergessen ist, sondern als anhaltende Beziehung mitspielt. >Medium allgemeinen Sinn einer Darbietungsform ${ }^{3}$ mit spezifischen Bedingungen und Möglichkeiten ist konzeptuell auf verschiedenen Ebenen ansetzbar. Ertragreicher als eine generelle Gegenüberstellung von Text und Bild erscheint hier der Vergleich zwischen den beiden (auch historisch) spezifischen Medien, dem literarischen Textgenre von Rabelais' bzw. Fischarts Büchern einerseits und der Landkarte mit Erklärung andererseits. Das liegt allein schon daran, dass Karten ein besonders sunreines` oder multimediales Medium sind. Als Zeichen- und Medienverbundsysteme von Bild, Schrift und Zahl vereinen sie in speziellem Ausmaß unterschiedliche Symbolsysteme. ${ }^{4}$ Dieses Zusammenspiel hat zugleich geschichtliche Dimensionen, die für den vorliegenden Fall einschlägig sind: In seiner Komplexität entsteht dieses Verbundsystem erst im 16. Jahrhundert durch den Zusammenfluss verschiedenster Traditionen der Raumaufzeichnung. ${ }^{5}$ Nicht nur hinsichtlich der geopolitischen Territorialisierung, sondern auch seitens der medialen Raumrepräsentation wird die Karte in der Frühen Neuzeit in kurzer Zeit zum Leitmedium, was sich unter anderem in der Entwicklungs-

3 Umschreibungen mit >Übertragung « und ,Übermittlung « betonen dagegen vom Begriff her stärker den Aspekt des Instrumentellen (Übertragung von etwas, Botschaftsübermittlung), auch wenn sich das medientheoretische Interesse dabei auf den >Boten selbst konzentriert. Für eine Orientierung der Medienkonzeption am Boten als Urfigur der Übertragung vgl. Sibylle Krämer: Medium, Bote, Übertragung. Kleine Metaphysik der Medialität, Frankfurt a.M. 2008. Zur Karte als »welterzeugend[em] « Medium in spezifischem Sinn vgl. ebd., v.a. S. 85, und eingehend Dünne: Die kartographische Imagination, bes. S. 17-87.

4 Zum `Zeichenverbundsystem< Landkarte vgl. Robert Stockhammer: Kartierung der Erde. Macht und Lust in Karten und Literatur, München 2007, bes. S. 12f., und unter (noch) verstärkter Akzentuierung als >Medienverbundsystem` Dünne: Die kartographische Imagination, v.a. S. 35-42.

5 Vgl. Dünne, ebd., S. 35, der die Karte »für die Frühe Neuzeit als eine Art Metamedium« fungieren sieht, »in dem sich verschiedene räumliche Imaginationspraktiken bündeln und gleichzeitig voneinander unterscheidbar bleiben« $($ S. 67). 
geschwindigkeit der Drucktechniken zur Wiedergabe und Verbreitung in großer Zahl äußert. ${ }^{6}$ Die Schlaraffenlandkarte steht im Zeichen der (relativ) neuen Möglichkeiten und Errungenschaften, namentlich der komplexen Integration von Textelementen in die bildliche Darstellung - ein Moment, das die dichte Beschriftung der Tabula und die Ausführlichkeit der begleitenden Erklaerung exzessiv weitertreiben.

Aus dem vergleichenden Blickwinkel wird sich gerade der Medienwechsel von der Literatur zur Landkarte als kongeniale Erfindung erweisen, die ebenso frappant zur literarischen Bezugswelt passt wie sie diese gleichzeitig völlig verwandelt. Nach einer Skizze der Beziehung auf inhaltlicher Ebene, mit der auch das Etikett >Utopie direkt zusammenhängt, steht deshalb der Vergleich von Darstellungsverfahren im Mittelpunkt. Dabei kommen Verbindungen zu anderen Intertexten ${ }^{7}$ neben den weiter hergeholten zur Rabelais-Fischart'schen Literaturwelt ebenfalls zum Zug.

\section{Grand-Goschier, Kaiser über Schlaraffia-Utopia}

Die versteckte Verbindung ist zentral platziert. - Bewusst gegen die "gewoehnliche Ordnung aller Erdbeschreiber" beginnt der Verfasser seine Erklaerung der »Haupt=Provintzen « im »Mittel=Punct unsers Utopiæ oder Schlaraffenlands" (E 38f.). Denn die Region namens »TERRITORIUM SCHLARRAFFENBURGI« (Abb. 8 in Kap. I; OV 229; E 38) liegt nicht nur geografisch (ungefähr) im Zentrum der Darstellung. Weil - nach Art eines weiteren mise en abyme - in den hiesigen Städten und gleichnamigen »Aempter[n] (E 39) alle schlaraffischen Provinzen nochmals vertreten sind, enthält die Zentralprovinz in nuce die ganze allegorische Geografie des LasterLandes. Die Liste dieser Lokalitäten liest sich wie ein Inhaltsverzeichnis (»kurtze[s] Compendio«), d.h. eine Art Appetizer: von »Reichseyn«, »Goldmachen « und »Verschwenden «, über »Sauffausen «, »Grobehagen «, »Ludersheim« und »Geilhausen«, »Pralen«, »Stehlen-Leuten«, »Faullentzen« und

6 Dünne, ebd., mit Verweis u.a. auf den Forschungsüberblick in der Einleitung des Bandes Text-Bild - Karte. Kartographien der Vormoderne, hg. von Jürg Glauser u. Christian Kiening, Freiburg i.Br. 2007.

7 Grundlegend zur Diskussion über (frühneuzeitliche) Intertextualität vgl.den Sammelband Intertextualität in der Frühen Neuzeit. Studien zu ibren theoretischen und praktischen Perspektiven, hg. von Wilhelm Kühlmann u. Wolfgang Neuber, Frankfurt a.M. u.a. 1994, und darin bes.: Jan-Dirk Müller: »Texte aus Texten. Zu intertextuellen Verfahren in frühneuzeitlicher Literatur, am Beispiel von Fischarts Ehzuchtbüchlein und Geschichtklitterung «, S. 63-109. 
$»$ Schwelgendorff«bis zu»Spielen«,»Narrnheim«,»Fluchenfein«und»Rauffengern " (E 39-44). Die Spiegelung in verdichteter Form wird politisch motiviert, indem jede schlaraffenburgische Stadt bzw. jedes "Ampt" vom »Groß=Maularchen « mit der Regierung des entsprechenden schlaraffischen Königreichs betraut ist (E 40).

Der kaiserliche »Groß=Maularch «, Monarch über den Königen der einzelnen Königreiche Schlaraffias, hat seinen Regierungssitz im Zentrum der Zentralprovinz, in der Stadt, wo fast alles erlaubt ist, ausser von den "armen Leuten Geld [sprich Steuern] zu nehmen« (E 52). Sie muss zur Potenzierung ihrerseits Schlaraffenburg heißen - gemäß der Stadtgeschichte übrigens auch zur Ablenkung des göttlichen Zorns von der durch einstige Bewohner des zerstörten biblischen Babels gegründeten Kolonie (vgl. E 45-47). Bei seiner ellenlangen Reihe von erlauchten und erbauchten Namen und Titeln führt der im geografisch-politischen »Mittel=Punct « sitzende Oberregent besonders prominent denjenigen des französisch angehauchten "Grand-Goschier» (E 39, 51 u.ö.).

Dieser Name ist nicht nur sprechend wie die Ortsbezeichnungen der sinnreichen Schlaraffengeografie, sondern erinnert zugleich an die deftige Erzählwelt, die Rabelais - unter parodierender Aufnahme insbesondere von Stoffen der Ritterromane und keltischen Märchen - in seiner zwischen 1531 (oder 1532) und 1564 erschienenen Pentalogie um eine Dynastie von Riesen mit gigantischem Durst und Appetit wirkmächtig kreiert hatte. Die Haupthelden, der Riesen-Vater und sein Sohn, die mit den erfolgreichsten ersten beiden Bänden des Romanzyklus berühmt geworden waren, heißen zwar Gargantua und Pantagruel. Ihre - ebenfalls sprechenden ${ }^{8}$ - Namen sind bis heute international beliebt für Restaurants ${ }^{9}$ und werden noch im aktuellen Französisch deonymisch verwendet, wenn etwa von einem >buffet gargantuesque geschwärmt oder vor einem sappétit pantagruélique gewarnt wird. Doch der Großvater von Pantagruel, Vater von Gargantua, heißt Grandgosier (bzw. Grand Gosier) nach ’gosier ‘ für `Kehle‘, ,Schlund`, oder Grandgousier (bzw. Grand Gousier), unter zusätzlichem Mitklang von sgoût . Schon in der mutmaßlichen Vorlage als grant Gosier präsent, kommt er bei Rabelais erst im

8 Gargantua von altfranz. >gargante $<$ = Gurgel. Der Name Pantagruels, der während einer extremen Trockenzeit in Afrika geboren wurde, wird im Buch selbst erklärt: Sein Vater nannte ihn so, "[c]ar Panta en Grec vault autant à dire comme tout, et Gruel en langue Hagarene [d.h. im Maurischen - C.W.] vault autant comme alteré« (R 318). Es handelt sich

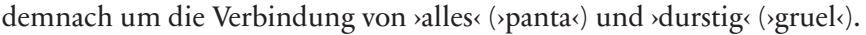

9 Etwa die Osteria / Braceria Pantagruel im süditalienischen Ostuni. 
Gargantua gewichtig vor. ${ }^{10}$ Gargantua ist in der Erscheinungschronologie der beiden von Rabelais unter dem anagrammatischen Pseudonym Alcofrybas Nasier veröffentlichten Bücher der zweite Band (1534 oder 1535), erzählt jedoch gemäß Handlungschronologie die Vorgeschichte zum zuerst erschienenen Pantagruel (1531 oder 1532), sodass er neudeutsch als Prequel, Gegenstück von Sequel, zu bezeichnen wäre. ${ }^{11}$ Vater bzw. Großvater Grandgousier spielt in Rabelais' Gargantua eine recht große Rolle - und eine noch größere in der Geschichtklitterung, Fischarts äußerst erfinderischer >Übertragungく der französischen Vorlage. ${ }^{12}$ Bei Fischart, der seine ausspinnende Version in unser deutscher MutterLallen mit den drei Fassungen $(1575,1582,1590)$ mehr und mehr erweiterte, bis sie im Textumfang schließlich auf das Dreifache des Gargantua angeschwollen war, steht Grandgusier bzw. Grandgoschier bereits im Titel (von 1575 bzw. 1590). ${ }^{13}$ Innerhalb des Buchs wird der Name im Fischart'schen Sprachspielstrudel bisweilen weiter variiert, unter anderem zu Greingussier,

10 Im Pantagruel wird er nur erwähnt in einem Brief Gargantuas an seinen Sohn (vgl. R 350). Rabelais übernahm die Namen z. T. seinerseits aus älteren Traditionen, v.a. keltischen Volksmärchen, die zeitgenössisch besonders durch die anonyme Kompilation Grandes \& Inestimables Chronicques du grant \& enorme geant Gargantua (1532) bekannt waren (vgl. dazu die Bemerkungen des Herausgebers in R 297). Dort heißen Gargantuas Eltern grant Gosier und Galemelle.

11 Die beiden Bände werden in vielen Ausgaben, wie in der hier benutzten, nach der Handlungschronologie als Livre I ( = Gargantua) und Livre II ( = Pantagruel) präsentiert. $\mathrm{Zu}$ den unbekannten genauen Erscheinungsjahren vgl. Demerson (R 47 bzw. 297).

12 Komparatistisch zum Verhältnis der beiden Bücher vgl. bes. Nicola Kaminski: "Gigantographie: Fischarts Geschichtsklitterung zwischen Rabelais-imitatio und aemulatio mit des Gargantua >vnnachzuthuniger stärck «, in: Die Präsenz der Antike im Übergang vom Mittelalter zur Frühen Neuzeit, hg. von Ludger Grenzmann, Klaus Grubmüller, Fidel Rädel u. Martin Staehelin, Göttingen 2004, S. 273-304, sowie die Beiträge von Beate Kellner: "Spiel mit gelehrtem Wissen. Fischarts Geschichtklitterung und Rabelais' Gargantua «, in: Text und Kontext: Fallstudien und theoretische Begründungen einer kulturwissenschaftlich angeleiteten Mediävistik, hg. von Jan-Dirk Müller, München 2007, S. 219-243; »Verabschiedung des Humanismus - Johann Fischarts Geschichtklitterung «, in: Humanismus in der deutschen Literatur des Mittelalters und der Frühen Neuzeit, hg. von Nicola McLelland, Hans-Jochen Schiewer u. Stefanie Schmitt, Tübingen 2008, S. 155-181; "Fischarts Geschichtklitterung und Rabelais' Gargantua: komparatistische Perspektiven «, in: Germanisch-romanische Monatsschrift 59 (2009/1), S. 149-167. Des Weiteren die in diesen Aufsätzen angegebene Literatur.

13 Affentheurlich Naupengeheurliche Geschichtklitterung. Von Thaten und Rhaten der vor kurtzen langen unnd je weilen Vollenwolbeschreiten Helden und Herren Grandgoschier Gorgellantua und de $\beta$ deß Eiteldurstlichen Durchdurstlechtigen Fürsten Pantagruel von Durstwelten [...] (3. Fassung). Für eine Synopse vgl. Johann Fischart: Geschichtklitterung (Gargantua), synoptischer Abdruck der Fassungen von 1575, 1582 und 1590, neu hg. von Hildegard Schnabel, 2 Bde., Halle (Saale) 1962. 
worin 'greinen zu Grandgauchier mit Links-Linkischem-Drall. ${ }^{14}$

Auf der Basis des mittig installierten »Grand-Goschier«, der von seiner Burg "auf einem hohen Berg der Einbildung / in den Wassern der Trunkenheit" (E 48) oder, wie es die Karte verzeichnet, im Truncken See samt Sumpfgebiet Schlamp Pampus aus regiert, ließe sich eine lange Liste von Korrespondenzen zur Geschichtklitterung beginnen. Fischart redet seine Leser etwa beim anfänglichen "Ein und VorRitt [...] inn die Chronick vom Grandgoschier, Gurgellantual und Pantadurstlingern «als "meine Schlampampische[n] gute[n] Schlucker, kurtzweilige Stall und Tafelbrüder « an (F 19), wobei das liebevolle erste Adjektiv von sschlampampen< für sgierig schlürfen< (wie ein Hund oder Schwein), 'prassen 'Schwelgerei< oder `Gelage< zusammenhängt. ${ }^{15}$ Die erklärte Tabula teilt mit der Geschichtklitterung besonders viel - multilinguales - Vokabular namentlich aus dem großen Gebiet der `Gurgel ${ }^{16}$ und dem ganzen »lustigen Freß=« und »Sauff=Discurs« (E 4), übrigens samt inniger Verbindung des körperlichen mit ökonomischem `Materialismus` sowie ausdrücklicher Anknüpfung an die grobianische Tradition und den Bauernhelden Markolf. ${ }^{17}$

Das Trinken und die Trunkenheit sind in beiden Fällen nicht allein obsessiv Thema, sondern werden darüber hinaus eng mit dem (eigenen) Schreiben verknüpft. Unter Ausbau eines bereits bei Rabelais auftauchenden Leitmotivs tritt Fischart den Zusammenhang von Trinken und Dichten in seiner eigenen Lallen breit, indem er etwa die lautlichen Anklänge zwischen >Poeta und 'potare auskostet, um vom Lateinischen aus Volten zum französischen und deutschen Vokabular zu schlagen (vgl. F 28f. ${ }^{18}$, oder als

14 Für einen Überblick der Namensvarianten vgl. Ute Nyssen in ihrem Glossar zu F: Geschichtklitterung. Glossar, Worterläuterungen zum Text der Ausgabe letzter Hand von 1590 nach der Neuausgabe 1963, Düsseldorf 1964, S. 17.

15 Vgl. Nyssen: Glossar, S. 25.

16 Bei Fischart ist dieser Bereich allein schon durch die wild weiter variierten Übertragungen der Rabelais'schen Namen Gargantua, Gargamelle und Grandgosier/-gousier omnipräsent; auch z.B. in Leseranreden wie »Witzersauffte Gurgelhandthirer (F 7) oder »Gargurgulianer" (F 19). In der Schlaraffenlandkarten-Imagination ist etwa »Gurgelmella (E 142) die Hauptstadt von »BIBULIA«, dem »versoffenen Weiber-Ländlein« (E 141) - um nur ein Beispiel herauszugreifen.

17 Im Westen des Schlaraffenlandes gibt es das »Koenigreich MARCOLFI« oder »Bauren= Paradeis« mit der Provinz der »rebellische[n] Bauren=Vogten« namens »PRÆFECTURA GROBIANA« (E 231 bzw. 235). Fischart referiert auf Caspar Scheidts Grobianus / Von groben sitten und unhöflichen geberden (1551), die Übersetzung von Friedrich Dedekinds Grobianus. De morum simplicitate (1549), und spricht von »Marcolfe" (vgl. F 28). Vgl. Kaminski: Gigantographie, bes. S. 297f.; Kellner: Spiel mit gelehrtem Wissen, S. 240f. 
8. Kapitel seiner Geschichtklitterung (E 117-145) eine ausufernde »Truncken Litanei (E 117) hält. Auf der Accurata Utopiae Tabula bietet besonders das Königreich Bibonia am Versoffenen Meer mit Örtlichkeiten wie Lallsingen, Potolia, Vivat, Bechersgmund, Hundsrausch, Aimersheim (in doppelter französisch-deutscher Anspielung auf die angestachelten Liebesgelüste und auf den Trinkfolgen auffangenden Eimer, der zugleich ein Schankmaß war) oder Creta (im Verweis auf das In-der-Creide[ ]-Stehen und das Schreiban als Losung zahlungsunfähiger Zecher) ähnlich assoziativ und sprachlich gemischte Trinkgenüsse wie Fischart (Abb. 22; OV 234f.; E 86-112). Die fantasierte Geografie der erklärten Karte mit ihrer Verortung der Region Bacchanalia innerhalb des "Koenigreich[s] aller Narren" oder Stultorum Regnum (Abb. 21 in Kap. III; OV 240f.; E 148-167), das zugleich als Produktionsstätte dieser schlaraffischen Schalck=Welt« (z.B. E 23) selbst ausgegeben wird, ${ }^{19}$ legt zudem die Trinkfreudigkeit jener gewitzten NarrenAutoren mehr als nahe. Auch bei ihnen geht Schreiben mit Bechern einher.

Mit diesem Aspekt verbunden ist - hier wie dort - Eigenwerbung für das dargebotene Werk als Mittel gegen die Melancholie. So werden die alten Topoi vom Nutzen der komischen Dichtung neu aufgelegt. Fischart gruppiert seine Geschichtklitterung gleich eingangs zu den »Grillenbůcher[n]« (F 14) und empfiehlt sie unter Anspielung auf Rabelais' Arztberuf als Remedium

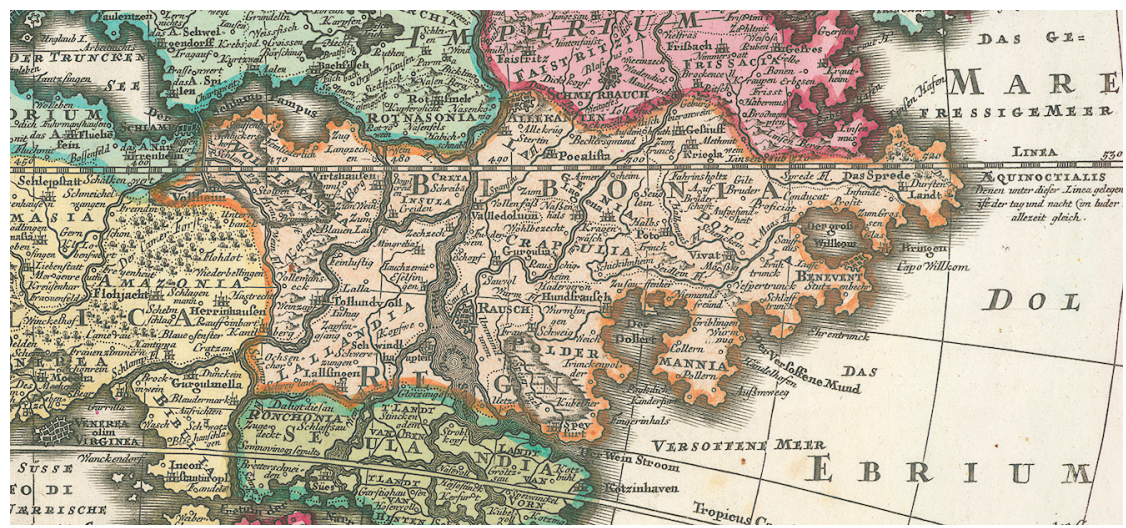

Abb. 22: Trinken von Prosit bis Tollundvoll: Das Königreich Bibonia

(Detail aus Abb. 6)

19 Vgl. oben in Kap. III, bes. S. 78 . 
zur Kur der »melancholi $\ll\left(\right.$ F 15). ${ }^{20}$ Die kartierte »Schalck=Welt « preist sich im Untertitel ihrerseits zur Ergetzung von melancholischen Gemuethern (Abb. 5 in Kap. I) an und gestaltet jenes selbstbezügliche Narrenreich regional zu Schalcklandia in Nachbarschaft zu Grillilandia und verwandten Zonen der aufheiternden Einbildungen aus.

Ausgehend vom prominent platzierten "Grand-Goschier « lässt es die Häufung solcher Korrespondenzen, deren Liste beliebig fortsetzbar wäre, wahrscheinlich werden, dass der Erfinder von Karte und Erklaerung zumindest Fischarts Buch gekannt hat. Vielleicht hat er sogar den französischen Gargantua (und weitere Bücher der Pentalogie) gelesen, von dem er freilich auch nur über Fischarts Deklaration der Geschichtklitterung als Umsetzung von Rabelais' >Entwurf^ gewusst haben könnte. ${ }^{21}$ Natürlich ist bei aller Korrespondenz stets unabhängige Konvergenz möglich. Das vereitelt jedoch nicht die Möglichkeit und den Ertrag eines intertextuellen Vergleichs. Unabhängig von der Frage der inspirierenden Lektüre des Autors: Wer immer die Schlaraffenlandkarte mit Erklaerung las und zugleich Fischarts Buch kannte, kam spätestens beim Auftauchen des Grand-Goschier auf die Spur frappanter Parallelen.

Nimmt man die Inthronisierung von Grand-Goschier, Vater bzw. Großvater der Haupthelden bei Rabelais und Fischart, als "großmagigsten / unübertrincklichsten Fürsten und Herrn « (E 51) der ganzen Vorstellung »unsers Utopiæ oder Schlaraffenlands« (E 38f.) genealogisch ernst, präsentiert sich die nachträgliche kartografische Darstellung gleichsam als Vorgeschichte, als Hergangs- und Herkunftserzählung zu den Abenteuern Gargantuas und Pantagruels. Sie ist ihrerseits eine Art Prequel - und also eine konsequente Fortsetzung des Verhältnisses von Rabelais' (und Fischarts) Gargantua zum Pantagruel. Wenn gängige Rabelais-Ausgaben den Gargantua entgegen der Erscheinungschronologie dem Pantagruel voranstellen, ${ }^{22}$ wäre in dieser Logik die Karte an die eröffnende Position vor den Pantagruel zu rücken.

Wie derart der Großvater im Vergleich >vergrößert erscheint, so auch das Thema des Schlaraffenlandes. Die Schlaraffia-Motivik im engeren Sinn kommt bei Rabelais als bloße Episode im Quart Livre (1552) vor (vgl. R

20 Zum bei Rabelais angedeuteten und von Fischart ausgewalzten Melancholiediskurs im Kontext einer generellen Anverwandlung des gelehrten Affektdiskurses vgl. Kellner: Spiel mit gelehrtem Wissen, S. 240.

21 Schon im Titel: entworfen [1575] bzw. entworffen [1582/90] von M. Francisco [1575] bzw. Frantz Rabelais [1582/90]).

22 Vgl. oben Anm. 11. 
1075-1105);23 bei Fischart wird sie in einer kurzen Passage mit deutlicher Anlehnung an Hans Sachs' Gedicht aufgerufen (vgl. F 136f.). ${ }^{24}$ Die erklärte Karte macht hingegen das sagenhafte Land schon mit dem Titel zum Hauptthema, dem alle anderen Elemente untergeordnet bzw. einverleibt werden, und präsentiert es als buch- und raumfüllendes Sujet. In vergleichender Perspektive ist diese Differenz als Übertreibung beschreibbar, als Verdeutlichung und Verwandlung zugleich, die das Schlaraffia-Thema zum Herzen, oder eher zum Bauch der Darstellung uminterpretiert. Eine solche Aufblähung wirkt passend nicht nur mit Blick auf die enormen Fress- und Saufkapazitäten der Rabelais-Fischart'schen Helden, sondern auch hinsichtlich der Verfahren jener Texte, die ihrerseits hingebungsvoll übertreiben.

Dabei setzt die kartografisch-literarische Fantasie 'Schlaraffenland direkt mit >Utopiar gleich (im Titel von Kartusche und Buch; E 38f. u.ö.). Das ist zunächst nicht selbstverständlich, zumal im Licht von Thomas Morus' Utopia (1516), dem Text, der den Begriff initiiert und die philosophischliterarische Tradition der Entwürfe idealer Staaten oder Gesellschaften in der Folge entscheidend geprägt hatte. Mit dieser Tradition, für die Werke wie Tommaso Campanellas Civitas solis (1602), Christianopolis (1619) von Johann Valentin Andreae oder Francis Bacons Nova Atlantis (1624/27) stehen, haben Schlaraffenland-Darstellungen wenig gemein. ${ }^{25}$ Deshalb kann das Schlaraffia-Etikett zur Verspottung oder Kritik von programmatischen Entwürfen als idealistisch-unrealistisch dienen. ${ }^{26}$ Und deshalb betont der Verfasser der Erklaerung, sein "Concept « folge nicht dem "Tractaetlein" des »Weltbekannten Englischen Cantzlers / Thomæ Mori«, das »in dem

23 Zur Gaster-Episode vgl. z.B. Michel Jeanneret: Le Défi des signes. Rabelais et la crise de l'interprétation à la Renaissance, Caen 1994, S. 149ff.; Terence Cave: »Transformation d'un topos utopique. Gaster et le Rocher de Vertu«, in: Rabelais en son demi-millénaire, hg. von Jean Céard u. Jean-Claude Margolin, Genève 1988, S. 319-325. Vgl. auch Michail Bachtin: L'CEuvre de Rabelais et la culture populaire au Moyen Âge et sous la Renaissance, Paris 1970, S. 296ff. Richter integriert diese Episode in gekürzter Übersetzung in seine Anthologie, vgl. Richter: Schlaraffenland, S. 159-166.

24 Auf diese Passage der Geschichtklitterung referieren jeweils Schlaraffia-Motivzusammenstellungen (vgl. z. B. Wunderlich: Schlaraffenland, S. 60).

25 Zur Diskussion von Schlaraffia-Vorstellungen mit Bezug auf Begriffe von >Utopie >Anti-Utopie<, namentlich zur These (in der Nachfolge) Le Goffs von der einzigen >veritablen mittelalterlichen Utopie‘, die die gesellschaftliche Realität radikal kritisiere und die Vision einer ganz anderen Welt ohne Natur-Kultur-Gegensatz entwerfe (bes. Jacques Le Goff: »L'utopie médiévale: Le pays de Cocagne«, in: Revue europoéenne des sciences sociales 27 [1989], S. 271-286), vgl. zusammenfassend Velten: Europäischer Mythos?, S. 253-255; vgl. auch Gilomen: Das Schlaraffenland und andere Utopien im Mittelalter, v.a. S. 240, 242f., 246.

26 Dies ist in Kap. I am Beispiel Wielands deutlich geworden, vgl. S. 21. 


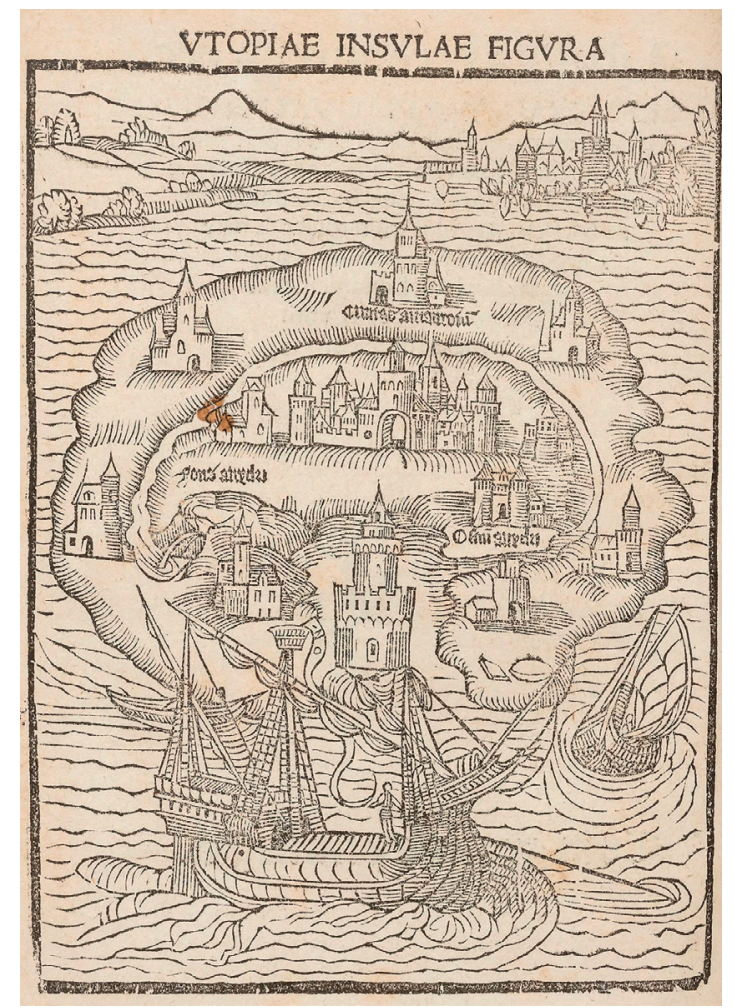

Abb. 23: Titelholzschnitt der Erstausgabe von Thomas Morus'Utopia (1516) (Gallica.bnf.fr/BnF)

Frontispicio mit dem Woertlein Utopia intituliret worden« sei (E 19). Zu Recht betont er diese Differenz, obwohl seine Imagination ansonsten einiges mit derjenigen Morus' verbindet: namentlich die an historisch-reale Entdeckungen angelehnte Präsentation von Utopia als neu entdecktem Land (das bei Morus freilich eine Insel ist) einschließlich einer kartografischen Darstellung, die indes allein schon aufgrund der älteren Kavaliersperspektive grundsätzlich anders geartet ist als die Schlaraffen-Tabula in weitgehender Draufsicht (Abb. 23).

$\mathrm{Zu}$ den Büchern, von denen er sich abgrenzt, schlägt der Autor der Erklaerung auch Jakob Bidermanns Utopia (vgl. E 19). Allerdings ist Utopia in diesem neulateinisch verfassten und 1640 postum erstmals erschienenen Werk gerade auch kein Idealstaat, sondern trägt ähnlich schlaraffische 


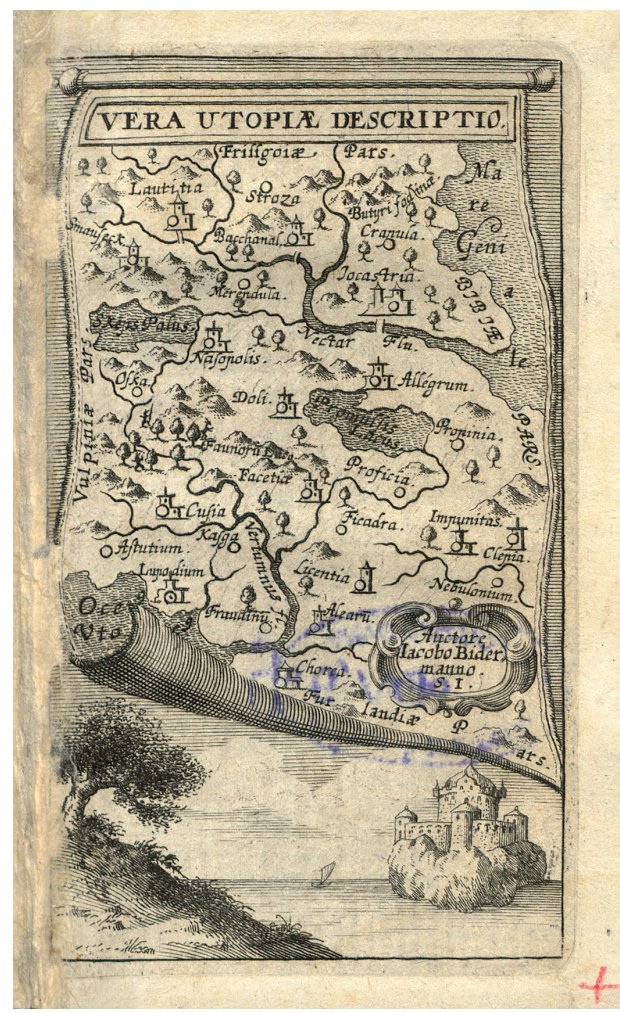

Abb. 24: Frontispiz der zweiten Ausgabe von Jakob Bidermanns Utopia, Dillingen 1670 (Bayerische Staatsbibliothek München)

Züge, die satirisch beschrieben werden. ${ }^{27}$ Eine in der Darstellungsweise noch verstärkte Ähnlichkeit besteht zur zweiten Ausgabe von 1670, der zusätzlich eine Landkarte mit sprechenden Ortsnamen wie Frissgoia, Bibia oder Furlandia ${ }^{28}$ beigedruckt ist (Abb. 24). Einen Grand-Goschier oder Verwandten gibt es in Bidermanns Utopia hingegen nicht.

27 Vgl. dazu Schusters Kommentar in: Jakob Bidermann: Utopia. Edition mit Übersetzung und Monographie nebst vergleichenden Studien zum beigedruckten Plagiat des Christoph Andreas Hörl von Wattersdorf (Bacchusia oder Fassnacht-Land [...]), hg. von Margrit Schuster, 2 Bde., Bern u.a. 1984, Bd. 1, S. 7f. und 49-52.

28 In Fall von Furlandia findet sich sogar eine wörtliche Übereinstimmung: Vgl. die gleichnamige Region in der schlaraffenburgischen Zentralprovinz (Abb. 8 in Kap. I; OV 229). Direkte Inspiration - in die eine oder aber in die andere Richtung (vgl. dazu auch in Kap. I, S. 27) - ist wahrscheinlich. 
Für das Unternehmen, das seinem Vorhaben bisher »zum naehesten kommen« (E 19) sei, verweist der Erklaerer ohne Nennung des Titels, aber erschließbar auf Mundus Alter et Idem, eine damals bekannte Satire des englischen Bischofs Joseph Hall, die seit ihrer lateinischen Ersterscheinung um 1605 auch in englischer (1608/9) und deutscher Übersetzung (1613) zirkulierte. Darin sind »verschiedene Laster in gewisse Land-Chaertlein getheilet / und ueberaus anmuthig / mit allerhand Facetiis [i.S. von 'Witzigkeiten <C.W.] und zierlichen Redens=Arten beschrieben " (E 19f.). Offenbar hat er sich nicht zuletzt im Ton von diesem imaginären Reisebericht inspirieren lassen. Halls Örtlichkeiten wie "Crapulia oder Schlampampen«, "Yuronia [bzw. Yvronia] oder SauffLandt«, »Viraginia, sonst new Gynia oder [...] Weiberlandt«, »Moronia oder Narragonien« und »Lavernia oder [...] Land zu Dieben« tragen schlaraffisch sprechende Namen (übrigens schon in der Originalversion unter multilingualen Beimischungen zum lateinischen Tenor). ${ }^{29}$ Dieses Buch enthält auch vier Landkarten als Illustrationen, die jedoch im Kontrast zur Akribie der Accurata Utopiae Tabula nur rudimentär ausgeführt sind (Abb. 25).

Halls schlaraffische Laster-Welt heißt zwar nicht konkret Utopia, aber zumal die deutschsprachige Version verkauft das Werk mit dem vorangestellten Utopiae Pars II im Titel - samt entsprechendem Kolumnentitel (Von der Insel Utophia / Utopia) - als eine Art ironische Fortsetzung von Morus' Utopia. ${ }^{30}$ Weil darin alles andere als die Imagination eines Idealstaats geboten wird, ergibt sich, ganz ähnlich wie bei der erklärten Tabula, eine von programmatischen Entwürfen abweichende Allianz des Utopiebegriffs mit SchlaraffiaAspekten. Neben Differenzen wie etwa derjenigen, dass es der interkonfessionellen Schlaraffenlandkarte erklärtermaßen weniger um den Stachel gegen katholische Auffassungen geht als dem protestantischen MundusAutor (vgl. E 20), fällt angesichts dieser Gemeinsamkeit ein Unterschied besonders ins Gewicht: Während ausführlich vom Herrscher gehandelt wird, ${ }^{31}$ taucht hier so wenig wie bei Bidermann ein Grand-Goschier auf.

29 Joseph Hall: Utopiae Pars II. Mundus alter \& idem. Die heutige newe alte Welt. [...], Leipzig 1613, Zitate S. 3, 51, 88, 114, 205. Für ein Verzeichnis der Namen (z.B. »Kotzunga« oder "Nuchternmagen«) zur lateinischen Ausgabe vgl. im Register von: Joseph Hall: Mundus Alter et Idem (An Old World and a New), hg. von H. J. Anderson, London 1908, S. 109-117. Bereits eine oberflächliche Lektüre zeigt, wie abwegig es ist, die Erklaerung als eine bloße Übersetzung von Halls Buch zu sehen (was v.a. Angaben in Bibliothekskatalogen immer wieder suggerieren).

30 Den Bezug zu dieser Utopietradition betont auch ein Reprint von 1643 zusammen mit Campanellas Civitas Solis und Bacons New Atlantis.

31 Vgl. Hall: Mundus alter \& idem. Die heutige newe alte Welt, S. 40-48. 


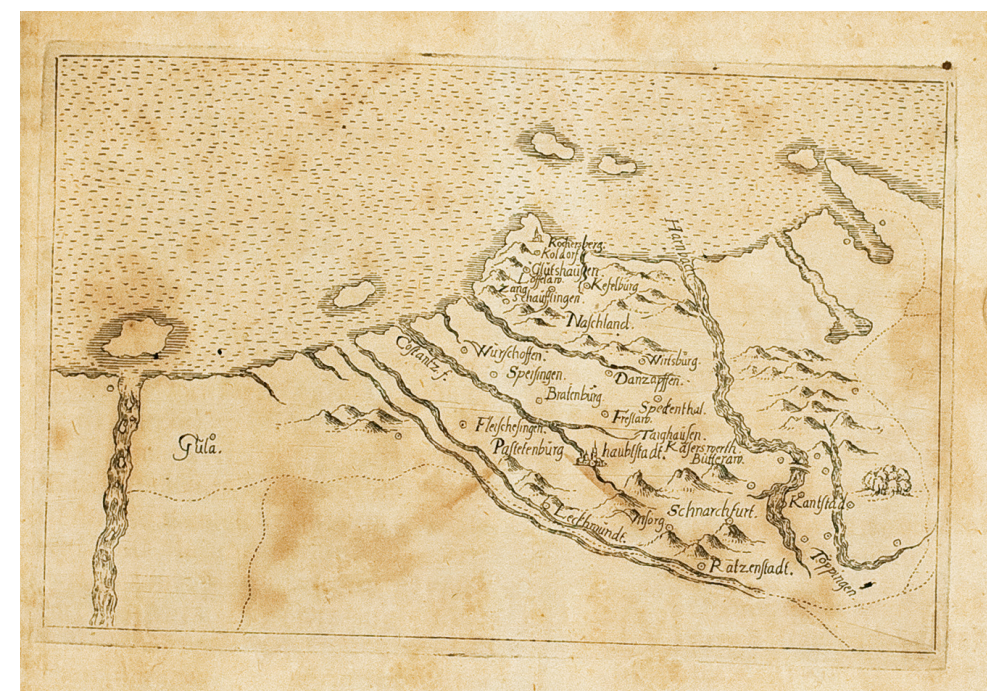

Abb. 25: Die Landschaft Gula in der deutschsprachigen Version von Joseph Halls Mundus alter \& idem (1613), Kupferstich zwischen S. 114 und 115

(Herzog August Bibliothek Wolfenbüttel)

Wenn man, inspiriert von der exklusiven Begegnung mit Grand-Goschier im Zentrum der Tabula, zusätzlich zu den vom Verfasser der Erklaerung erwähnten Gewährstexten nun Rabelais' bzw. Fischarts Textwelt beizieht, ${ }^{32}$ erscheint die intrikate Verschmelzung von >Utopia und 'Schlaraffenland definitiv nicht mehr aus dem Nichts und Nirgendwo kreiert, sondern folgerichtig: Die Heimat der Riesen mit Schlaraffen-Allüren heißt nämlich »Utopie« bei Rabelais (z.B. R 314, 356, 362, 442, 448, 474, 496). Fischart stellt die Herren Grandgoschier[,] Gorgellantua und [...] Pantagruel gleich im Titel als Könige[ ] in Utopien vor und reitet mit variierenden Verdeutschungen weiter auf dem Nichtort herum: Jederwelt,,] Nullatenenten und Nienenreich, [...] Nichilburg, [...] Nullibingen, Nullenstein und Niergendheym (F 5, Titel der Ausgabe 1590).

Umgekehrt schärft diese Perspektive die Aufmerksamkeit für die Rolle von Rabelais' Gargantua-Pantagruel und dessen Rezeption in der Begriffsgeschichte der Utopie. Der Import von Morus' Begriff in den französischen

32 Dabei geht es nicht darum, die Bezüge zu ersetzen; in der vergleichenden Perspektive reichern sie sich vielmehr gegenseitig an. 
Sprachraum verdankte sich wohl maßgeblich Rabelais' Roman(en). ${ }^{33}$ Dabei ist zugleich die Abzweigung von einem Idealstaatentwurf bewusst zu halten, die Rabelais nahm bzw. vertiefte mit seinen riesenhaften Utopiern als exzessiv leiblichen Fress- und Saufhelden, mit seinen Verkörperungen des Karnevalistischen par excellence in Bachtins Sinn. ${ }^{34}$ Dieser >Abweg< war markant, obwohl satirische Momente und ironische Brechungen schon bei Morus' Utopia mitschwangen, die ihrerseits in Verbindung mit der Menippeischen Satire gebracht werden kann. ${ }^{35}$ Er wurde durch die produktive Rezeption von Rabelais' Romanwelt wirkmächtig, im deutschsprachigen Bereich dominant über Fischarts Geschichtklitterung, die etwa auch Bidermanns Verbindung des Utopiebegriffs mit der Schlaraffia-Satire beeinflusst haben könnte. ${ }^{36}$ Die Abzweigung dürfte an der Vervieldeutigung des Utopiebegriffs entscheidend mitbeteiligt gewesen sein, indem sie eine Variante von >Utopie< jenseits programmatischer Fantasien etablierte, die zur Fusion mit `Schlaraffia< prädestiniert war.

Die Accurata Utopiae Tabula hat ihrerseits wohl nicht wenig beigetragen zur weiteren Verfestigung der sabwegigen< Fusion, die seit Beginn des 17. Jahrhunderts nachweisbar ist: ${ }^{37}$ Dort, wo der Zedler Schlaraffenland als deutsches Wort für das lateinische >Utopiar angibt, werden als Systematisierungsversuch »dreyerlei Absichten« von Darstellungen unterschieden..$^{38}$ Den Erdichtungen »eine[r] gantz vollkommene[n] Regierung“ stellt der Verfasser zunächst den Typus der Schlaraffia-Motivik gegenüber und führt schließlich eine dritte Variante an, deren Beschreibung klingt, als hätte er die Schlaraffenlandkarte vor Augen gehabt: "Noch andere stellen darunter die lasterhaffte Welt vor, und mahlen die Laster unter Bildern der Laender ab, z. E. die Landschafft Bibonia, die Republic Venerea, Pigritia und andere mehr. « 39

33 So die gängige Auffassung der Forschung. Vgl. etwa Stroup: French Utopian Thought, S. 2f.: »Having been coined by More (1516), the word utopia< quickly entered French usage with Rabelais's Pantagruel (1532)."

34 Entsprechend ist die utopische Funktion, die Bachtin dem Karnevalistischen zuschreibt, in erster Linie als Subversion und Auflösung bestehender Lebens- und Denkformen, nicht als direkte Konstruktion positiv-programmatischer Gegenmodelle zu verstehen.

35 Vgl. bes. Werner von Koppenfels: Der andere Blick. Das Vermächtnis des Menippos in der europäischen Literatur, München 2007, S. 127-152. Er sieht dabei die menippeischen Elemente bei Morus 'platonisiert‘, während sich Rabelais' Gargantua stärker an Lukian hält.

36 Letzteres vermutet Schuster in: Bidermann: Utopia, Bd. 1, S. 50.

$37 \mathrm{Zu}$ dieser Verbindung vgl. Ludwig Stockinger: Ficta respublica, S. 103f., mit Verweis auf einen ersten Beleg von 1618, den Grimms Wörterbuch anführt.

38 Zedler: Universal-Lexicon, Bd. 34 [1742], Sp. 1828f., Zitat hier Sp. 1828.

39 Ebd., Sp. 1829. 
Der schlaraffisch eingefärbte Utopiebegriff ist auch im Auge zu behalten, wenn Rabelais' und Fischarts Bücher auf Programmatisch-Utopisches hin diskutiert werden, namentlich mit Blick auf die Passagen zur Abtei Thélème (Gargantua) bzw. Willigmuth (Geschichtklitterung). Thélème, wie es am Ende des Romans geschildert wird, ist ein luxuriös ausgestattetes Antikloster ohne Mauern und Uhren für schöne Männer und Frauen, die dort heiraten und in aller Freiheit nach dem Motto "FAY CE Que vouldra" (R 284; »FAIS CE QUE voudras«) leben können. Zwar lässt sich die Beschreibung als utopischer Entwurf, als Manifestation humanistischer Leitideen - optimistische Einschätzung der Natur des Menschen, Vervollkommnung durch Bildung, Selbstbestimmtheit, freier Wille, Würde - lesen, die dann in Fischarts konfessionalisierender Bearbeitung mit Willigmuth als verbarrikadiertem Bollwerk gegen die päpstlichen Bullen ebenso programmatisch verwandelt oder zerstört werden. ${ }^{40}$ Gleichzeitig ist jedoch bedeutsam, dass in den Texten selbst hier das Utopie-Vokabular mit keinem Wort fällt - und stattdessen für die deftigen Schlaraffia-Affinitäten ohne idealistische Essenz zum Einsatz kommt.

\section{Sprachluxus im Medienwechsel: Vom flächigen Erzählen zur Wortschatzkarte}

Die schlaraffische Abzweigung von programmatischen Utopien lässt sich nicht durch den Verweis auf die moralsatirischen Züge mit didaktischem Anstrich entschärfen. Dieser Aspekt ist von der (älteren) Forschung vor allem für Fischarts Geschichtklitterung beansprucht worden, ${ }^{41}$ um sein Unternehmen zu einer negativen Utopie, einer Dystopie im Dienste einer Utopie zu erklären. Tatsächlich verkauft Fischart seine monströsen

40 Vgl. bes. Kellner: Verabschiedung des Humanismus. Für die Lektüre der Thélème-/ Willigmuth-Passagen unter dem Aspekt der Utopie vgl. etwa auch Michael Stolz: "Weltinnenräume. Literarische Erkundungen zwischen Spätmittelalter und früher Neuzeit (am Beispiel des Fortunatus-Romans und der Geschichtsklitterung von Johann Fischart)«, in: Innenräume in der Literatur des deutschen Mittelalters, hg. von Burkhard Hasebrink, Tübingen 2008, S. 427-443, der die Abtei v.a. bei Fischart »[i]m Rahmen der utopischen Diegese« zugleich als Heterotopie im Sinne Foucaults beschreibt (vgl. S. 439f., Zitat S. 440).

41 Vgl. die bei Kellner: Verabschiedung des Humanismus, S. 158, Anm. 12, bzw. S. 163, Anm. 36, kritisch angeführte Literatur. Gemessen an Rabelais' Ton als moralsatirische Vereindeutigung wurde Fischarts Text (abwertend) bedacht bes. von Florence M. Weinberg: Gargantua in a convex mirror: Fischart's view of Rabelais, New York u.a. 1986; dies.: »Fischart's Geschichtklitterung: A Questionable Reception of Rabelais's Gargantua«, in: The Sixteenth Century Journal 13 (1982), S. 23-35. 
»Unfläter« in der Vorrede als abschreckende Beispiele und rechtfertigt sein Unterfangen als dazu notwendiges »[V]orspiegeln" des Unflätigen: »Was kan ein Spiegel dazu, daß er ein lützelhüpschen lützelhüpsch anzeigt? «(F 8). Doch schon bei Rabelais und gesteigert bei Fischart mit seinen opulent erweiterten Ausmalungen erhält das unflätig-grobianische, undiätetischaffektive Gebaren Gargantuas und seiner Genossen zugleich eine unwiderstehliche Faszinationskraft und wird via negationis geradezu gefeiert. ${ }^{42}$ So entziehen sich die schlaraffischen (Anti-)Helden der Verwertbarkeit für Erziehungsprogramme.

Diese Ambivalenz der Darstellungsweise erscheint beim vergleichenden Blick auf die Accurata Utopiae Tabula und Erklaerung wie unter dem Vergrößerungsglas. Die sflankierenden Maßnahmen < - das Laster-Etikett des genüsslich Dargebotenen, die moralisierende Rahmung in doppelter Medienausführung durch die Kartierung drohender Umländer Schlaraffias und durch die abschreckende »Anweisung «zu jeder »possirliche[n] Beschreibung (E 56) - vergällen nicht die unverhohlene Lust am lasterhaften Land, der die detailverliebte Darstellung frönt. ${ }^{43}$

Vergrößerung, Übertreibung: Die Stichworte, die angesichts des aufgeblähten Großvaters schon gefallen sind, treffen generell eine maßgebliche Dimension der Darstellungsverfahren der erklärten Karte im Vergleich zu den Textwelten Rabelais'/Fischarts. Gerade auch der Medienwechsel von der Literatur zur Landkarte lässt sich als eine Art Übertreibung verstehen, als Weitertreiben von charakteristischen Merkmalen Rabelais'scher bzw. Fischart'scher Verfahren, wobei der Effekt der Verwandlung mindestens so gewichtig ist wie derjenige der Verdeutlichung. Dies möchte ich im Folgenden zeigen.

Übertreiben heißt hier zunächst: nicht illustrieren. Das Verhältnis der Accurata Utopiae Tabula zu jenen Textwelten ist ein ganz anderes als bei Kartendarstellungen, die - oft durchaus eigenständig - von Literatur erfundene Orte visualisieren, wie es etwa bei Morus' Utopia (Abb. 23) oder

42 Unter Bezug auf eine exemplarische Passage vgl. Kellner: Verabschiedung des Humanismus, bes. S. 162f., im Anschluss an Gumbrecht, der solche Negationen in den Texten jener Zeit allgemein einschlägig beschrieben hat als Verfahren, die jede Dichotomisierung in eine richtige und eine - ex negativo auf die richtige verweisende - verkehrte Welt unterlaufen (vgl. Hans Ulrich Gumbrecht: »Literarische Gegenwelten, Karnevalskultur und die Epochenschwelle vom Spätmittelalter zur Renaissance«, in: Literatur in der Gesellschaft des Spätmittelalters, hg. von Hans Ulrich Gumbrecht, Heidelberg 1980, S. 95-144, hier bes. S. 131-144).

43 Vgl. in Kap. I, bes. ab S. 34, und in Kap. III, bes. ab S. 73 (zu den Umländern). 
dann im 18. Jahrhundert unter veränderten kartografischen Konventionen bei Jonathan Swifts Gulliver's Travels und Johann Gottfried Schnabels Insel Felsenburg geschieht. ${ }^{44}$ Die Tabula, unabhängig von den Büchern ihres diskreten Bezugs erschienen und genießbar, bebildert hingegen keine Handlungsorte jenes Erzählens, obschon ihre Darstellung über den Namen Utopia mit der Heimat von Rabelais'/Fischarts Riesen assoziiert ist. Vielmehr kartiert oder 'verortet die allegorische Landkarte umgekehrt Kernelemente von Handlung und Vokabular der Geschichten um die riesigen Säufer, Fresser, Faulenzer, Flucher, Spieler, ... Darin ähnelt ihr Verfahren der bekannten, ungefähr zeitgenössischen Carte de Tendre (Abb. 26) und deren - komplizierter - Beziehung zu Madeleine de Scudérys galantem Roman Clélie (16541660). ${ }^{45}$

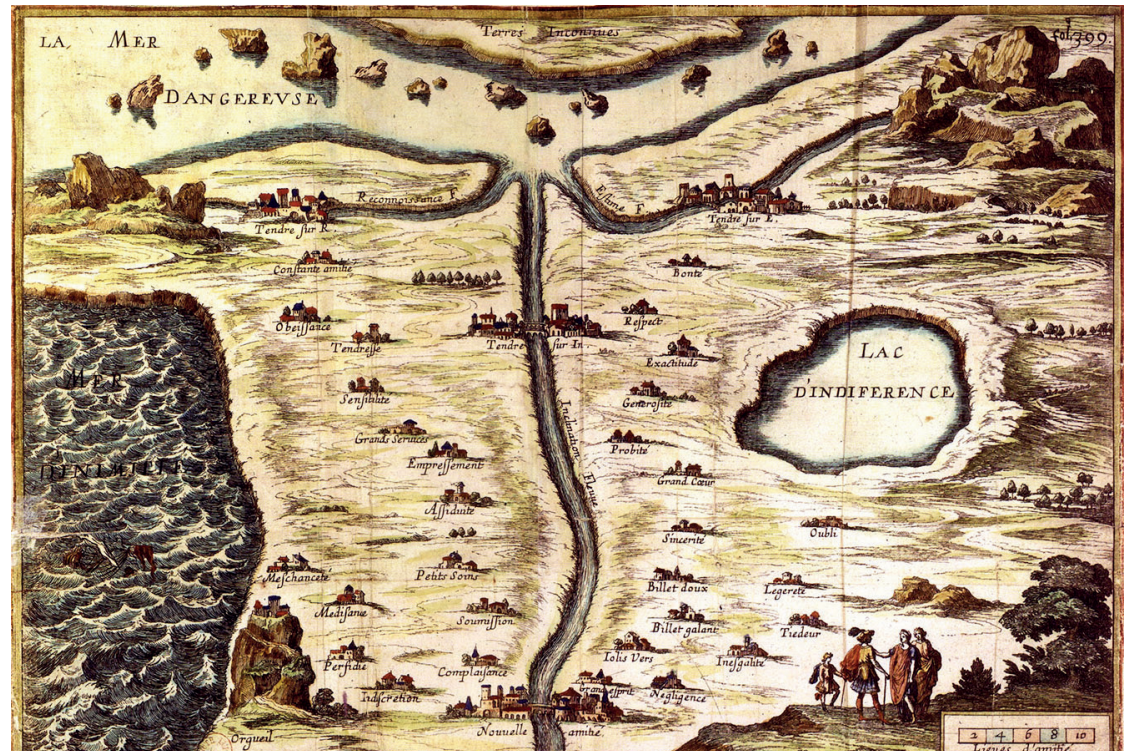

Abb. 26: Amouröse Geografie: Carte de [du] Tendre, gelegentlich dem 1. Band (1654) von Madeleine de Scudérys Clélie beigebunden (Gallica.bnf.fr/BnF)

$44 \mathrm{Zu}$ diesen und weiteren Beispielen vgl. Stockhammer: Kartierung der Erde, S. 62-67, 115f.; 91-111 (zu Swift), 113-135 (zu Schnabel).

45 Vgl.dazu z.B. Florian Gelzer: »Konversation und Geselligkeit im `galanten Diskurs (16801730)«, in: Konversationskultur in der Vormoderne. Geschlechter im geselligen Gespräch, hg. von Rüdiger Schnell, Köln u.a. 2008, S. 473-524, hier S. 500-506. 
Eine solche Versetzung ins Medium der Landkarte ist mit Blick auf die Rabelais-Fischart'schen Textwelten in mehrfacher Hinsicht sinnig, und zwar sowohl im Kontext der Kartografiegeschichte wie hinsichtlich zentraler Verfahren der Texte.

Das Jahrhundert von Rabelais' und Fischarts Büchern ist eine besonders intensive Zeit folgenreicher Neuerungen auf dem Gebiet der Kartografie. Der Umbruch im ausgehenden 15. Jahrhundert vom mittelalterlichen Kartentypus der Mappae mundi, der die Welt nach heilsgeschichtlichen Aspekten organisiert, zu den neuzeitlichen topografischen Darstellungen gemäß aktueller geografischer Kenntnisse entfaltet im 16. Jahrhundert eine enorme Dynamik. ${ }^{46}$ Im Zuge weltweit verstärkter Seefahrerei und der Entdeckungen in der Neuen Welt werden die Karten unter beschleunigter Innovation in hoher Frequenz überarbeitet und erweitert. Nach der (Wieder-) Entdeckung der ptolemäischen Geografie im 15.Jahrhundert etablieren sich Darstellungsverfahren wie das (wiedereingeführte) Gradnetz aus Längenund Breitengraden, das seither allen professionellen Karten explizit oder implizit zugrunde liegt. ${ }^{47}$ Das Gradnetz, das ein >globales Liniendenken< ermöglicht und - erstmals 1494 im Vertrag von Tordesillas zwischen Spanien und Portugal - eine Aufteilung der zu kolonisierenden Welt entlang von Meridianen als arbiträren Linien im Gegensatz zu den natürlich begründeten Breitengraden vornimmt, ${ }^{48}$ setzt sich dann im 16. Jahrhundert flächendeckend durch. Neue Maßstäbe setzen namentlich Gerhard Mercators Seefahrerweltkarte von 1569 als erste winkeltreue Projektion ${ }^{49}$ und Abraham Ortelius' Theatrum Orbis Terrarum (1571), die erste, übrigens auch kommerziell äußerst erfolgreiche, Sammlung von Landkarten in Buchform nach Art der (etwas später so genannten) Atlanten. ${ }^{50}$ Mit der zunehmenden gedruckten Verbreitung in der 2. Hälfte des 16. Jahrhunderts werden solche Karten

46 Für einen reich bebilderten Überblick vgl. Ute Schneider: Die Macht der Karten. Eine Geschichte der Kartographie vom Mittelalter bis heute, 2. überarb. Aufl., Darmstadt 2006; zum Umbruch an der Schwelle zur Neuzeit vgl. hier bes. S. 10f., 16. Vgl. auch Dünne: Die kartographische Imagination, S. 35-59, v.a. S. 35-37.

47 Zusammenfassend zur Etablierung des Rasters vgl. Stockhammer: Kartierung der Erde, S. 16.

48 Vgl. Dünne: Die kartographische Imagination, S. 35.

49 Gerhard Mercator: Nova et aucta orbis terre descriptio ad usum navigantium emendate accomodata, Düsburg 1569; vgl. dazu Schneider: Geschichte der Kartographie, bes. S. 53f.

50 Abraham Ortelius, Franz Hogenberg, Hans Jakob vom Staal der Ältere u. Wilhelm Tugginer: Theatrum orbis terrarum, Antwerpen 1570; vgl. Schneider: Geschichte der Kartographie, bes. S. 50-53. Den Begriff >Atlas < verwendete indes Mercator erstmalig, nämlich für seinen Atlas sive Cosmographicae meditationes de fabrica mundi et fabricati figura (1595); vgl. Schneider, ebd., S. 54. 
einem größeren Publikum in ganz Europa und darüber hinaus zugänglich; die kartografische >Literalität< steigt, und Karten bzw. Kartensammlungen werden ein wichtiges Medium zur Aktivierung der Einbildungskraft. ${ }^{51}$

Die erwähnten und weitere epochale Kartenwerke erscheinen im unmittelbaren zeitlichen Vor- und Umfeld von Fischarts Geschichtklitterung. Bei seinem Buch spielt - eine Zutat gegenüber Rabelais - die Kartografie merklich mit, wie aus einer von der Schlaraffenlandkarte geeichten Optik auffällt. Fischart war kartografisch beschlagen; er hat nachweislich Sebastian Münsters Cosmographia (1544-48) in einer aktualisierten Ausgabe von 1574 benutzt, die durch eine moderne Weltkarte unter spezieller Hervorhebung der Einteilung in Meridian oder MittagsCirckel[ ] eröffnet wird. ${ }^{52}$ Auf Fischarts Titelblatt heißt es im Erstdruck Etwan von M. Francisco Rabelais Französisch entworfen: Nun aber uberschrecklich lustig auf den Teutschen Meridian visirt. So präsentiert sich die deutschsprachige $>$ Nachäffung ${ }^{53}$ nicht bloß im linguistischen Sinn als Übersetzung, sondern topografisch im Vorstellungshorizont einer translatio imperii. ${ }^{54}$ Ich würde noch einen Schritt weiter gehen und das Bild ernst nehmen: Die Deklaration als auf den Teutschen Meridian visirte Version des französischen `Entwurfs` verknüpft Literatur mit dem zu jener Zeit - speziell in jüngster Vergangenheit seit Erscheinen des französischen Werks - rasant sich entwickelnden (Leit-)Medium der Kartografie. Fischart verspricht, Rabelais' Roman gleichsam medial zu aktualisieren, indem er ihn nicht nur geografisch adaptiert, sondern auch metaphorisch zur Landkarte macht. Das kartografische Schreiben, wie es auf unterschiedli-

51 So Dünnes These der kartographischen Imagination (vgl. bes. S. 52, 54f., 58).

52 Sebastian Münster u.a.: Cosmographey oder beschreibung aller Laender/ Herrschafften/ fürnembsten Stetten/geschichten/gebreüchen/ handtierungen/ etc. [...] jetzunder aber biß auff das M.D.LXXIIII.jar [...] gemehret/ darzu mit etlich neüwen Landtaflen [...] bezieret, Basel 1574. Die werbende Überschrift der eröffnenden Karte lautet vollständig: Die Erste General oder gemeine Tafel/ innhaltend den gantzen umbkreiß und Kugel der Welt/ zerleit auff die Ebne/ und unterscheiden mit Meridian od. MittagsCirckeln/ mit Parallelen und jbren Zalen/ dardurch leichtlich gefunden wirt/ eins jeden Lands Lenge und Breite. Für den Nachweis, dass Fischart diese Ausgabe verwendet hat, vgl. Ulrich Seelbach: Ludus lectoris: Studien zum idealen Leser Johann Fischarts, Heidelberg 2000 (Beihefte zum Euphorion 39), S. 385f.; dazu auch Kaminski: Gigantographie, S. 282.

53 Im Titelbegriff Affenteurliche (1. Ausg.) bzw. Affentheurlich (2./3. Ausg.) ist rabenteuerlich zum Anklang an den (nachäffenden) Affen, das für die humanistische Imitatio-Debatte wichtige Tier, verschoben - korrespondierend zum Neologismus Geschichtklitterung (zu >klittern`: >zusammenschreiben<, >zusammenschmieren`, >zusammenstückeln` bzw. lat. >colligere`, >conscribere`, scompilare $)$. Vgl. dazu etwa Kaminski: Gigantographie, S. 276, im Anschluss an Joseph K. Glowa: Johann Fischart's Geschichtklitterung. A Study of the Narrator and Narrative Strategies, New York 2000, S. 15.

54 Vgl. Kaminski: Gigantographie, S. 278. 
chen Ebenen bei literarischen Texten der Frühen Neuzeit allgemein prominent zu beobachten ist, ${ }^{55}$ geht aber noch weiter.

Fischart hält das Titelversprechen und bietet in seinem Roman eine bei Rabelais nicht vorgespurte - Perspektive, die als Atlasoptik beschreibbar ist. Besonders markant ist diese in der Szene, die erzählt, wie der Sarg Pantagruels aufgefunden wird (vgl. F 40-44; R 56f.), und die hier wie bei Rabelais entgegen einem konventionellen Beginn mit der Geburt am Anfang steht. ${ }^{56}$ Fischart verlegt den Fundort zunächst aus der Tourraine, Heimat Rabelais, ins Alemannische Augst, mithin in die Nähe seiner eigenen Heimatstadt Straßburg. Doch dominanter als eine Versetzung auf den Teutschen Meridian ist eine andere Transformation: Fischart malt daraufhin die gigantischen Ausmaße des Sargs (ein »kupffern Todenkasten«, der bis "zu den vier Eckmören" reicht [F 41], d.h. zu den vier Meeren, die auf einem Atlas wie dem Münster'schen den Weltkreis begrenzen) bzw. dessen Inhalts aus. Er positioniert lediglich Pantagruels »Achssel « bei Augst, den Kopf aber zwischen Marseille und Genua, den Fuß in »Engelland«, Bauch, Geschlechtsteil und Hände auf weiteren Regionen Europas (F 41). So dehnt die Geschichtklitterung Rabelais' >regionalen Roman< buchstäblich europäisch oder gar zur Weltliteratur aus. ${ }^{57}$ Diese Darstellung ist nicht nur, ganz gemäß gigantischem Gegenstand, >gigantografisch, 58 sondern auch kartografisch inspiriert. Der Erzähler schildert den toten Riesen, als könnte er den über die Erde sich erstreckenden Körper von oben überblicken - aus der unrealistischen Perspektive eines Atlasses.

In diesem Sinn ist die Schlaraffia-Karte eine konsequente Weitererfindung: Den Medienwechsel, den Fischarts Geschichtklitterung mit der bildlichen Kartierung von Rabelais' Riesenwelt metaphorisch vollzieht, setzt die Accurata Utopiae Tabula wörtlich um. Sie verwandelt Literatur tatsächlich zur Landkarte. Dabei hält sie sich an die aktuellen Darstellungskonventionen der Kartografie - und spielt mit ihnen. Bis in die Verbindung von genereller Draufsicht mit Elementen in Kavaliersperspektive (v.a. für die Dar-

55 Vgl. bes. Dünne mit exemplarischen Analysen zu spanisch- und portugiesischsprachigen Texten (Die kartographische Imagination, zur These S. 61-66), im Anschluss an Ricardo Padrón: The Spacious Word: Cartography, Literature, and Empire in Early Modern Spain, Chicago 2004, sowie an Stockhammers Bestimmung der `Kartizität ‘ von moderner Literatur als Dekonstruktion von (herkömmlichem) kartografischem Schreiben (Kartierung der Erde, v.a. S. 80-89).

56 Für eine treffende Analyse dieser Szene unter einem anderen Akzent vgl. Kaminski: Gigantographie, S. 280-283.

57 Vgl. ebd., S. $281 f$.

58 So Kaminski: Gigantographie, generell bezüglich Fischarts Textverfahren. 
stellung von Bergen) sichtlich an zeitgenössischen Atlanten im Stil der Homann'schen orientiert (Abb. 27), ist die Darstellung durch das gängige Gradnetz gerastert. In seiner Verbindung mit der Fressthematik mag auf der Fantasiekarte untergründig die kardinale Rolle des kartografischen Gradnetzes bei der Kolonialisierung der realen Welt als Einverleibung konkret werden.

Die Meridiane sind zugleich im Sinne einer dritten Hemisphäre bzw. eines Hemisphärenüberzugs über $360 \mathrm{Grad}$ hinausfantasiert, ${ }^{59}$ sodass nicht bloß das Sujet der Karte, sondern ebenso ihre Präsentationsweise utopisch wirkt. Entsprechend schlaraffisch sind die Maßeinheiten, größere und kleinere, aber allesamt riesige (einverleibend-gefräßige) Mäuler, wie üblich am Rand (unten links) angegeben und um die bescheidenere Vergleichseinheit Teutsche Geometrische Meilen ergänzt. Auch die Kartusche mit ihren umrandenden Szenerien und Figuren, die gleichermaßen auf soziale Gegebenheiten wie auf Mythisch-Märchenhaftes anspielen (Abb. 3 und 4 in Kap. I), ist nicht etwa freie Zutat der fiktionalen Karte, sondern eng an die kartografischen Gepflogenheiten angelehnt. Solche Kartuschen gehören zu den häufigen Rahmungen, die - mehr als bloß schmückendes Beiwerk die Karten in die Diskurse ihrer Zeit, namentlich politische und wissenschaftliche Kontexte, einbetten. ${ }^{60}$ Wie bei der orientalischen Szenerie als Umgebung der Kartusche auf der Homann'schen Asien-Karte deutlich wird (Abb. 28), verschwimmen in den Rahmungen, etwa in den seit dem 17. Jahrhundert beliebten Entdecker- und Eroberermotiven, die Sphären von Geschichte und Fiktion gerade auch auf `richtigen< Karten.

Schließlich erscheint die Begleitung der Karte durch eine Erklaerung ihrerseits aus der Welt der Kartografie übernommen, gibt es doch in jener Zeit immer wieder solche erläuterte Karten, wobei die `Erklärung` die Gestalt eines Buches annehmen kann. ${ }^{61}$ Letzteres lässt sich in einer größeren Entwicklungslinie der Kartografie seit der Frühen Neuzeit sehen: Vormals in

59 Vgl. dazu in Kap. III, S. 82.

60 Vgl. allgemein Schneider: Geschichte der Kartographie, S. 134-141.

61 Vgl. z.B. in Homanns Verlag: [Johann Gabriel Doppelmayr:] Ausfübrliche Erklärung uber zwey neue Homännische Charten, als über das Systema solare et planetarium CopernicoHugenianum, und Europam eclipsatam [...], Nürnberg 1707; oder auch Erklärung der Charte von den Neuen Entdeckungen welche gegen Norden des Süder-Meers durch den Herrn von L'Isle Mitglied der Königl. Academie der Wissenschaften zu Paris, und Professor der Mathematic in dem Königl. Collegio, gemacht worden sind, aus dem Franz. v. Johann Victor Krause, Berlin 1753 [ = Übersetzung der älteren, nicht genau datierbaren Explication de la carte des nouvelles découvertes au nord de la mer du sud]; Johann Gottfried Schenk: Summarische Erklärung über die Schreiberischen und Seutterischen Haupt-Charten [...], Dresden u.a. [ca. 1777]. 


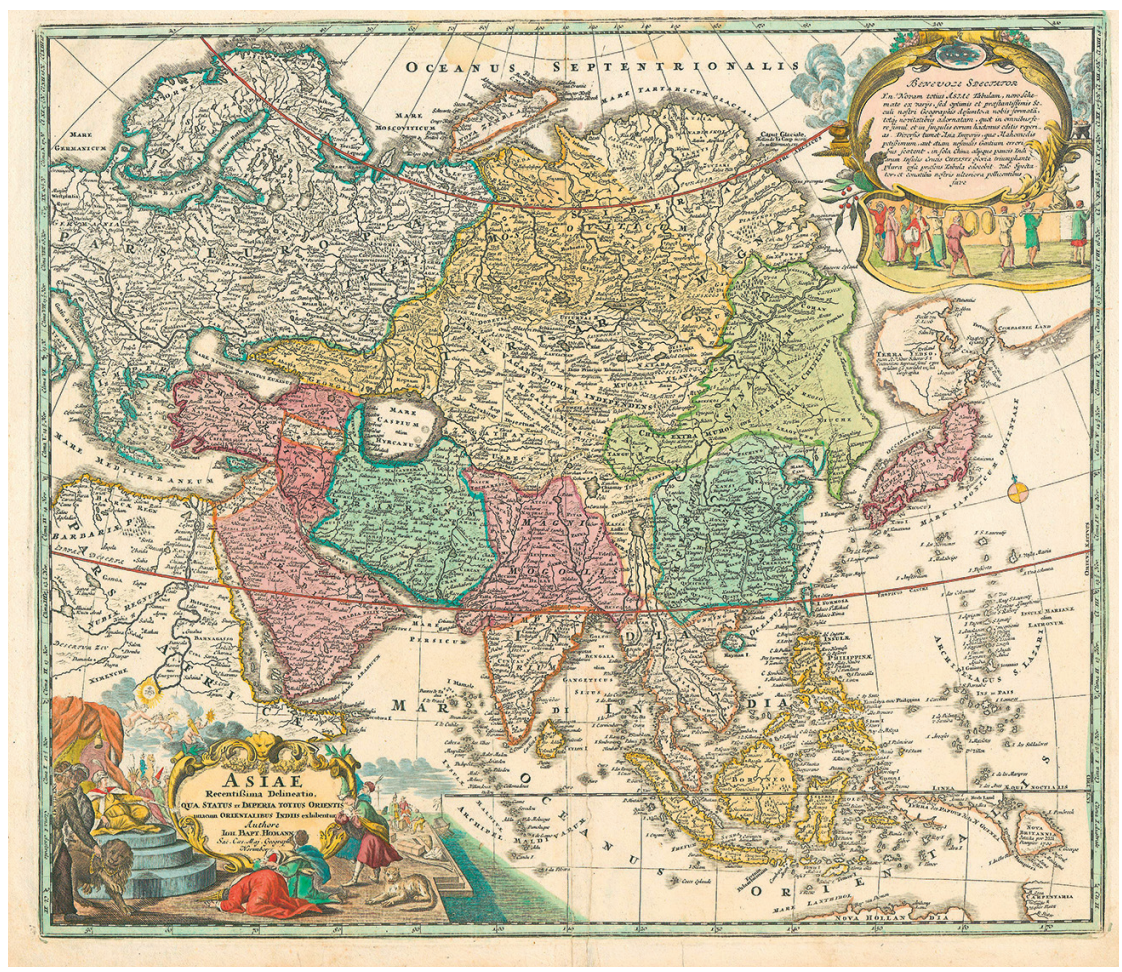

Abb. 27: Draufsicht \& Kavaliersperspektive der Karte von Asien, in: Johann Baptist Homann: Atlas novus terrarum orbis imperia regna et status exactis tabulis geographice demonstrans, Nürnberg ca. 1729

(Universitätsbibliothek Heidelberg)

die Karten integrierte Textelemente wie Legenden und Indices werden im Druck zunehmend ausgelagert. ${ }^{62}$ Das medial gemischte Ensemble von tonangebender Tabula mit begleitender Erklaerung orientiert sich demnach in erster Linie an einem zeitgenössischen Genre der Geografie - und nicht an Literatur mit Kartendarstellungen nach dem Beispiel von Joseph Halls Mundus Alter et Idem. Daher die umgekehrte Hierarchie der Medien: Die Karte ist keine Illustration zum Buch, vielmehr das Buch eine immens ausgebaute Legende zur Karte. In die literarische Tradition von Schlaraffenland-

62 Vgl. dazu ausführlich Christian Jacob: L'empire des cartes, Paris 1992, S. 310-342, zusammenfassend Dünne: Die kartographische Imagination, S. 69. 


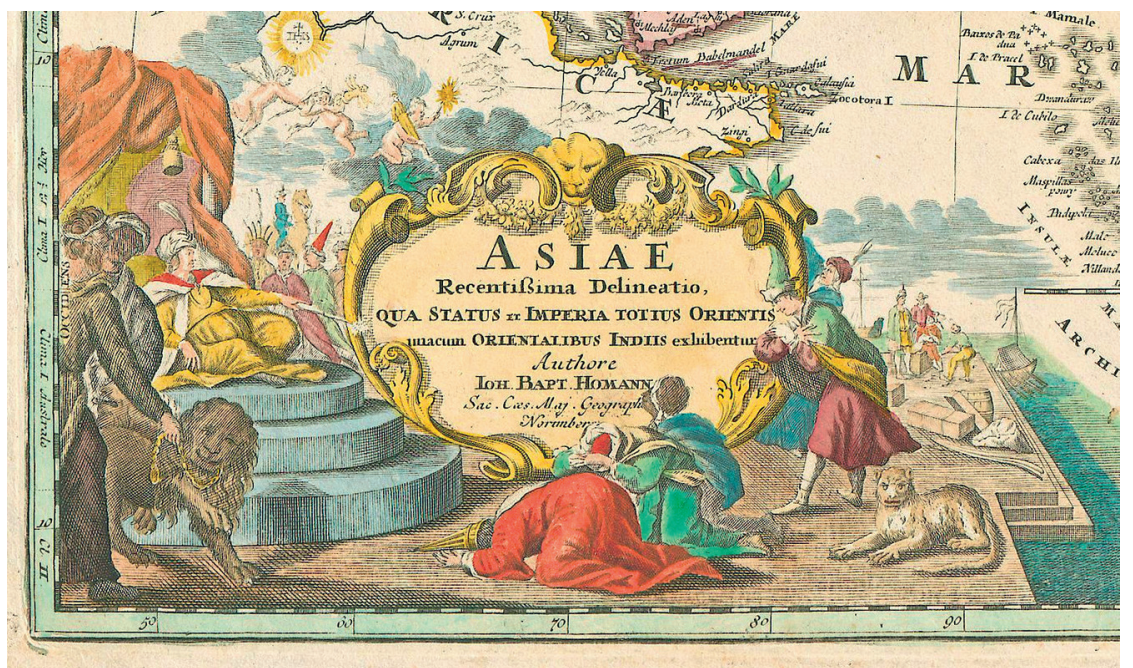

Abb. 28: Rahmengeschichten zwischen Historie und Märchen:

Die Kartusche der Asien-Karte (Detail aus Abb. 27)

Darstellungen eingereiht, handelt es sich beim insgesamt als Kartenerklärung verfahrenden Buch gleichzeitig um einen Spezial- und Extremfall von kartografischem Schreiben oder Kartizität von Literatur.

Nicht nur im Hinblick auf die kartografisch inspirierte Dimension zumal der Geschichtklitterung liest sich der Medientransfer zur erklärten Landkarte raffiniert weiterfantasiert, sondern auch mit Bezug auf genuin literarische Kennzeichen der Riesenromane Rabelais' bzw. Fischarts.

Bei allen saftigen Sujets äußert sich eine unbändige Lust an der Sprache selbst. Bereits bei Rabelais tragend, wird diese Dimension von Fischart nochmals grandios erweitert oder, mit dem rhetorischen Begriff, samplifiziert.${ }^{63}$ Sie ist hauptverantwortlich für den massiv angeschwollenen Textumfang und zeigt sich überall - besonders beispielhaft etwa in der Freude am Fluchen als einer Art Sprachkarneval.

Während durchweg fluchfreudig erzählt wird, verdichtet sich die anstößige Redekunst ausgerechnet in der Figur eines Mönchs: Dem ebenso fluch-

63 Auf mehreren Ebenen kann Fischarts Verfahren im Vergleich zu Rabelais' Text als `Amplificatio gefasst werden (vgl. Kaminski: Gigantographie, bes. S. 273, 282, 285). 
wie leutseligen Bruder Jan Onkapaunt »entfährts« (F 361) andauernd bei seinen nicht allzu frommen Geschichten zur besten Unterhaltung seiner Zuhörer (vgl. F 354-361). Einer von ihnen, Lobkün, fragt aber anlässlich eines mönchischen »Bei dem Kreutzleiden Lots« dann doch nach: »Wie? [...] schwert ihr Bruder Jan? « Worauf der Mönch mit einer Lobtirade auf die Macht seiner Flüche als »der Ciceronischen Retorich Zirfarben« antwortet:

Damit schlegt man den Türcken, von solchem Raparmentdonnern, ${ }^{64}$ thut sich die Erd uff, zerkliben die Felsen, entferbt sich die Sonn: mehr als wann die Hexen Hagel sieden. Vil ungewitters mißt man den Unholden zu, welchs ein durchelementtringender ${ }^{65}$ fluch hat verursacht. [...] Ich könt dannoch wol Basilien, Quendel, und Kressen setzen, dann dieselben vom Fluchen gedeien, unnd sind doch gut zu Artzeneien [...]. (F 361)

Seine Rhetorik ist so überzeugend und ansteckend, dass sich Zuhörer Artsichwol daraufhin gar nicht mehr genug wundern kann, weshalb »man die Mönch von aller guten Gesellschaft verstoßt « und beschimpft als »Trubelefest, Glückstüber, Senffversaurer, Freudenstörer, Freudenversenffer, spilverderber, Stupffelhaaß, Binenhummel, Mußversalzer, Kalklescher, Zechmilben, Schwalbentreck, der Gänßheisern Beichtwolff, Arons Kälber, Bruder Unlust und den Teuffel auff dem gerüst« (F 362). ${ }^{66}$

Mehr noch, als dass der belehrte Artsichwol seine Vorurteile über Mönche verabschiedet, lässt er sich die Schimpfwörter auf der Zunge zergehen. An den Tiraden und Kaskaden des Fluchens und Schimpfens, oft rhythmisiert oder gar gereimt und ausgiebig mit Alliterationen oder anderen rhetorischen Figuren garniert, wird besonders augen- und ohrenfällig: Bei dieser Schreibweise stehen Sprachspiel und Sprachspaß stets im Vordergrund.

Das gilt ebenso für die Darstellungweise der Accurata Utopiae Tabula, die vor allen Dingen eine Wortschatzkarte ist. Konkreter noch: Neben einer vergleichbaren makkaronischen Sprachmischung, die bei deutschem Grundton besonders mit lateinischen und französischen Konnotationen spielt, ${ }^{67}$ teilt sie insbesondere ihren Sprachluxus, sstylus luxurians $\triangleleft{ }^{68}$ mit

64 >Botz Rasperment`: (elsässische) Glimpfform für Sakrament (vgl. Nyssen: Glossar, S. 82).

65 `Element ist ein Fluchwort (vgl. ebd., S. 49). Das Bild vom Element durchdringenden Fluch spielt hier gleichzeitig mit dieser Bedeutung von >Element

66 Für einige Worterklärungen zu dieser Passage der Geschichtklitterung, deren Sprachspiele jedoch insgesamt bei Weitem noch nicht erschlossen sind, vgl. ebd., S. 165.

67 Zur >makkaronischen Schreibweise Rabelais' und Fischarts vgl. z. B. Kellner: Verabschiedung des Humanismus, S. 165 f.

68 Vgl. dazu in Kap. I, bes. S. 32f., und in Kap. II, S. 52. 
der Schreibart Fischarts. Darin Rabelais einmal mehr übertreffend, lässt es Fischart in seinen mutwillig überladenen Sätzen niemals genug sein mit weiteren Formulierungsvarianten, zusätzlichen Umschreibungen, Bildern und Beispielen; er hält »in Tropis, Figuren, zuvörderst aber Synonymien, Exergasien, und dergleichen « wahrlich »keine Maasse« ${ }^{69}$ Das gehört zum rhetorischen Verfahren der Amplificatio, die namentlich auf Variatio etwa durch Accumulatio oder Enumeratio setzt, und hat der Geschichtklitterung das Etikett des Manierismus eingebracht. ${ }^{70}$

Die Wortschatzkarte ergeht sich ihrerseits nicht zuletzt in der Sprachlust am Fluchen. Ein ganzes Königreich, Iuronia (Abb. 29; OV 244), ist dem Einsatz dieser Machtworte gewidmet, den eines der Zehn Gebote ${ }^{71}$ ins Laster- und Sündensujet einbindet. Es liegt entsprechend höllennah direkt an jener Südgrenze aus Papier oder Spinnweben (Abb. 18 in Kap. III). Mit Orten wie Botzblech, Beygost, Botz Hennement, Hagelhofen und Element (!), aber auch Blasphemia und Selverpfende wird unter den obligaten warnenden Zwischentönen in Schimpf- und Glimpfformen geschwelgt. Mit Nider Fluch am Schelt-Fluss, Fluchers Gmund, Gr. Scheltach, Kl. Scheltach und so weiter wird wiederholend und variierend auf dem Thema herumgeritten. Das Auskosten von Worten und Wendungen setzt die Erklaerung fort in ihren Beschreibungen und Erzählungen, etwa von den Zwisten zwischen den beiden internen »Nationen der Flucher« (E 192): Den »Hohen-Fluch[ern] « (E 188) - unter sich nochmals gespalten in der Frage der effizienteren Reihenfolge von Beten und Fluchen (vgl. E 189) - stehen die "NiederFluch $[$ er $]$ « gegenüber, die sich mit glimpflichen »Narren=Fluechen « aus der Affäre der Versündigung zu ziehen suchen (E 190). Glücklicherweise besteht in der Hauptstadt Schweren, wo die beiden Parteien in »Paritaet « leben, eine Art Waffenstillstand: Alle »Feindseligkeiten« sind bei hoher Strafe »verboten«, weshalb »die Hohenflucher die Kleinscheltachere Maeußleinbeisser / Hermetschaender und Botzbleacher [sic] nicht auslachen / diese aber gleichfalls die Donnersperger / Wetterschlager und Hagelhofer nicht schmaehen doerffen / womit die gantze Stadt in guter Ruhe und Einigkeit erhalten wird (E 192).

69 Art. stylus luxurians`, in: Zedler: Universal-Lexicon, Bd. 40 [1744], Sp. 1474.

70 Vgl. bes. Rüdiger Zymner: Manierismus. Zur poetischen Artistik bei Johann Fischart, Jean Paul und Arno Schmidt, Paderborn u.a. 1995, S. 86-167.

71 ,Du sollst den Namen des Herrn, deines Gottes, nicht missbrauchen; denn der Herr wird den nicht ungestraft lassen, der seinen Namen missbraucht.< (Ex. 20, 7/Dtn. 5, 11) 


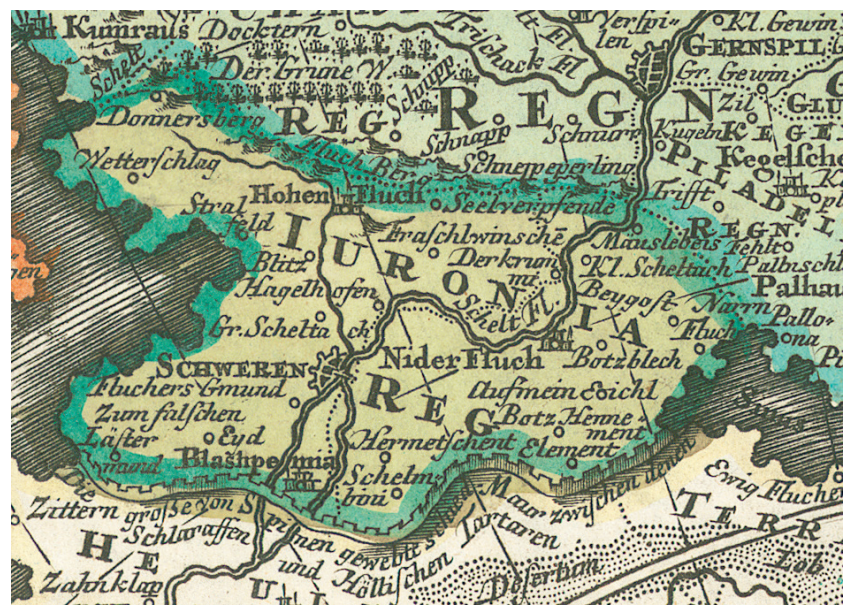

Abb. 29: Wortschatzkarte des Fluchens: Das Königreich Iuronia

(Detail aus Abb. 6)

Literatur und Landkarte treiben ihren Sprachluxus medienbedingt auf völlig verschiedene und doch verwandte Weise: Die An-, Auf- und Überhäufungen geschehen bei Rabelais und verstärkt bei Fischart vornehmlich als ellenlange Reihungen, auf der Karte dagegen in Form von akribisch ausgefüllten Flächen. Die Verwandtschaft der Verfahren deutet sich jedoch bereits darin an, dass Rabelais' und mehr noch Fischarts Schreibweise allgemein als sflächig oder >paradigmatisch ‘ charakterisiert werden kann: ${ }^{72}$ Wenn in den maßlosen Anspielungen und Abwegen, Ausmalungen und Assoziationen, rauschhaften Wortspielen und weiteren Anreicherungen die Geschichte fast untergeht, der Handlungsfaden über weite Strecken verloren geht, funktioniert dieses Erzählen primär paradigmatisch, nicht syntagmatisch. Der Text ist kaum mehr durch einen syntagmatischen Zusammenhang bestimmt, löst sich vielmehr in einen Raum paradigmatischer Bezüge auf.

72 Für diese gängige Kennzeichnung vgl. etwa Kaminski: Gigantographie, bes. S. 285 (»paradigmatisch-flächiges Erzählen«); Kellner: Spiel mit gelehrtem Wissen, bes. S. 223, 233 und 236; Kellner: Verabschiedung des Humanismus, bes. S. 157 und 177f. Sie erfolgt - oft unter Hervorhebung des Ausnahmecharakters bei vormodernen Texten - mit Bezug auf eine Typologie, die Rainer Warning generell (und speziell mit Blick auf die Literatur des Realismus) vorgeschlagen hat: Rainer Warning: "Erzählen im Paradigma. Kontingenzbewältigung und Kontingenzexposition«, in: Romanistisches Jahrbuch 52 (2001), S. 176-209, hier bes. S. 178f. 
Dieser Grundzug erscheint dort am anschaulichsten, wo das aufzählende Erzählen buchstäblich in Listen verfällt. So nicht nur bei klassischem Schlaraffischem ${ }^{73}$ sondern etwa auch - ebenso stimmig - beim Thema von Gargantuas zeitverschwenderischem Spielen: Rabelais wie Fischart unterbrechen hier den Fließtext und bringen eine sich über mehrere Seiten erstrekkende einspaltige (Gargantua) bzw. zweispaltige (Geschichtklitterung) Liste mit Evokationen von allerlei Kartenspielen, Brettspielen, Glücksspielen, Geschicklichkeitsspielen, Rätselspielen, Spielen im Freien... (vgl. R 142-152; F 239-249). Dabei werden manche Spiele mehrfach oder nochmals mit anderen Worten aufgerufen. Das geht bei Rabelais von

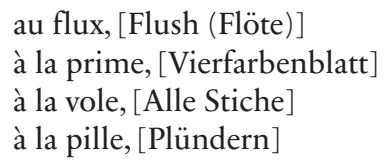

über

au marelles, [Mühle]

au vasches, [Schwarze und weiße Kuh]

à la blanche, [Weiße Dame]

à la chance, [Chance]

und

à éscorcher le renard, [Kotz dich aus]

à la ramasse, [Über den Boden schleifen]

à croc madame, [Beinchen stellen]

à vendre l'avoine, [Hafer verkaufen]

bis hin $\mathrm{zu}$

à taillecoup, [Schlag drauf]

au nazardes, [Nasenstüber]

aux allouettes, [Nasenkneifen]

aux chinquenaudes. [Nasenflitscher] (R 142-152) $)^{74}$

73 Vgl. bei Rabelais in der Gaster-Episode die lange Liste mit Bodenständigem bis Exquisitem in allen Varianten (R 1084-1090); nicht typografisch als Liste, indes als Aufzählung realisiert Fischart seine Ausstaffierung des Landes der »Schlauraffen« mit »Lebkuchenwänd, Schweinepratentröm, Malvasirpronnen « (F 136) usw.

74 Die deutschen Übersetzungen bzw. Entsprechungen nach: François Rabelais: Gargantua Pantagruel, mit 29 Holzstichen von Gustave Doré, aus dem Franz. und kommentiert von Wolf Steinsieck, Stuttgart 2013, S. 97-104. 
Bei Fischart reicht die Liste von

Der Flüssen:

Des Premiere:

Den Picarder:

Ticke tack:

Schachmatt:

über

Cock, Cock ey will.

Lausen oder Noppen.

Fingerschnellen

Den verkaufften gabelochssen mit Wasser zahln:

Wer kan siben Lügen verschweigen:

und

Der blinden würffel.

Deß Sacks im Wasserzuber.

Es brent, ich lesch.

Jungfrau küssen,

Im sack verbergen,

bis $\mathrm{zu}$

Ists Esel oder Edel?

Was krüselt sich, was mauset sich?

Ist nahe darbei, baß auff den Esel

Soll ich, bin ich,

Dem Blinden opfferen.
Rümpffen

Trumpffen

Rum und stich.

Auß und ein machen die Meydlin gern.

Fickmül:

Der drey würffel:

Der nickenocke:

Des Zäumlins:

Wisch auff:

Wann ich mein Hörnlin plas:

Sie thaten all also.

Inn Bernhards namen,

Ich hafft ich hang.

Rindenpfeiflin, Weidenböglin,

Vögel außnemmen
Der Heimlichkeit.

Was ich wünsch, sey dein halb, Immer wigen.

Ich bring dir ein Vögelin,

Was für Blumen zieren sie wol?

(F 239-249)

Man kann die endlosen Listen der Spielwelten aus Rabelais' und Fischarts Zeiten überschlagen (>usw. usf.く) - oder ganze Bücher darüber lesen. ${ }^{75}$ Man kann sich erklären lassen, dass es neben der Demonstration von Zeit-

75 Vgl. bes. Michel Psichari: »Les jeux de Gargantua«, in: Revue des Études Rabelaisiennes 6 (1908), S. 1-37, 124-181, 317-361; Von den Spielen des Gargantua. Geschichte und Anleitung von Brett-, Würfel-, Glücks- und Gesellschaftsspielen, wie sie von François Rabelais aufgezählt und seit Jahrhunderten [...] gespielt wurden, bearb. von Arnold Isler, hg. von René Simmen, Zürich 1965; Heinrich Adam Rausch: Das Spielverzeichnis im 25. Kapitel von Fischarts Geschichtklitterung (Gargantua), Straßburg 1908. 
vergeudung darum gehe, die Pedanterie von Faktenaufzählungen etwa der Scholastik zu verspotten. ${ }^{76}$ Oder man kann das Aufzählspiel der Wörter und Wendungen, Aufforderungen und Fragen, Miniszenen und Kürzestgeschichten zuallererst genießen und sich möglichem Sinn, Unsinn und Hintersinn (»Fickmül «77) hingeben.

Wo die durchweg dominanten Reihungen konkret zur Liste werden, erscheint der Text der Riesenromane schon auf dem Sprung zu einem anderen Medium: einem Medium, das die gelistete Sprache - hier die sprechenden Spielnamen - flächig im Wortsinn, in aller Länge und Breite einer Fläche verzeichnen würde.

Als hätte er diesen Ansatz zum Mediensprung weiterfantasiert, kartiert der Erfinder der Accurata Utopiae Tabula seinerseits ein ludistisches Universum (Abb. 30; OV 242f.). Lusoria oder das "Reich der Spielgurren" (E 13) mit seinen Provinzen Chartifolia, Schach- und Brettspilia, Glickshafnia und Piladelfia (als amerikanisch klingendes »Kegel= und Pallen=Reich « [E 174])

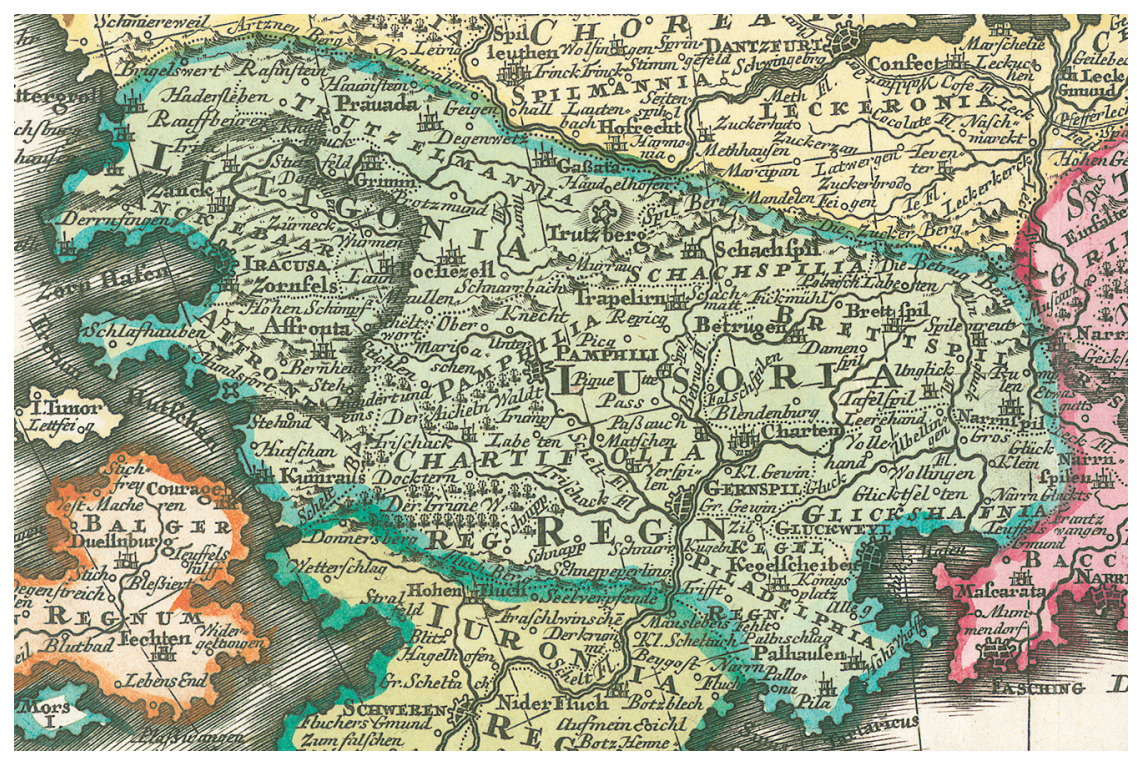

Abb. 30: Wortschatzkarte des Spielens:

Das Königreich Lusoria (Detail aus Abb. 6)

76 Gemäß Zusammenfassung von Erläuterungen der Forschung im Kommentar der genannten deutschen Übersetzung: Rabelais: Gargantua - Pantagruel, S. 464.

77 Für Dame-, Mühlespiel, aber auch unzüchtiges Spiel (vgl. Nyssen: Glossar, S. 88). 
deckt durch Ortschaften wie Schnipp, Schnapp, Schnupp und Schneppeperling, Damenspil, Schachmatt und Alle 9, Gr. Gewin, Blendenberg, Falschspielen, Leerehand oder Spilenreut die weite Welt damaliger Spiele samt Risiken und Nebenwirkungen ab. Auch ein Fickmübl fehlt nicht (über dem B von Brettspilia). Weil Chartifolia und die Vorstellung einer "Welt=beruehmte[n] Bibliothec der Karten=Blätter« (E 43) dabei zugleich eine Brücke von der Spiel- zur Landkarte schlagen, erweist sich diese Region als ein weiteres Herz- oder Bauchstück Schlaraffias.

Dieser Spaß am Spiel leuchtet doppelt ein. Die Accurata Utopiae Tabula samt Erklaerung ist im Kern eine Karte der Wortschätze und Sprachspiele. Um solche literarische Lust dreht sich ihr »Freß=« und »Sauff=Discurs", der mit ziemlich viel "Witzes" von so viel anderem spricht, von Luxus, Ökonomie oder Geografie. Zugleich lässt sich die Landkarte lesen als kongeniale Weiterverwurstung von Literatur, die ihre Spiellust just am Sujet des Spiels auf die Spitze treibt. Auch deshalb handelt es sich um eine besonders literarische Fantasie der Kartografie. 


\section{Literaturverzeichnis}

\section{Accurata Utopiae Tabula}

Anonym: Accurata Utopia Tabula Das ist Der Neu=entdeckten Schalck=Welt, oder des so offt benannten, und doch nie erkannten Schlaraffenlandes Neu=erfundene lächerliche Land=Tabell Worinnen all und jede Laster in besondere Königreich, Provintzien und Herrschafften abgetheilet Beyneben auch die nächst angräntzende Länder der Frommen des Zeitlichen Auff $\bar{u}$ : Unterg. auch ewigen Verderbens Regionen samt einer Erklarung anmuthig und nutzlich vorgestelt durch Authorem Anonymum, in: Johann Baptist Homann: Atlas novus terrarum orbis imperia regna et status exactis tabulis geographice demonstrans, handkolorierter Kupferdruck, 50 x 58,4 cm, Nürnberg 1716, Universitätsbibliothek Graz, Digitalisat auch unter: http://sosa2.unigraz.at/sosa/karten/schlaraffia/index.php [letzter Zugriff 18.06.2021]. (= Grazer Exemplar)

Anonym: Accurata Utopioe Tabula das ist Der Neu-entdeckten Schalck-Welt, oder des so offt benannten, und doch nie erkannten Schlarraffenlandes Neu erfundene lächerliche Land-tabelle Worinnen alle und jede Laster in besondere Königreiche, Provintzen und Herrschafften abgetheilet. Beyneben auch die nächst angräntzende Länder der Frommen: des zeitlichen Auff- und Untergangs auch ewigen Verderbens Regionen samt einer Erkloerung anmuthig und nutzlich vorgestellt werden durch Author anonymus. Prostat in Officina Homanniana, handkolorierter Kupferdruck, 47 x 55 cm, Homann [Nürnberg 1730?], Universitätsbibliothek Bern, Signatur: MUE Ryh 8303:28, Digitalisat auch unter: https://biblio.unibe.ch/web-apps/maps/ zoomify.php?col=ryh\&pic=Ryh_8303_28 [letzter Zugriff 18.06.2021]. (= Berner Exemplar)

Anonym: Karte des Schlaraffenlandes (Schlarraffenland) 1694, Rockstuhl: Bad Langensalza, Reprint 1999.

Ortsregister zur Accurata Utopiae Tabula, zusammengestellt von Harald Rockstuhl, in:Johann Andreas Schnebelins Erklärung der wunder-seltzamen Land-Charten Utopiae aus dem Jahr 1694, hg. von Franz Reitinger, Bad Langensalza 2004, S. 227-273. (= OV) 
Erklaerung

Anonym [Johann Andreas Schnebelin?]: Erklaerung der Wunder=seltzamen Land=Charten UTOPIE, so da ist/ das neu=entdeckte Schlarraffenland/ Worinnen All und jede Laster der schalckhafftigen Welt/ als besondere Koenigreiche/ Herrschafften und Gebiete/ mit vielen laeppischen Staedten/ Festungen/Flecken und Doerfern/Fluessen/Bergen Seen/Insuln/Meer und Meer=Busen/ wie nicht weniger Dieser Nationen Sitten/Regiment Gewerbe/ samt vielen leßwuerdigen/ naerrischen Seltenheiten/ und merckwuerdigen Einfaellen aufs deutlichste beschrieben; Allen thoerrechten Laster=Freunden zum Spott/ denen Tugend liebenden zur Warnung/ und denen melancholischen Gemuethern zu einer ehrlichen Ergetzung vorgestellet. Gedruckt zu Arbeitshausen/ in der Graffschafft Fleißig/ in diesem Jahr da Schlarraffenland entdecket ist, [Nürnberg ca. 1730?], Herzog August Bibliothek Wolfenbüttel, Signatur: M: Sf 224. (= E)

Johann Andreas Schnebelins Erklärung der wunder-seltzamen Land-Charten Utopiae aus dem Jahr 1694 [Transkription nach einem Exemplar der Württembergischen Landesbibliothek], hg. von Franz Reitinger, Bad Langensalza 2004. (= S)

Weitere Quellen

Anonym: Ein schönes new gebachens und wolgeschmackes Honigsüsses Liede [um 1600], Universitätsbibliothek Frankfurt a.M.: http://sammlungen. ub.uni-frankfurt.de/urn/urn:nbn:de:hebis:30-91010 [letzter Zugriff 18.06.2021].

Barbazan, Étienne de: Fabliaux et contes des poètes françois des XI, XII, XIII, XIV et XVe siècles. Tirés des meilleurs auteurs, 4 vols., nouv. éd., augm. et revue par Dominique Martin Méon, Paris 1808.

Bechstein, Ludwig: Sämtliche Märchen, hg. u. m. Anm. u. e. Nachw. von Walter Scherf, München 1971.

Bidermann, Johann Jakob: Utopia Didaci Bemardini [1640], Dillingen ${ }^{2} 1670$.

— : Utopia. Edition mit Übersetzung und Monographie nebst vergleichenden Studien zum beigedruckten Plagiat des Christoph Andreas Hörl von Wattersdorf (Bacchusia oder Fassnacht-Land [...]), hg. von Margrit Schuster, 2 Bde., Bern u.a. 1984.

Bloch, Ernst: Freiheit und Ordnung. Abriß der Sozialutopien, Berlin 1947.

Brecht, Bertolt: Der gute Mensch von Sezuan, Berlin 1964. 
Canisius, Petrus: Der Große Katechismus - Summa doctrinae chistianae (lat.dt.), übers. und hg. von Hubert Filser u. Stephan Leimgruber, Regensburg 2003.

[Doppelmayr, Johann Gabriel:] Ausfübrliche Erklärung uber zwey neue Homännische Charten, als über das Systema solare et planetarium CopernicoHugenianum, und Europam eclipsatam [...], Nürnberg 1707.

Ertl, Ignatius: Sonn- und Feyer-Tägliches Tolle Lege, Das ist: Geist- und Lehrreiche Predigen Auf alle Sonn- und Feyer-Täg des gantzen Jahr-Lauffs eingerichtet, 1. Dominical-Theil, Nürnberg ${ }^{2} 1708$.

Fénelon, François (François de Salignac de La Mothe-Fénelon): CEuvres, hg. von Jacques Le Brun, Paris 1983-1997.

Fischart, Johann: Geschichtklitterung (Gargantua), Text der Ausgabe letzter Hand von 1590 mit einem Glossar, hg. von Ute Nyssen, Düsseldorf 1963.

—: Geschichtklitterung. Synoptischer Abdruck der Fassungen von 1575, 1582 und 1590, neu hg. von Hildegard Schnabel, 2 Bde., Halle (Saale) 1962.

Grimm, Jacob und Wilhelm: Kinder- und Hausmärchen, Bd. 2, Berlin 1812/15. Grimmelshausen, Hans Jacob Christoffel von: Werke, hg. von Dieter Breuer, 3 Bde., Frankfurt a.M. 1989-1997.

Hall, Joseph: Utopiae Pars II. Mundus alter \& idem. Die heutige newe alte Welt. [...], Leipzig 1613.

— : Mundus Alter et Idem (An Old World and a New), hg. von H. J. Anderson, London 1908.

Hayn, Hugo und Alfred N. Gotendorf (Hgg.): Bibliotheca Germanorum erotica \& curiosa, 9 Bde., München 1912-1920.

Hoffmann, Ernst Theodor Amadeus: Sämtliche Werke, hg. von Wulf Segebrecht u. Hartmut Steinecke, 6 Bde., Frankfurt a.M. 1985-2004.

Hoffmann von Fallersleben, August Heinrich: Kinderlieder, hg. von Lionel von Donop, Hildesheim u. New York 1976.

Jandl, Ernst: Poetische Werke, hg. von Klaus Siblewski, 11 Bde., München 1997-1999.

Keyssler, Johann Georg: Fortsetzung Neuester Reisen, durch Teutschland, Böhmen, Ungarn, die Schweitz, Italien und Lothringen: worinn der Zustand und das merckwürdigste dieser Länder beschrieben wird, 2 Bde., Hannover 1740-1742.

Krause, Johann Viktor (Übers.): Erklärung der Charte von den Neuen Entdeckungen welche gegen Norden des Süder-Meers durch den Herrn von L'Isle Mitglied der Königl. Academie der Wissenschaften zu Paris, und Professor der Mathematic in dem Königl. Collegio, gemacht worden sind, Berlin 1753.

La Mettrie, Julien Offray de: Die Kunst, Wollust zu empfinden, hg. und eingel. von Bernd A. Laska, Nürnberg 1987. 
Leibniz, Gottfried Wilhelm: Sämtliche Schriften und Briefe, hg. von der Preußischen Akademie der Wissenschaften, Darmstadt u.a. 1923-1996.

Lukian: Die Hauptwerke des Lukian, griech.-dt. übers. u. hg. von Karl Mras, München ${ }^{2} 1980$.

Mackenzie, George: The Moral History of Frugality, London 1711.

Mandeville, Bernard: The Fable of the Bees, or Private Vices, Publick Benefits, hg. von Phillip Harth, London 1970.

Mann, Heinrich: Im Schlaraffenland. Ein Roman unter feinen Leuten, Frankfurt a.M. ${ }^{6} 2006$.

Mercator, Gerhard: Nova et aucta orbis terra descriptio ad usum navigantium emendate accomodata, Düsburg 1569.

Münster, Sebastian u.a.: Cosmographey oder beschreibung aller Laender/ Herrschafften/ fürnembsten Stetten/ geschichten/ gebreüchen/ handtierungen/ etc. [...] jetzunder aber biß auff das M.D.LXXIIII.jar [...] gemehret/ darzü mit etlich neüwen Landtaflen [...] bezieret, Basel 1574.

Ortelius, Abraham, Hogenberg, Franz, Staal der Ältere, Hans Jakob vom u. Tugginer, Wilhelm: Theatrum orbis terrarum, Antwerpen 1570.

Paracelsus: Sämtliche Werke, hg. von Karl Sudhoff u.a., München $1929 \mathrm{ff}$.

Rabelais, François: EEuvres complètes, édition établie, annotée et préfacée par Guy Demerson, 2., korrigierte Aufl., Paris 1995.

— : Gargantua - Pantagruel, mit 29 Holzstichen v. Gustave Doré, übers. u. komm. von Wolf Steinsieck, Stuttgart 2013.

Sachs, Hans: Meistergesänge, Fastnachtsspiele, Schwänke, hg. von Eugen Geiger, Stuttgart 1985.

Schenk, Johann Gottfried: Summarische Erklärung über die Schreiberischen und Seutterischen Haupt-Charten [...], Dresden u.a. [ca. 1777].

Smith, Adam: The theory of moral sentiments, hg. von David D. Raphael u. Alec L. Macfie, Oxford 1976.

Veblen, Thorstein: The Theory of the Leisure Class, New York 1926.

Wieland, Christoph Martin: Sämmtliche Werke, 45 Bde., Leipzig 1794-1798, Reprint Hamburg 1984.

— : Gesammelte Schriften, hg. von der Deutschen Kommission der Preußischen Akademie der Wissenschaften, 15 Bde., Berlin $1986 f$. 
Adelung, Johann Christoph: Grammatisch-kritisches Wörterbuch der hochdeutschen Mundart, 4 Bde., Wien 1811.

Ästhetische Grundbegriffe. Historisches Wörterbuch in sieben Bänden, hg. von Karlheinz Barck u.a., Stuttgart u. Weimar 2000-2005.

Grimm, Jacob und Wilhelm: Deutsches Wörterbuch, 16 Bde. in 32 Teilbänden, Leipzig 1854-1961.

Historisches Wörterbuch der Rhetorik, 12 Bde., hg. von Gert Ueding, Tübingen; Berlin, Boston u. New York 1992-2015.

Kluge, Friedrich: Etymologisches Wörterbuch der deutschen Sprache, bearb. von Elmar Seebold. 25., durchges. u. erw. Aufl., Berlin u. Boston 2011.

Lausberg, Heinrich: Handbuch der literarischen Rhetorik: Eine Grundlegung der Literaturwissenschaft, Stuttgart ${ }^{4} 2008$.

Zedler, Johann Heinrich: Großes vollständiges Universal-Lexicon [1731-1754], 68 Bde., photomech. Nachdr. Graz 1961-1964.

\section{Forschungsliteratur}

Bachtin, Michail: »Der Karneval und die Karnevalisierung der Literatur«, in: ders.: Literatur und Karneval. Zur Romantheorie und Lachkultur, München 1969, S. 47-60.

— : L'Euvre de Rabelais et la culture populaire au Moyen Âge et sous la Renaissance, Paris 1970.

Bergengruen, Maximilian: »Lässliche Todsünde oder Männerphantasie? Zur Funktion der Luxuria in der Venusberg-Episode des Simplicissimus«, in: Simpliciana 32 (2010), S. 83-100.

Berry, Christopher J.: The idea of luxury. A conceptual and historical investigation, Cambridge 1994.

Bossy, John: »Moral Arithmetic. Seven Sins into Ten Commandments«, in: Conscience and Casuistry in Early Modern Europe, hg. von Edmund Leites, Cambridge u.a. 1988, S. 214-234.

Briggs, Robin: Die Hexenmacher. Geschichte der Hexenverfolgung in Europa und der Neuen Welt, übers. von Dirk Muelder, Berlin 1998.

Brodl, Michaela (Red.) : Der verbotene Blick: Erotisches aus zwei Jabrtausenden, hg. von der Österreichischen Nationalbibliothek, Klagenfurt 2002.

Budde, Bernhard: Aufklärung als Dialog. Wielands antithetische Prosa, Tübingen 2000.

Piero Camporesi: Il paese della fame, Cernusco 2000. 
Cave, Terence: »Transformation d'un topos utopique. Gaster et le Rocher de Vertu«, in: Rabelais en son demi-millénaire, hg. v.Jean Céard u.Jean-Claude Margolin, Genève 1988, S. 319-325.

Davis, J. Ronnie: "Adam Smith on the providential reconciliation of individual and social interests: is man led by an invisible hand or misled by a sleight of hand? «, in: History of Political Economy 22/2 (1990), S. 341-352.

Dünne, Jörg: Die kartographische Imagination: Erinnern, Erzählen und Fingieren in der Frühen Neuzeit, Paderborn 2011.

Durst, Uwe: Theorie der phantastischen Literatur, Tübingen u. Basel 2001.

Faber, Richard u. Naumann, Barbara (Hgg.): Literatur der Grenze - Theorie der Grenze, Würzburg 1995.

Fontaine, Laurence u.a. (Hgg.): Des personnes aux institutions. Réseaux et culture du crédit du XVIe au XXe siècle en Europe, Louvain-le-Neuve 1997.

Fontaine, Laurence: »Espaces, usages et dynamiques de la dette dans les hautes vallées dauphinoises (XVII ${ }^{\mathrm{e}}$ XVIII ${ }^{\mathrm{e}}$ siècles)«, in: Annales, Histoire, Sciences Sociales 49/6 (1994), S. 1375-1391.

— : »Die Bauern und die Mechanismen der Kreditvergabe«, in: Schuldenlast und Schuldenwert. Kreditnetzwerke in der europäischen Geschichte 13001900, hg. von Gabriele B. Clemens, Trier 2008, S. 109-130.

Forstner, Gustav: Längenfebler und Ausgangsmeridiane in alten Landkarten und Positionstabellen, Neubiberg 2005.

Fried, Johannes: "Zins als Wucher. Zu den gesellschaftlichen Rahmenbedingungen der Predigt gegen den Wucherzins«, in: Jacques Le Goff: Wucherzins und Höllenqualen. Ökonomie und Religion im Mittelalter, aus dem Franz. von Matthias Rüb. 2., überarb. u. erw. Aufl. Stuttgart 2008, S. 134-174.

Gelzer, Florian: »Konversation und Geselligkeit im >galanten Diskurs` (16801730)«, in: Konversationskultur in der Vormoderne. Geschlechter im geselligen Gespräch, hg. von Rüdiger Schnell, Köln u.a. 2008, S. 473-524.

Gilomen, Hans-Jörg: »Das Schlaraffenland und andere Utopien im Mittelalter«, in: Basler Zeitschrift für Geschichte und Altertumskunde 104 (2004), S. 213-248.

Glauser, Jürg u. Kiening, Christian (Hg.): Text - Bild - Karte. Kartographien der Vormoderne, Freiburg i.Br. 2007.

Glowa, Joseph K.: Johann Fischart's Geschichtklitterung. A Study of the Narrator and Narrative Strategies, New York 2000.

Grugel-Pannier, Dorit: Luxus. Eine begriffs- und ideengeschichtliche Untersuchung unter besonderer Berücksichtigung von Bernard Mandeville, Frankfurt a.M. u.a. 1996. 
Gumbrecht, Hans Ulrich: »Literarische Gegenwelten, Karnevalskultur und die Epochenschwelle vom Spätmittelalter zur Renaissance«, in: Literatur in der Gesellschaft des Spätmittelalters, hg. von Hans Ulrich Gumbrecht, Heidelberg 1980, S. 95-144.

Häberlein, Mark: »Kreditbeziehungen und Kapitalmärkte vom 16. bis zum 19. Jahrhundert«, in: Soziale Praxis des Kredits. 16.-20. Jahrbundert, hg. von Jürgen Schlumbohm, Hannover 2007, S. 37-51.

Heil, Johannes und Wacker, Bernd (Hgg.): Shylock? Zinsverbot und Geldverleih in jüdischer und christlicher Tradition, München 1997.

Hobert, Winfried: Fénelon als Denker der politischen und sozialen Reform, Braunschweig 1974.

Hoffman, Philip T., Postel-Vinay, Gilles u. Rosenthal, Jean-Laurent: Priceless markets. The political economy of credit in Paris, 1660-1870, Chicago 2000.

Iser, Wolfgang: Das Fiktive und das Imaginäre. Perspektiven literarischer Anthropologie, Frankfurt a.M. 1991.

Jacob, Christian: L'empire des cartes, Paris 1992

Jeanneret, Michel: Le Défi des signes. Rabelais et la crise de l'interprétation à la Renaissance, Caen 1994.

Kaminski, Nicola: »Gigantographie: Fischarts Geschichtsklitterung zwischen Rabelais-imitatio und aemulatio mit des Gargantua vvnnachzuthuniger stärck «, in: Die Präsenz der Antike im Übergang vom Mittelalter zur Frühen Neuzeit, hg. von Ludger Grenzmann, Klaus Grubmüller, Fidel Rädel u. Martin Staehelin, Göttingen 2004, S. 273-304.

Kaute, Brigitte: »Paradoxien der Grenzüberschreitung in E.T.A. Hoffmanns Märchen Der goldene Topf«, in:Zeitschrift für Deutsche Philologie, Sonderheft zum Band 129 (2010): Grenzen im Raum - Grenzen in der Literatur, hg. von Eva Geulen u. Stephan Kraft, S.93-108.

Kellner, Beate: "Spiel mit gelehrtem Wissen. Fischarts Geschichtklitterung und Rabelais' Gargantua «, in: Text und Kontext: Fallstudien und theoretische Begründungen einer kulturwissenschaftlich angeleiteten Mediävistik, hg. von Jan-Dirk Müller, München 2007, S. 219-243.

—:»Verabschiedung des Humanismus - Johann Fischarts Geschichtklitterung «, in: Humanismus in der deutschen Literatur des Mittelalters und der Frühen Neuzeit, hg. von Nicola McLelland, Hans-Jochen Schiewer u. Stefanie Schmitt, Tübingen 2008, S. 155-181.

— : "Fischarts Geschichtklitterung und Rabelais' Gargantua: komparatistische Perspektiven «, in: Germanisch-romanische Monatsschrift 59 (2009/1), S. 149-167.

Kloft, Matthias Theodor: »Das christliche Zinsverbot in der Entwicklung von der Alten Kirche zum Barock. Eine Skizze«, in: Shylock? Zinsverbot 
und Geldverleih in jüdischer und christlicher Tradition, hg. von Johannes Heil u. Bernd Wacker, München 1997, S. 21-34.

Koppenfels, Werner von: Der andere Blick. Das Vermächtnis des Menippos in der europäischen Literatur, München 2007.

Kraft, Stephan: »Nicht mitten hindurch, sondern darüber hinweg und auf beiden Seiten zugleich.Zur deutsch-deutschen Grenze in Arno Schmidts Roman Das steinerne Herz", in: Zeitschrift für Deutsche Philologie, Sonderheft zum Band 129 (2010): Grenzen im Raum - Grenzen in der Literatur, hg. von Eva Geulen u. Stephan Kraft, S. 127-146.

Krämer, Sibylle: Medium, Bote, Übertragung. Kleine Metaphysik der Medialität, Frankfurt a.M. 2008.

Lamping, Dieter: Über Grenzen. Eine literarische Topographie, Göttingen 2001. Kühlmann, Wilhelm und Neuber, Wolfgang (Hgg.): Intertextualität in der Frühen Neuzeit. Studien zu ibren theoretischen und praktischen Perspektiven, Frankfurt a.M. u.a. 1994.

Lanavère, Alain: »L'imagination de Fénelon dans ses premiers écrits de fiction«, in: dix-septième siècle 206 (2000), S. 11-27.

Lausberg, Heinrich: Handbuch der literarischen Rhetorik: Eine Grundlegung der Literaturwissenschaft, Stuttgart ${ }^{4} 2008$.

Le Goff, Jacques: „L'utopie médiévale: Le pays de Cocagne«, in: Revue europoéenne des sciences sociales 27 (1989), S. 271-286.

- : Wucherzins und Höllenqualen. Ökonomie und Religion im Mittelalter, übers. von Matthias Rüb, 2., überarb. u. erw. Aufl., Stuttgart 2008.

Lipp, Carola: »Aspekte der mikrohistorischen und kulturanthropologischen Kreditforschung«, in: Soziale Praxis des Kredits. 16.-20. Jahrhundert, hg. von Jürgen Schlumbohm, Hannover 2007, S. 15-36.

Lotman, Juij M.: Die Struktur literarischer Texte, aus d. Russischen von RolfDietrich Keil, München 1989.

— : "Über die Semiosphäre", aus d. Russischen von Wolfgang Eismann u. Roland Posner, in: Zeitschrift für Semiotik 12 (1990/4), S. 287-305.

Meyer, Maurits de: Populäre Druckgraphik Europas: Niederlande, München 1970.

Moors, Derrick: »Imaginary Voyages«, in: The La Trobe Journal 41 (autumn 1988), S. 8-14.

Mühlmann, Horst: Luxus und Komfort. Wortgeschichte und Wortvergleich, Bonn 1975.

Müller,Jan-Dirk: »Texte aus Texten. Zu intertextuellen Verfahren in frühneuzeitlicher Literatur, am Beispiel von Fischarts Ehzuchtbüchlein und Geschichtklitterung «, in: Intertextualität in der Frühen Neuzeit. Studien zu ibren 
theoretischen und praktischen Perspektiven, hg. von Wilhelm Kühlmann u. Wolfgang Neuber, Frankfurt a.M. u.a. 1994, S. 63-109.

Müller, Martin: Das Schlaraffenland: Der Traum von Faulheit und Müßiggang: eine Text-Bild-Dokumentation, Wien 1984.

Muldrew, Craig: The economy of obligation. The culture of credit and social relations in early modern England, Basingstoke 1998.

North, Michael: Das Geld und seine Geschichte vom Mittelalter bis in die Gegenwart, München 1994.

Nyssen, Ute: Geschichtklitterung. Glossar, Worterläuterungen zum Text der Ausgabe letzter Hand von 1590 nach der Neuausgabe 1963, Düsseldorf 1964.

Padrón, Ricardo: The Spacious Word: Cartography, Literature, and Empire in Early Modern Spain, Chicago 2004.

Pleij, Herman: Der Traum vom Schlaraffenland. Mittelalterliche Phantasien vom vollkommenen Leben, übers. von Rainer Kersten, Frankfurt a.M. 2000.

Psichari, Michel: »Les jeux de Gargantua«, in: Revue des Études Rabelaisiennes 6 (1908), S. 1-37, 124-181, 317-361.

Rausch, Heinrich Adam: Das Spielverzeichnis im 25. Kapitel von Fischarts Geschichtklitterung (Gargantua), Straßburg 1908.

Reitinger, Franz: »Die wunder-seltzame Land-Charten Utopiae. Ein Hauptwerk barocker Lachkultur«, in: Johann Andreas Schnebelins Erklärung der wunder-seltzamen Land-Charten Utopiae aus dem Jahr 1694, hg. von Franz Reitinger, Bad Langensalza 2004, S. 275-336.

—: »Ein Stern geht unter, der andere erhebt sich`.Das erste Leben des Johann Baptist Homann «, in: Franz Reitinger u. Hans Joachim Schollenberger: Johann Jakob Schollenberger (1646-1689). Nürnberg und die Bildproduktion der Kunstverlage des Barock. Werkbiographie eines Verschollenen, Regensburg 2018, S. 297-318.

Richter, Dieter: Schlaraffenland. Geschichte einer populären Utopie, Frankfurt a.M. 1995.

Röhrich, Lutz: Art. ’Kerbholz‘, in: Lexikon der sprichwörtlichen Redensarten, Freiburg i.Br. 2009, Bd. 2, S. 831-833.

Schlumbohm, Jürgen: »Zur Einführung«, in: Soziale Praxis des Kredits. 16.20. Jahrhundert, hg. von Jürgen Schlumbohm, Hannover 2007, S. 7-14.

Schneider, Ute: Die Macht der Karten. Eine Geschichte der Kartographie vom Mittelalter bis heute, 2. überarb. Aufl., Darmstadt 2006.

Schnyder, Peter: "Satire in saturierter Zeit. Heinrich Manns Roman Im Schlaraffenland und die Poesie des Geldes", in: Luxus. Die Ambivalenz des Überflüssigen in der Moderne, hg. von Christine Weder u. Maximilian Bergengruen, Göttingen 2011, S. 217-232. 
Seelbach, Ulrich: Ludus lectoris: Studien zum idealen Leser Johann Fischarts, Heidelberg 2000 (Beihefte zum Euphorion 39).

Seidel, Wolfgang: Sternstunden: Die abenteuerliche Geschichte der Entdeckung und Vermessung der Welt, Köln 2012.

Simmen, René (Hg.): Von den Spielen des Gargantua. Geschichte und Anleitung von Brett-, Würfel-, Glücks- und Gesellschaftsspielen, wie sie von François Rabelais aufgezählt und seit Jahrhunderten [...] gespielt wurden, bearb. v. Arnold Isler, Zürich 1965.

Stockhammer, Robert: Kartierung der Erde. Macht und Lust in Karten und Literatur, München 2007.

Stockinger, Ludwig: Ficta respublica: gattungsgeschichtliche Untersuchungen zur utopischen Erzählung in der deutschen Literatur des frühen 18. Jahrbunderts, Tübingen 1981.

Stolz, Michael: „Weltinnenräume. Literarische Erkundungen zwischen Spätmittelalter und früher Neuzeit (am Beispiel des Fortunatus-Romans und der Geschichtsklitterung von Johann Fischart)«, in: Innenräume in der Literatur des deutschen Mittelalters, hg. von Burkhard Hasebrink, Tübingen 2008, S. 427-443.

Stroup, Alice: »French Utopian Thought: The Culture of Criticism«, in: Studies in Early Modern France, Bd. 4 = Utopia I: 16th and 17th centuries, hg. von David Lee Rubin, Charlottesville 1998, S. 1-30.

Sturm, Beate: ")Borg macht Sorgく: Schuldkonflikte im frühneuzeitlichen Hannover«, in: Soziale Praxis des Kredits. 16.-20. Jabrhundert, hg. von Jürgen Schlumbohm, Hannover 2007, S. 53-79.

Väänänen, Veikko: »Le >fabliau< de Cocagne«. In: Neuphilologische Mitteilungen 48 (1947), S. 3-36.

Velten, Hans Rudolf: »Das Schlaraffenland - ein europäischer Mythos? Zur historischen Semantik einer literarischen >Dekonstruktion«", in:Praktiken europäischer Traditionsbildung im Mittelalter: Wissen - Literatur - Mythos, hg. von Manfred Eikelmann u. Udo Friedrich, Berlin 2013, S. 245-268.

Vogl,Joseph: Art. `Luxus`, in: Ästhetische Grundbegriffe. Historisches Wörterbuch in sieben Bänden, hg. von Karlheinz Barck u.a., Stuttgart u. Weimar 20002005, Bd. III, S. 694-708.

Volkmann, Laurenz: »Mandeville's Beehive and Smith's Invisible Hand: Conflicting Voices of Ethics and Economics in Early Industrialism«, in: Talking Forward, Talking Back: Critical Dialogues with the Enlightenment, hg. von Kevin L. Cope u. Rüdiger Ahrens, New York 2002, S. 13-42.

Warning, Rainer: »Erzählen im Paradigma. Kontingenzbewältigung und Kontingenzexposition «, in: Romanistisches Jahrbuch 52 (2001), S. 176-209. 
Weder, Christine u. Bergengruen, Maximilian: »Moderner Luxus« (Einleitung), in: Luxus. Die Ambivalenz des Überflüssigen in der Moderne, hg. von Christine Weder u. Maximilian Bergengruen, Göttingen 2011, S. 7-31.

Weder, Christine: »Poesie als/statt Polizei.Zum Verhältnis von Sexualität und Gesetz in Wielands Goldnem Spiegel und im polizeiwissenschaftlichen Kontext«, in: Sexualität-Recht-Leben. Die Entstehung eines Dispositivs um 1800, hg. von Maximilian Bergengruen, Johannes F. Lehmann u. Hubert Thüring, München 2005, S. 217-235.

— : »Wie gelangt man ins Schlaraffenland? Topologische und poetologische Konsequenzen besonders phantastischer Grenzen«, in: Zeitschrift für Deutsche Philologie, Sonderheft zum Band 129 (2010): Grenzen im Raum - Grenzen in der Literatur, hg. von Eva Geulen u. Stephan Kraft, S. 75-92.

—: »Literarischer Luxus im Umbruch: Die Modernisierung des Schlaraffenlandes um 1700«, in: Luxus. Die Ambivalenz des Überflüssigen in der Moderne, hg. von Christine Weder u. Maximilian Bergengruen, Göttingen 2011, S. 93-108; 162-167.

— : »Mangel im Überfluss: Kredit und Ruin im Schlaraffenland und in der Ökonomie der Frühen Neuzeit«, in: Kredit und Bankrott in der deutschsprachigen Literatur, hg. von Maximilian Bergengruen, Jill Bühler u. Antonia Eder, Stuttgart 2021 (= Reihe Kulturwissenschaft), S. 87-104.

Weinberg, Florence M.: "Fischart's Geschichtklitterung: A Questionable Reception of Rabelais's Gargantua«, in: The Sixteenth Century Journal 13 (1982), S. 23-35.

— : Gargantua in a convex mirror: Fischart's view of Rabelais, New York u.a. 1986.

Weller, Emil: Die falschen und fingierten Druckorte. Repertorium der seit der Erfindung der Buchdruckerkunst unter falscher Firma erschienenen deutschen, lateinischen und französischen Schriften, Bd. 1, 2. vermehrte u. verbesserte Aufl., Leipzig 1864.

Wood, Denis: The power of maps, New York u.a. 1992.

Wunderlich, Werner: »Das Schlaraffenland in der deutschen Sprache und Literatur«, in: Fabula 27 (1986), S. 54-75.

Zymner, Rüdiger: Manierismus. Zur poetischen Artistik bei Johann Fischart, Jean Paul und Arno Schmidt, Paderborn u.a. 1995. 


\section{Abbildungsverzeichnis}

Abb. 1 Anonym: Cuccagna delle Donne, Italien, ca. 1650. Civica Raccolta delle Stampe Achille Bertarelli, Castello Sforzesco, Milano: Popolari Profane m. 11c-2.

Abb. 2 Detail aus Abb. 1.

Abb.3 Detail aus: Anonym: Accurata Utopiae Tabula (= Abb. 6, Grazer Exemplar, vgl. Literaturverzeichnis), in: Johann Baptist Homann: Atlas novus terrarum orbis imperia regna et status exactis tabulis geographice demonstrans, Nürnberg 1716, Universitätsbibliothek Graz (IV 26.291).

Abb. 4 Anonym: Detail aus Accurata Utopiae Tabula (Berner Exemplar, vgl. Literaturverzeichnis),[Nürnberg 1730?],Universitätsbibliothek Bern, Signatur: MUE Ryh 8303:28.

Abb. 5 Anonym: Titelblatt der Erklaerung der Wunder=seltzamen Land= Charten UTOPI/E [...], [Nürnberg ca. 1730?], Exemplar der Herzog August Bibliothek Wolfenbüttel, Signatur: M: Sf 224.

Abb. 6 Anonym: Accurata Utopiae Tabula (Grazer Exemplar, vgl. Literaturverzeichnis), in: Johann Baptist Homann: Atlas novus terrarum orbis imperia regna et status exactis tabulis geographice demonstrans, Nürnberg 1716, Universitätsbibliothek Graz (IV 26.291).

Abb. 7 Detail aus Abb. 6.

Abb. 8 Detail aus Abb. 6.

Abb. 9 Detail aus Abb. 6.

Abb. 10 Detail aus: Hendryk van der Putte: [Luy Lekkerland] Indien gy trage Jeugd te Luy syt yet te Leeren / Zo volgd my op dit spoor; en wil uw ooren keeren! / En hord of leesd het selfs / den Jnhoud van deez'print / Luy lekkerland genaemd; Soekt voorts so lang gy 't vind. ... (Wenn ihr träge Jugend noch zu faul seid etwas zu lernen, / dann folgt mir auf dieser Spur; es wird euch die Ohren umdrehen! / Und hört oder lest es selbst, I den Inhalt dieses Drucks, / Schlaraffenland genannt; sucht, bis ibr es findet....], Amsterdam 1761-1765, Rijksmuseum Amsterdam, RPP-OB-204.859.

Abb. 11 Detail aus Abb. 6.

Abb. 12 Detail aus Abb. 6.

Abb. 13 Detail aus Abb. 6.

Abb. 14 Doppeltessel von der Alp Blümatt, spätes 19.Jahrhundert, Alpines Museum der Schweiz, Depositum Gmürsche Familienstiftung (880.006). 
Abb. 15 Anonym: Traurige Klag / Ober den erbärmlichen Abschied deß wolbekandten Herrn Credits / welcher heutigs Tags schier an allen Orten tod gefunden wird, o.O. nach 1637, Herzog August Bibliothek Wolfenbüttel: http://diglib.hab.de/drucke/ie-191/start.htm [letzter Zugriff 18.06.2021].

Abb. 16 Ernst Jandl: peter frißt seinen weg ins schlaraffenland, in: ders.: Poetische Werke, hg. von Klaus Siblewski, Bd. 6, München 1997, S. 129.

Abb. 17 Detail aus Abb. 6.

Abb. 18 Detail aus Abb. 6.

Abb. 19 Detail aus Abb. 6.

Abb. 20 Detail aus Abb. 6.

Abb. 21 Detail aus Abb. 6.

Abb. 22 Detail aus Abb. 6.

Abb. 23 Titelholzschnitt aus Thomas Morus: Libellus vere aureus nec minus salutaris quam festivus de Optimo reip. statu deque nova insula Utopia, Löwen 1516, Quelle: gallica.bnf.fr/BnF.

Abb. 24 Anonym: Frontispiz aus: Johann Jakob Bidermann, Utopia Didaci Bemardini, Dillingen ${ }^{2} 1670$, Bayerische Staatsbibliothek München: P.o.lat. 215 d, Frontispiz, urn:nbn:de:bvb:12-bsb10608809-2.

Abb. 25 Anonym: Landschaft Gula, in: Joseph Hall: Utopiae Pars II. Mundus alter \& idem. Die heutige newe alte Welt. [...], dt. Leipzig 1613, zwischen S. 114 und 115, Herzog August Bibliothek Wolfenbüttel: 139 Pol. (2), http://diglib.hab.de/drucke/139-pol-2s/start.htm [letzter Zugriff 18.06.2021].

Abb. 26 François Chauveau: Carte de [du] Tendre, in: Madeleine de Scudéry: Clélie, histoire romaine, Bd. 1, Paris 1654, Quelle: gallica.bnf.fr/BnF.

Abb. 27 Karte von Asien, in: Johann Baptist Homann: Atlas novus terrarum orbis imperia regna et status exactis tabulis geographice demonstrans, Nürnberg ca.1729, Universitätsbibliothek Heidelberg: https://igi. ub.uni-heidelberg.de/diglit/homann1729/0114 [letzter Zugriff 18.06.2021].

Abb. 28 Detail aus Abb. 27.

Abb. 29 Detail aus Abb. 6.

Abb. 30 Detail aus Abb. 6. 
Dank

Diese Publikation ist durch die Finanzierung des Schweizerischen Nationalfonds ermöglicht worden. Für die ideelle, formale und technische Unterstützung danke ich allen, die bei einer Stufe der Obsession mit- oder gegengewirkt haben, insbesondere Maximilian Bergengruen, Katrin Birzele, Matt Erlin, Markus Heinz, Cornelia Herberichs, Alexander Honold, Christian Kiening, Markus Oehrli, Philipp Ramer, Kristina Reinders, Franz Reitinger, Irmgard Trummler, Peter Wittemann, Friederike Wursthorn - und Lucas. 
Adelung, Johann Christoph 58

Andreae, Johann Valentin 93

Bacon, Francis 93,96

Bachtin, Michail 36,93,98

Barbazan, Étienne de 16,47

Barbon, Nicholas 42

Bartoli, Daniello 37

Baudrillard, Jean 18

Bayle, Pierre 42

Bechstein, Ludwig 46, $48 f$.

Bergengruen, Maximilian 19,36

Berry, Christopher J. 16, 18, 21f., 39, 42-45

Bidermann, Jakob 27, 85, 94-96,98

Bloch, Ernst 19

Bossy, John 34

Brant, Sebastian 39

Brecht, Bertolt 57

Briggs, Robin 34

Britannicus, Mercurius [Pseuodonym v. Gentilis, Albericus] 27

Brodl, Michaela 11

Budde, Bernhard 21

Campanella, Tommaso 93,96

Camporesi, Piero 46

Canisius, Petrus 34

Cave, Terence 93

Certeau, Michel de $76 f$.

Cicero 32

Columbus, Christopher 30

Davies, J. Ronnie 18

Dedekind, Friedrich 90

Demerson, Guy 89

Doré, Gustave 111

Dschingis Khan 55

Dünne, Jörg 30,77, 86f., 102-104

Durst, Uwe 71
Eikelmann, Manfred 16

Ertl, Ignatius $39 \mathrm{f}$.

Faber, Richard 64

Fallersleben, August Heinrich

Hoffmann von 72

Fénelon, François de Salignac de

La Mothe 13, 41-45, 70

Fischart, Johann 13, 85-87, 89-93, 97-100, 102-104, 107, 109-112

Fontaine, Laurence $56,60 \mathrm{f}$.

Forstner, Gustav 82

Foucault, Michel 99

Fried, Johannes 61

Friedrich, Udo 16

Geiler von Kaysersberg, Johann 39

Gelzer, Florian 101

Gentilis, Albericus 27

Geulen, Eva 83

Gilomen, Hans-Jörg 19, 30, 46, 93

Glauser, Jürg 87

Glowa, Joseph K. 103

Gotendorf, Alfred N. 25f.

Gregor der Große 27

Grimm, Jacob 52, 71,98

Grimm, Wilhelm 52,71,98

Grimmelshausen, Hans Jacob

Christoffel von $35 \mathrm{f}$.

Grugel-Pannier, Dorit 42

Gumbrecht, Hans Ulrich 100

Häberlein, Mark 56

Hall, Joseph 27, 85, 96, 106

Hayn, Hugo $25 f$.

Heil, Johannes 61

Hobert, Winfried 44

Hoffman, Philip T. 60

Hoffmann, E.T.A. 19

Hogenberg, Franz 102 
Homann, Johann Baptist 10, 22-24, $26,29,105 f$.

Horaz 32, 38

Iser, Wolfgang $83 \mathrm{f}$.

Jacob, Christian 106

Jacoserius, Wahrmund 85

Jandl, Ernst 65

Jeanneret, Michel 93

Jørgensen, Sven-Aage 21

Kaminski, Nicola 89f., 103f., 110

Kaute, Brigitte 81,84

Kellner, Beate 89f., 92, 99f., 108, 110

Keyssler, Johann Georg 26

Kiening, Christian 87

Kloft, Theodor 61

Kluge, Friedrich 52

Koeman, Cornelis 23

Koppenfels, Werner von 98

Kraft, Stephan 81,83

Krämer, Sibylle 86

Kühlmann, Wilhelm 87

La Mettrie, Julien Offray de $20 \mathrm{f}$.

Lamping, Dieter 64, 69, 83

Lanavère, Alain 41

Lausberg, Heinrich 32

Le Goff, Jacques 61,93

Leibniz, Gottfried Wilhelm 27,36f.

Lipp, Carola 59-62

Lotman, Jurij L. 66, 81

Lukas [Evangelist] 54

Lukian 19, 41, 70f., 98

Mackenzie, George 39

Mandeville, Bernard 18, 42f.

Mann, Heinrich 68

Mercator, Gerhard 102

Montchrétien, Antoine de 42

Moors, Derrick 27

Morus, Thomas 27, 77, 85, 93f., 97f., 100
Mühlmann, Horst 34

Muldrew, Craig 56

Müller, Jan-Dirk 87

Müller, Martin 15f., 30, 67

Münster, Sebastian 103

Nasier, Alcofrybas [Pseudonym v.

Rabelais, François] 89

Naumann, Barbara 64

Neuber, Wolfgang 87

North, Michael 59

Nyssen, Ute 90, 108, 113

Ortelius, Abraham 77, 102

Padrón, Ricardo 104

Paracelsus 35

Psichari, Michel 112

Pleij, Herman 36

Postel-Vinay, Gilles 60

Putte, Hendrik van der 48

Quintilian 32

Rabelais, François 13, 85-93, 97-100, 102-104, 107, 109-113

Rausch, Heinrich Adam 112

Reitinger, Franz 11, 22f., 25-27, 34, 37, 52, 85

Richter, Dieter $11,15 f ., 19,30,36$, 38-40, 47, 49, 64, 67, 69, 71, 93

Rockstuhl, Harald 11

Röhrich, Lutz 59

Rosenthal, Jean-Laurent 60

Rosenthal, Ludwig 26

Sachs, Hans 20, 48, 67-71, 73, 83, 93

Saint-Évremond, Charles de 42

Scheidt, Caspar 90

Schenck, Peter/Pieter 23

Schenk, Johann Gottfried 105

Schlumbohm, Jürgen 62

Schnabel, Gottfried 101

Schnebelin, Johann Andreas 10, 26 
Schneider, Ute 102,105

Schnyder, Peter 38

Schuster, Margrit 95,98

Scudéry, Madeleine de 37, 101

Seelbach, Ulrich 103

Seidel, Wolfgang 11

Seneca 32

Seutter, Matthäus / Matthias 23

Simmel, Georg 69

Simon, Jordan 21

Smith, Adam 18

Staal (der Ältere), Hans Jakob vom 102

Stockhammer, Robert 86, 101f., 104

Stockinger, Ludwig 11,98

Stolz, Michael 99

Stroup, Alice 98

Sturm, Beate 61f.

Swift, Jonathan 101

Tugginer, Wilhelm 102
Väänänen, Veikko 16

Veblen, Thorstein 16

Velten, Hans Rudolf 16, 19f., 30,33, $36,47,71,93$

Vogl, Joseph 33, 35, 42f., 45

Volkmann, Laurenz 18

Wacker, Bernd 61

Warning, Rainer 110

Weder, Christine 19, 45

Weinberg, Florence M. 99

Weller, Emil 26

Wieland, Christoph Martin 15, 18-22, 44f., 69, 93

Wittenwiler, Heinrich 16

Wood, Denis 30

Wunderlich, Werner 20,93

Zedler, Johann Heinrich 21, 32, 98, 109

Zymner, Rüdiger 109 
